Universidade de São Paulo

Faculdade de Medicina de Ribeirão Preto

\title{
2016
}

Adaptação Transcultural para o Português-brasileiro,

Validação e Confiabilidade do Questionário para

Avaliação de Dor Cervical Profile Fitness Mapping neck
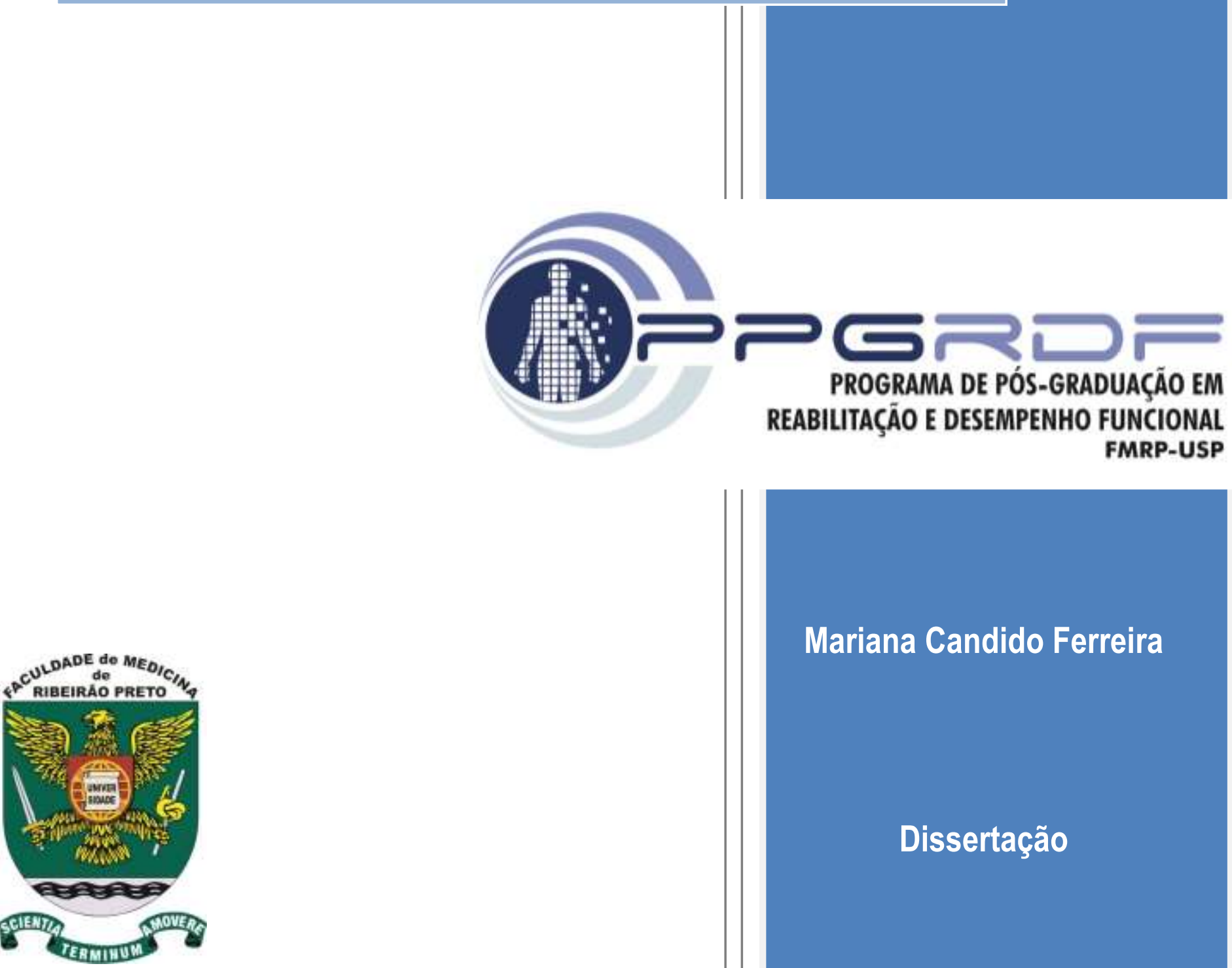

Mariana Candido Ferreira

Dissertação 
UNIVERSIDADE DE SÃO PAULO

FACULDADE DE MEDICINA DE RIBEIRÃO PRETO

Departamento de Neurociências e Ciências do Comportamento

Mariana Candido Ferreira

\section{Adaptação Transcultural para o Português-brasileiro, Validação e Confiabilidade do Questionário para Avaliação de Dor Cervical Profile Fitness Mapping neck}

Dissertação apresentada à Faculdade de Medicina de Ribeirão Preto da Universidade de São Paulo junto ao Departamento de Neurociências e Ciências do Comportamente, para obtenção do título de mestre em Reabilitação e Desempenho Funcional

Orientadora: Profa. Dra. Thaís Cristina Chaves

Ribeirão Preto 
Autorizo a reprodução e divulgação total ou parcial deste trabalho, por qualquer meio convencional ou eletrônico, para fins de estudo e pesquisa, desde que citada a fonte.

\section{Catalogação da Publicação}

Faculdade de Medicina de Ribeirão Preto da Universidade de São Paulo

Ferreira, Mariana Candido

Adaptação Transcultural para o Português-brasileiro, Validação e Confiabilidade do Questionário para Avaliação de Dor Cervical Profile Fitness Mapping Neck. Ribeirão Preto, 2016.

$$
\text { p.155: } \mathrm{il} .2 ; 30 \mathrm{~cm}
$$

Dissertação de Mestrado, apresentada à Faculdade de Medicina de Ribeirão Preto/USP - Programa de Pós Graduação Reabilitação e Desempenho Funcional. Área de concentração: Fisioterapia.

Orientador: Chaves, Thaís Cristina.

1.Adaptação Transcultural. 2.Validação. 3.Dor Cervical. 4.Desordens Musculoesqueléticas. 5.Profile Fitness Mapping neck. 6.Questionário. 
UNIVERSIDADE DE SÃO PAULO

FACULDADE DE MEDICINA DE RIBEIRÃO PRETO

Departamento de Neurociências e Ciências do Comportamento

MARIANA CANDIDO FERREIRA

Adaptação Transcultural para o Português-brasileiro, Validação e Confiabilidade do Questionário para Avaliação de Dor Cervical Profile Fitness Mapping neck 


\section{FOLHA DE APROVAÇÃo}

Mariana Candido Ferreira

Adaptação Transcultural para o Português-brasileiro, Validação e Confiabilidade do Questionário para Avaliação de Dor Cervical Profile Fitness Mapping neck

Dissertação apresentada à Faculdade de Medicina de Ribeirão Preto da Universidade de São Paulo junto ao Departamento de Neurociências e Ciências do Comportamento, para obtenção do título de mestre em Reabilitação e Desempenho Funcional

Aprovado em:

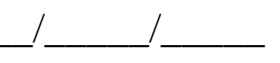

\section{Banca Examinadora}

Profa Dra Thaís Cristina Chaves

Instituição: Departamento de Neurociência e Ciências do Comportamento - Faculdade de Medicina de Ribeirão Preto - USP

Assinatura:

Prof Dra

Instituição:

Assinatura:

Profa Dra

Instituição:

Assinatura: 
Dedico a minha mãe, Mária Candido, com todo o meu amor e orgulho da mulher que olha a vida de frente e sempre com muita coragem. 


\section{Agradecimentos}

Agradeço a Deus pela oportunidade que me foi dada de estar aqui, na Faculdade de Medicina de Ribeirão Preto da Universidade de São Paulo (FMRP-USP), que é um lugar que eu amo e que é motivo de muito orgulho na minha vida. Amo e admiro cada um dos meus Professores e agradeço a eles por todos os momentos dedicados a me ensinar e participar da construção de quem eu sou hoje, bem como de tudo o que ainda pretendo ser.

Agradeço a minha mãe por sempre ter me incentivado ao estudo, a cultura, as artes e ao que a vida poderia me oferecer de edificador. Ela sempre esteve ao meu lado me apoiando e exigindo que eu fosse o melhor que pudesse ser, me fez descobrir um mundo partucular em cada livro, provocou a minha curiosidade e me ensinou a buscar por respostas. Ela me abriu a porta do conhecimento e por ela a manterei sempre aberta, de modo a mostrar minha gratidão por todo o esforço feito para que hoje eu estivesse aqui. Me deixou, em vida, a maior de todas as heranças que poderia, o conhecimento, herança essa que pretendo passar aos meus filhos, dando a eles tanto suporte quanto me foi dado.

Queria agradecer a minha família pelo apoio sempre demonstrado em todos os momentos de carinho e de a torcida para que as coisas dessem sempre certo. Sou grata por todas as conversa que me guiaram em direção ao caminho certo, por cada conselho oferecido e cada lagrima de cansaço compartilhada. O caminho foi mais leve com vocês.

Gostaria de agradecer a Professora Dra. Thais Chaves, com quem trabalho desde 2010, pela confiança que sempre me foi depositada, pela paciência e compreensão que teve com os meus momentos de dificuldades e por me dizer repetidamente em todos esses momentos “Calma Mari, nós somos humanos, nós temos dúvidas, nos decepcionamos com os outros e com nós mesmos e surtamos às vezes, muitas vezes na verdade”. Ela acompanhou todos os meus momentos de crise, amadurecimento, quedas, medos, decisões e inúmeras indecisões. Me olhou como um Ser Humano e não somente como aluna, me deu toda a sua amizade e 
empatia nos momentos certos da vida. Sem esse apoio eu jamais teria concluído meu mestrado e não teria evoluído tanto como pessoa e nas minhas opiniões e visões a respeito da vida. Com essa experiência de convivência entre orientadora e aluna eu não só tive a chance de receber mais um título, como também tive a chance de crescer como pessoa.

Gostaria de agradecer também aos meus colegas de laboratório. Aprendi muito com cada um por meio da convivência, da troca de experiências, pela cumplicidade com as mesmas dificuldades e aflições e por todo apoio que recebi nos momentos em que precisava. Com vocês eu aprendi que trabalhar em aquipe é sempre o melhor caminho e que falar sobre as dificuldades não é uma demonstração de fraqueza, nem vergonha e sim um modo de seguir com mais confiança e leveza. Cada um de vocês ficará no meu coração, cada um ao seu modo, cada um ao seu tempo. Obrigada por tudo.

Por fim, gostaria de agradecer a Fundação de Amparo a Pesquisa do Estado de São Paulo, FAPESP que financiou essa pesquisa por meio da aprovação da bolsa de mestrado de processo $n^{\circ} 2013 / 26513-4$.

"Renova-te e segue adiante, trabalhando e servindo. E a medida que avances, caminho a fora, entre a bênção de compreender e o comportamento de ser útil, perceberás que todos os obstásculos e sombras de ontem se fizeram lições e experiências, enriquecendote o coração de segurança e de alegria para que sigas em paz, no rumo de conquistas imperecíveis, ante o novo amanhecer." 
"Pense que todo o conhecimento adquirido por você está contido em uma ilha e que o oceano que a rodeia é todo o desconhecido que você ainda pode desvendar. Quanto mais você conhece do mundo, maior se torna a margem entre a sua ilha e o mar, logo é maior o contato entre o que você conhece e o que ainda é desconhecido." 


\section{Resumo}

Objetivo: O presente estudo teve como objetivo realizar a adaptação transcultural e verificar a confiabilidade, consistência interna, validade estrutural e a validade de construto do ProFiMap-neck em indivíduos com relato de dor cervical crônica. Método: Participaram deste estudo pacientes do sexo feminino com relato de dor cervical há mais de 3 meses durante o movimento ou repouso A amostra foi composta por 30 indivíduos $(33,43 \pm 10,32$ anos) para a etapa de teste da versão pré-final, 100 indivíduos $(38,89 \pm 10,84$ anos) para a confiabilidade e 180 indivíduos $(37,49 \pm 11,86$ anos) para a validadade de construto, para a análise da consistência interna e validade estrutural. O processo de tradução e retrotradução ocorreu em 5 etapas: 1) Tradução inicial para o português, 2) Síntese de traduções, 3) Retrotradução, 4) Comitê de especialistas, e 5) O teste da versão pré-final. Para validade de construto a pontuação do ProFitMap-neck foi correlacionada com a pontuação do Neck Disability Index (NDI), além disso, foram utilizados para fins de correlação a Escala de Ansiedade e Depressão Hospitalar (HADS-A e HADS-D), a Escala Tampa de Cinesiofobia e o Short Form - 36 (SF-36). Para a análise fatorial exploratória foi utilizada a Análise de Componentes Principais, o indice de Kaiser-Meyer-Olkin (KMO) e \% de variância cumulativa. Para a análise da consistência interna foi utilizado o coeficiente de $\alpha$ de Cronbach. Para a confiabilidade foi utilizando o Coeficiente de Correlação Intraclasse (CCI). O coeficiente de correlação de Pearson foi utilizado para verificação das correlações. A magnitude da correlação foi graduada da seguinte maneira: $\mathrm{R}<0,29$ : pobre; $0,3<\mathrm{R}<0,69$ : moderada; R>0,7: forte. Resultados: Durante o processo de teste da versão pré-final não foram relatadas dúvidas pela amostra de pacientes ao responder o instrumento. Para a escala de Sintomas/Intensidade do ProFitMap-neck versão português brasileiro foram verificados dois domínios (Escala de Sintomas/Intensidade Geral e Escala de Sintomas/Intensidade Equilíbrio) com porcentagem de variância cumulativa de 57,33\% e índice $\mathrm{KMO}=0,66$. Para a escala de Sintomas/Frequência do ProFitMap-neck foi verificado apenas 1 domínio com porcentagem de variância cumulativa de $56,20 \%$ e $\mathrm{KMO}=0,84$. Para a escala de Limitação Funcional do ProFitMap-neck foram verificados 2 domínios (Postura e AVDs e Movimento e Percepção de Saúde) com porcentagem de variância cumulativa de 56,28\% e KMO=0,57. Todos os itens apresentaram carga fatorial superior a 0,2. A análise de consistência interna demonstrou valores de alpha de cronbach adequados (alpha $>0.70$ ) para todos os domínios do ProFitMap-neck. Na reprodutibilidade foram verificados valores de CCI excelentes para todos os domínios e escalas (ICC >0,75). Nossos achados demonstraram correlações moderadas/fortes e negativas entre a pontuação total do NDI e as pontuações dos domínios e escalas Sintomas/Intensidade, Sintomas/Frequencia e Limitação Funcional do ProFitMapneck $(\mathrm{R}=-0,65, \mathrm{R}=-0,56$ e $\mathrm{R}=-0,71$, respectivamente). Foram verificadas correlações no geral moderadas/fortes e positivas entre os escores das ferramentas SF-36 e ProFitMap-neck. Para as correlações entre Ansiedade, Despressão e Cinesiofobia e as Escalas do ProFitMap-neck versão português brasileiro foram verificadas correlações em sua maioria moderadas e fortes $(-0,32<\mathrm{R}<-0,82)$. Conclusão: O ProFitMap-neck versão português-Brasil apresentou índices psicométricos adequados e, dessa forma, está disponível para ser empregado na prática clínica e pesquisa em pacientes com dor cervical crônica.

Palavras-chave: Profile Fitness Mapping neck questionnaire, Dor cervical crônica, Adaptação transcultural, Validação, Confiabilidade, Consistência Interna, Validade de construto, Análise Fatorial Exploratória. 


\begin{abstract}
Objective: This study aimed to perform the cultural adaptation and verify the reliability, internal consistency, structural validity and construct validity of the Profile Fitness Mapping neck questionnaire (ProFiMap-neck) in individuals reporting chronic neck pain. Method: This study recruited female patients with neck pain for more than three months during motion or at rest The sample consisted of 30 individuals $(33.43 \pm 10.32$ years $)$ to test the pre-final version, 100 individuals $(38.89 \pm 10.84$ years) for reliability and 180 individuals $(37.49 \pm$ 11.86 years) for construct validity, analysis of internal consistency and structural validity. The process of translation and back translation occurred in 5 steps: 1) Initial translation into Portuguese, 2) Summary of translations, 3) Back-translation, 4) Committee of Experts, and 5) The test of the pre-final version. Construct validity was verified correlating scores on ProFitMap-neck and Neck Disability Index (NDI), Hospital Anxiety Depression Scale (HADS-A and HADS-D), Tampa Scale of Kinesiophobia and the Short Form - 36 (SF-36). Exploratory factor analysis was perfomed considering Principal Component Analysis, the Kaiser-Meyer-Olkin index (KMO) and percentange of cumulative variance. For the analysis of internal consistenc, we used $\alpha$ Cronbach and for reliability Intraclass Correlation Coefficient (ICC) was used. The Pearson correlation coefficient was used to investigate correlations and the strength was graded as follows: $\mathrm{R}<0.29$ : poor; $0.3<\mathrm{R}<0.69$ : moderate; R> 0.7: Strong. Results: During the test of the pre-final version, volunteers did no report doubts. Structural validity retained two domains for Symptoms/Intensity ProFitMap-neck Brazilian Portuguese version (General Symptoms Intensity and Symptoms Intensity/ Balance) with cumulative percentage of variance of $57.33 \%$ and $\mathrm{KMO}=0.66$. For the Scale Symptoms/Frequency of ProFitMap-neck we identified one domain, with cumulative percentage of variance of $56.20 \%$ and $\mathrm{KMO}=0.84$. For Functional Limitation of the ProFitMap-neck, we identified two domains (Posture and Movement and Diary Life Activities and Health Perception) with cumulative percentage of variance of $56.28 \%$ and $\mathrm{KMO}=0.57$. All items had factors loadings greater than 0.2. The internal consistency analysis revealed adequate alpha Cronbach values (alpha>0.70) for all ProFitMap-neck domains. We obtained excellent ICC values for all domains and scales (ICC>0.75). Our findings showed moderate/strong and negative correlations between the total score of the NDI and the scores of the domains and scales Symptoms/Intensity, Symptoms/Frequency and Functional Limitation of ProFitMap-neck brazilian portuguese version $(R=-0.65, R=-0.56$ and $\mathrm{R}=-0.71$, respectively). Correlations between the scores of the SF-36 and ProFitMapneck tools were in the majority moderate/strong and positive. For correlations between anxiety, depression and kinesiophobia and the scales of the ProFitMap-neck brazilian portuguese version were observaded moderate and strong values $(-0.32<\mathrm{R}<-0.82)$. Conclusion: ProFitMap-neck portuguese-Brazil version showed adequate psychometric indexes and, therefore, it's available to be apllied in clinical practice and research in patients with chronic neck pain.
\end{abstract}

Key-words: Profile Fitness Mapping neck questionnaire, Chronic Neck Pain, Transcultural Adaptation, Validation, Reliability, Internal Consistency, Construct Validity, Exploratory Factor Analysis. 


\section{LISTA DE TABELAS}

Tabela 1. Caracterização da Amostra para cada Etapa de Validação do ProFitMap-neck......30

Tabela 2. Dados antropométricos e escolaridade da amostra completa $(n=180)$, da etapa de reprodutibilidade $(\mathrm{n}=100)$ e teste da versão pré-final $(\mathrm{n}=30)$ .44

Tabela 3. Dados antropométricos dos subgrupos de pacientes com Dor cervical, Dor cervical + Cefaléia, Dor cervical + DTM e Dor cervical + Fibromialgia

Tabela 4. Valores médios e intervalos de confiança 95\% para as pontuações das escalas do ProFitMap-neck, Neck Disability Index (NDI), Escala de Ansiedade e Depressão Hospitalar (HADS-A e HADS-D), Escala Tampa de Cinesiofobia (TSK) e Short Form-36 (SF-36) nos subgrupos de pacientes com Dor cervical, Dor cervical + Cefaléia, Dor cervical + Disfunção Temporomandibular (DTM) e Dor cervical + Fibromialgia $(n=180)$ 46

Tabela 5. Dados da Análise Fatorial Exploratória: valores de carga fatorial, Eigenvalues e \% de variância cumulativa dos itens e domínios da Escala de Sintomas/Intensidade $(n=180) \ldots .53$

Tabela 6. Dados da Análise Fatorial Exploratória: valores de carga fatorial, Eigenvalues e \% de Variância Explicada dos itens e domínios da Escala de Sintomas/Frequência $(n=180) \ldots . . .54$

Tabela 7. Dados da Análise Fatorial Exploratória: valores de carga fatorial, Eigenvalues e \% de Variância cumulativa dos itens e domínios da Escala de Limitação Funcional (n=180).....55 
Tabela 8. Valores médios das pontuações de cada questão, Erro Padrão da Medida (EPM) e Mínima Mudança Detectável (MMD) do ProFitMap-neck para a Escala de Sintomas/Intensidade $(\mathrm{n}=180)$

Tabela 9. Valores médios das pontuações de cada questão, Erro Padrão da Medida (EPM) e Mínima Mudança Detectável (MMD) do ProFitMap-neck para a Escala de Sintomas/Frequência $(\mathrm{n}=180)$ .58

Tabela 10. Valores médios das pontuações de cada questão, Erro Padrão da Medida (EPM) e Mínima Mudança Detectável (MMD) do ProFitMap-neck para a Escala de Limitação Funcional $(\mathrm{n}=180)$ .59

Tabela 11. Valores médios de CCI e IC $95 \%$ para a reprodutibilidade $(n=100)$ das pontuações dos domínios da Escala de Sintotomas/Intensidade. 61

Tabela 12. Valores médios de CCI e IC $95 \%$ para a reprodutibilidade $(n=100)$ das pontuações dos domínios da Escala de Sintomas/Frequência .62

Tabela 13. Valores médios de CCI e IC $95 \%$ para a reprodutibilidade $(n=100)$ das pontuações dos domínios da Escala de Limitação Funcional. 63

Tabela 14. Descrição dos valores de $\alpha$ de Cronbach e Correlação Total do Item de cada domínio e questão da Escala se Sintomas/Intensidade (n=180) .65 
Tabela 15. Descrição dos valores de $\alpha$ de Cronbach e Correlação Total do Item de cada domínio e questão da Escala se Sintomas/Frequência $(n=180)$. .66

Tabela 16. Descrição dos valores de $\alpha$ de Cronbach e Correlação Total do Item de cada......67

Tabela 17. Tabela de Valores de Correlação entre as pontuações totais e domínios do ProFitMap-neck e os instrumentos Short Form - 36 (SF-36), o Neck Disability Index (NDI), Escala de Ansiedade e Depressão Hospitalar (HADS) e Escala Tampa de Cinesiofobia (TSK) para $\mathrm{n}=180$ .72

Tabela 18. Itens do COSMIN que foram considerados no estudo de adaptação transcultural e validação do ProFitMap-neck versão português Brasil .75 


\section{LISTA DE FIGURAS}

Figura 1. Etapas do processo de adaptação transcultural realizadas no estudo conforme preconizado por Beaton et al (2000)... 
LISTA DE SIGLAS

\begin{tabular}{|c|c|}
\hline COSMIN & COnsensus-based Standards for the selection of Health Measurement INstruments \\
\hline CSOQ & Cervical Spine Outcome Questionnaire \\
\hline CNPQ & Come Neck Pain Questionnaire \\
\hline IC & Intervalo de Confiança \\
\hline CCI & Coeficiente de Correlação Intraclasse \\
\hline CTI & Correlação Total do Item \\
\hline DTM & Disfunção Temporomandibular \\
\hline EPM & Erro Padrão da Medida \\
\hline HADS-A/HADS-D & Escala de Ansiedade e Depressão Hospitalar \\
\hline KMO & Ìndice de Kaiser-Meyer-Olkin \\
\hline MMD & Mínima Mudança Detectável \\
\hline NDI & Neck Disability Index \\
\hline NPQ & Northwich Park Neck Pain \\
\hline NPDS & Neck Pain and Disability Scale \\
\hline ProFitMap-neck & Profile Fitness Mapping neck questionnaire \\
\hline PSFS & Patient-Specific Function Scale \\
\hline SF-36 & Short Form - 36 \\
\hline RT & Retrotradução \\
\hline RT1 & Retrotradução Português-Inglês realizada pelo tradutor leigo quanto ao construto \\
\hline RT2 & Retrotradução Português-Inglês realizada pelo tradutor leigo quanto ao construto \\
\hline RT3 & Retrotradução Português-Sueco realizada pelo tradutor leigo quanto ao construto \\
\hline RT123 & Síntese das retrotraduções \\
\hline TSK & Escala Tampa de Cinesiofobia \\
\hline T1 & Tradução Inglês-Português realizada pelo tradutor com conhecimento do construto \\
\hline T2 & Tradução Inglês-Postuguês realizada pelo tradutor leigo quanto ao construto \\
\hline
\end{tabular}




\section{Sumário}

1. INTRODUÇÃO

1.1. Dor cervical

1.2. Incapacidade, Funcionalidade e Instrumentos de avaliação.

1.3. Adaptação transcultural e propriedades de medida

2. OBJETIVOS

2.1. Objetivo geral

2.2. Objetivos específicos

3. MÉTODOS

3.1. Amostra, critérios de inclusão e exclusão

3.2. Profile Fitness Mapping neck questionnaire (ProFitMap-neck) ......................... 32

3.3. Adaptação transcultural da ProFitMap-neck para o português-brasileiro

3.3.1 Tradução inicial para o português

3.3.2 Síntese das traduções e Consenso entre tradutores

3.3.3. Retrotradução ou Backtranslation

3.3.4. Reunião do Comitê de Especialistas

3.3.5. Teste da versão pré-final

3.4. Consistência interna e Validade de Construto .................................................... 39

3.5. Reprodutibilidade da medida .................................................................. 40

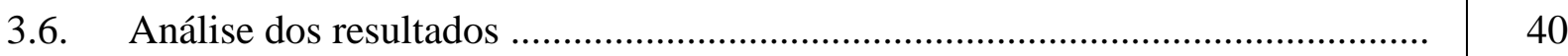

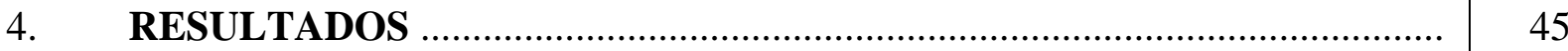

4.1. Diferenças entre subgrupos de dor cervical e Teste da versão pré-final ...............

4.2. Validade Estrutural das Escalas do ProFitMap-neck ........................................ 53

4.3. $\quad$ Erro padrão da medida, Mínima Diferença Detectável e Reprodutibilidade das 58 Escalas do ProFitMap-neck 
4.4. Consistência Interna das Escalas do ProFitMap-neck.......................................

4.5. Validade de Construto...........................................................................

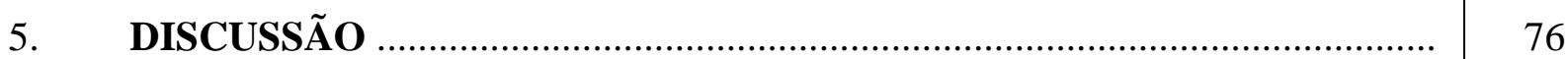

5.1. Amostras do estudo e Diferenças entre os subgrupos de dor cervical .................. 78

5.2. Adaptação Transcultural do ProFitMap-neck versão português-Brasil ................ 79

5.3. Confiabilidade e Erro Padrão da Medida do ProFitMap-neck versão portuguêsBrasil

5.4. Validade Estrutural e Consistência Interna do ProFitMap-neck versão português-Brasil

5.5. Validade de Construto do ProFitMap-neck versão português-Brasil ................... $\quad 86$

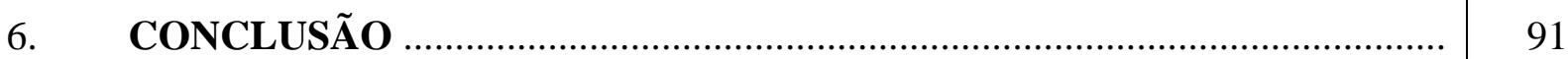

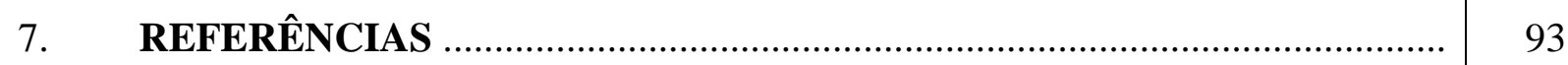

ANEXO 1 - Profile Fitness Mapping Neck revisado original ...................................... 105

ANEXO 2 - Aprovação do Comitê de Ética em Pesquisa ............................................. 108

ANEXO 3 - Autorização para a adaptação transcultural do ProFitMap-neck ............... 109

ANEXO 4 - Neck Disability Index ................................................................ 110

APÊNDICE 1 - ProFitMap-neck versão síntese de tradução T123 ............................... 112

APÊNDICE 2 - ProFitMap-neck versão tradução sueco-português $\quad$................................. 120

APÊNDICE 3 - ProFitMap-neck versão retrotradução português-sueco ....................... 122

APÊNDICE 4 - ProFitMap-neck versão síntese de retrotradução RT12 _....................... 125

APÊNDICE 5 - ProFitMap-neck pré-final e final .................................................... 135

APÊNDICE 6 - Questionário semi-estruturado teste da versão pré-final ..................... 145

APÊNDICE 7 - Termo de Consentimento Livre e Esclarecido ................................... 147 


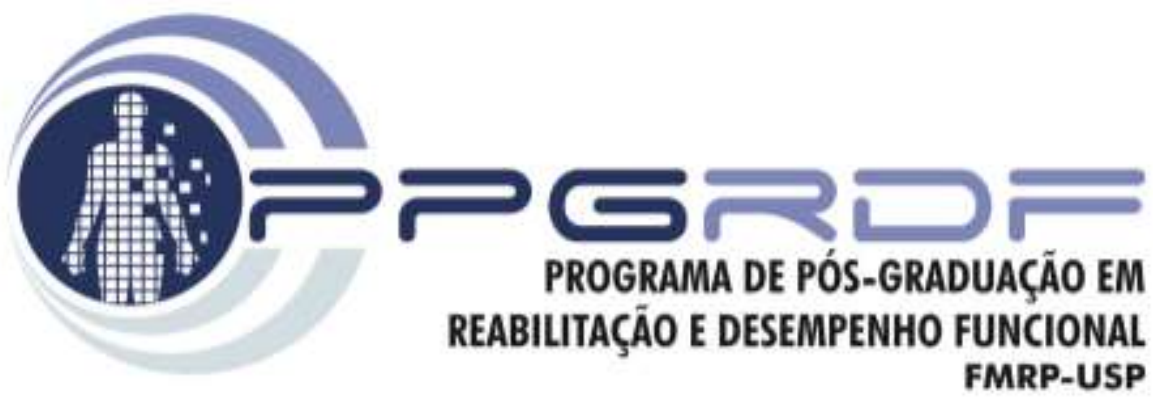

INTRODUÇÃO

"Não estou preocupado com a morte, mas com a vida, para que ela não seja banal e fútil. A vida é muito curta para ser pequena. Quando morrer, o que vai deixar?”.

Mário Sergio Cortella 


\section{INTRODUÇÃO}

\subsection{Dor cervical}

A dor cervical é uma disfunção musculoesquelética comum, cuja ocorrência é estimada em torno de 30-50\% da população adulta em geral (HOGG-JOHNSON et al., 2008). Estipula-se que 54\% da população tenha tido dor cervical nos últimos seis meses, essa prevalência parece aumentar com o envelhecimento, com pico de prevalência por volta dos 45 anos de idade (CHILDS et al., 2008; HOY et al., 2014). É definida como uma dor percebida dentro da região limitada superiormente pela linha da nuca, lateralmente pelas margens laterais do pescoço e inferiormente pela linha horizontal imaginária que passa através do processo transverso de T1, sem o pressuposto de que a causa da dor encontre-se dentro desta área (BOGDUK, 2003).

As causas da dor cervical podem ser variadas, como tumores, traumas, infecções, doenças inflamatórias e congênitas, e as queixas podem surgir de algumas estruturas do pescoço e da cabeça, como discos intervertebrais, ligamentos, facetas articulares, músculos e raízes nervosas (BOGDUK, 1988). De acordo com os sintomas apresentados e exame clínico, a dor cervical pode ser classificada em dor cervcical; dor na coluna torácica; cefaleia; síndrome craniocervical; espondilólise com radiculopatia e disfunção discal cervical com radiculopatia (CHILDS et al., 2008). A dor cervical frequententemente coexiste com outras comorbidades tais como outras dores musculoesqueléticas, cefaleia, distúrbios do sono e trauma cervical (EVANS, 2014). A literatura relata forte evidência para essa associação e pior prognóstico (HOGG-JOHNSON et al., 2008).

Apesar da história e do exame clínico sugerirem causas em potencial, na maioria dos casos, a fisiopatologia da dor cervical não é clara e, por isso, é rotulada como não específica (MAROUFI et al., 2012). Na grande maioria dos casos, os mecanismos fisiopatológicos subjacentes não são claros e esses casos não específicos são onerosos em termos de incapacidade e absenteísmo no trabalho, assim como acontece para a dor lombar (AKER et al., 1996). Na ausência de fatores etiológicos bem definidos, os tratamentos são direcionados para o alívio dos sintomas e os 
programas de reabilitação direcionados para melhora da incapacidade resultante (BJORKLUND et al., 2012). Dessa forma, torna-se importante a validação de questionários/instrumentos para avaliação da dor e outros sintomas relacionados, bem como a limitação funcional/incapacidade relacionada à dor cervical.

\subsection{Incapacidade, Funcionalidade e Instrumentos de avaliação}

A definição dos conceitos de incapacidade e funcionalidade é foco de intenso debate na literatura atual (IMRIE, 2004). O modelo biomédico tem origem na profissão médica e é focado na deficiência, doença ou "anormalidade" corporal e na maneira como isso produz algum grau de incapacidade ou limitação funcional (SAMPAIO; LUZ, 2009). A perspectiva biomédica reduz a deficiência à categoria de doença corporal e foca no paciente, e não na pessoa. A incapacidade é então entendida como consequiência biológica do mau funcionamento do organismo (SAMPAIO; LUZ, 2009).

Por outro lado, a sociologia sugere que o significado de deficiência e de incapacidade deve estar atrelado aos contextos sociais e culturais (SAMPAIO; LUZ, 2009). Para alguns autores, a incapacidade não tem um significado universal, e estudos antropológicos apontam que em alguns idiomas e culturas não existe o termo "incapacidade" (SAMPAIO; LUZ, 2009). Dessa maneira, considerado a visão sociológica não é a incapacidade que prediz a interação social, mas o contexto social que dá significado à incapacidade. A incapacidade seria então o resultado de uma interação entre biologia, estrutura social e institucional (SAMPAIO; LUZ, 2009).

Para a Organização Mundial de Saúde (OMS) através da Classificação Internacional de Funcionalidade, Incapacidade e Saúde (WHO, 2001), incapacidade pode ser representada por dimensões distintas, mas inter-relacionadas. Deficiência (impairment) incluíria sistemas ou partes do corpo que não funcionam apropriadamente; incapacidade (disability) centra-se em coisas que as pessoas não podem fazer, especialmente atividades básicas da vida diária e o desempenho de 
papéis socialmente esperados. Por outro lado, o termo funcionalidade (functionning) engloba os aspectos da saúde que não apresentam problemas (neutros), agrupados sob o termo guarda-chuva “funcionalidade" (estrutura e função corporal, atividade e participação) (WHO, 2001).

Existem alguns quesionários destinados à avaliação dos sintomas cervicais e da funcionalidade/incapacidade resultante. A maior parte deles focado no conceito de incapacidade. O mais utilizado na literatura é o Neck Disability Index (NDI) (VERNON; MIOR, 1991). Há, ainda o Pain Disability Index (POLLARD et al., 1984), Neck Pain and Disability Scale (NPDS) (WHEELER et al., 1999), o Patient-Specific Functional Scale Self-Reports with Neck Dysfunction (PSFS) (WESTAWAY; STRATFORD; BINKLEY, 1998), Copenhagen neck functional disability scale (JORDAN et al., 1998), o Northwick Park Neck Pain Questionnaire (NPQ) (LEAK et al., 1994), Extended Aberdeen Back Pain Scale (WILLIAMS; WILKINSON; RUSSELL, 2001), o Bournemouth Questionnaire (BOLTON; HUMPHREYS, 2002), o Cervical Spine Outcome Questionnaire (CSOQ) (BENDEEBA et al., 2002), o Core Neck Pain Questionnaire (CNPQ) (WHITE; LEWITH; PRESCOTT, 2004), o Spine Functional Index (GABEL et al., 2013) e o Core Outcome Measures Index (COMI) for the neck (MONTICONE et al., 2014).

Para o português Brasileiro apenas a ferramenta Neck Disability Index e o Neck Pain and Disability Scale estão adaptados transculturalmente (COOK et al., 2006) e os resultados disponíveis na literatura sobre suas propriedades psicométricas são controversos. Na revisão sistemática de MacDermid et al. (2009) sobre as propriedades de medidas das várias versões linguísticas do NDI, o processo de adaptação e validação foi considerado de alta qualidade, já na revisão de Schellingerhout et al. (2011), o NDI versão português Brasil não foi incluído, já que o processo de adaptação transcultural não atingiu os critérios mínimos recomendados pelos guidelines internacionais e pelo COSMIN. Na revisão de MacDermid et al. (2009), a qualidade do processo de tradução não foi considerada. 
Wiitavaara et al. (2009) em uma revisão da literatura verificaram que apenas dois dos 10 questionários destinados a avaliar dor, funcionalidade/incapacidade, realizaram adequadamente o processo de validação de face e conteúdo, etapa em que o público alvo para o qual a ferramenta é destinada e os experts na área fazem sugestões para composição da ferramenta. Na maioria dos casos os itens foram selecionados em teorias e questionários já existentes. Além disso, 6 de 10 questionários para avaliação cervical eram instrumentos para dor lombar modificados para avaliação da incapacidade/funcionalidade relacionada à dor cervical. Bjorklund et al. (2012) sugerem que esse é um problema que compromete a validade de conteúdo dessas ferramentas, já que muitas ferramentas utilizadas na dor cervical são baseadas em ferramentas elaboradas para pacientes com dor lomabar. No entanto, a dor cervical tem especificidades não contempladas pelas ferramentas originalmente elaboradas para dor lombar.

Fejer e Hartvigsen (2008) relataram uma correlação fraca entre dor e incapacidade em pacientes com sintomas moderados de dor cervical. Os dados deste estudo (FEJER; HARTVIGSEN, 2008) sugerem que a dor e a incapacidade devem ser interpretadas como dimensões distintas para melhorar a capacidade das ferramentas em detectar subgrupos de pacientes. Em questionários como NDI (VERNON; MIOR, 1991) e o Northwick Park neck pain questionnaire (LEAK et al., 1994) todos os itens são organizados em apenas uma dimensão, o que pode mascarar alterações em itens específicos da ferramenta uma vez que o paciente pode obter melhora em um domínio e piora em outro, sem alterações na pontuação total da ferramenta. Esse tipo de fenômeno é chamado de item-masking score bias (MÜLLER; RÖDER; GREENOUGH, 2006). Contudo, o Profile Fitness Mapping neck questionnaire (ProFitMap-Neck) é a única ferramenta que apresenta diferentes domínios destinada à avaliação de pacientes com dor cervical.

O ProFitMap-neck foi desenvolvido originalmente em Sueco (BJORKLUND et al., 2012). Este é composto de 44 itens em 2 escalas (Escala de sintomas - contendo 26 itens e Escala de Limitação Funcional - contendo 18 itens). Além de intensidade dos sintomas, o questionário 
também prevê a graduação da frequência de ocorrência desses sintomas, bem como a graduação de dificuldade da escala de funcionalidade. Foi testado em três grupos de indivíduos, o primeiro com lesão em chicote cervical em atendimento clínico $(n=127)$, o segundo de pacientes com dor cervical inespecífica $(n=83)$ e o terceiro de indivíduos com dor cervical inespecífica e que não estavam recebendo atendimento para dor cervical $(n=104)$.

O ProFitMap-neck mostrou boa consistência interna em todos os três grupos, níveis adequados de confiabilidade e boa correlação com NDI. De acordo com a Classificação Internacional de Funcionalidade, Incapacidade e Saúde, a escala de sintomas do ProFitMap-neck foi principalmente classificada para o domínio de funções e deficiências de corpo, e a escala de limitação funcional para o domínio limitação da atividade. A combinação de uma classificação total de sintomas e função faz o ProFitMap-neck a única ferramenta disponível na literatura que engloba a avaliação de ambos os construtos: incapacidade e funcionalidade. E dessa forma, pode ser considerado mais adequado para aplicação na pesquisa, bem como na prática clínica (BJORKLUND et al., 2012).

Wiitavaara et al. (2009) compararam os sintomas relatados por pacientes com dor cervical crônica ao conteúdo de 10 questionários específicos para dor cervical. Em geral, os autores verificaram baixa correlação entre os sintomas dos pacientes e o conteúdo dos questionários. No entanto, na análise do conteúdo do ProFitMap-neck foi observada grande correspondência com os sintomas relatados, diferentemente das demais ferramentas revisadas, ressaltando a importância do ProFitMap-neck ter sido elaborado considerando-se a contribuição dos pacientes para criação dos itens. 


\subsection{Adaptação transcultural e propriedades de medida}

A maior parte dos instrumentos disponíveis na literatura para avaliação da disfunção cervical foram originalmente desenvolvidos na língua inglesa. Assim, em países cuja língua nativa não é o inglês, é importante a adequada adaptação do instrumento para a língua local, respeitandose uma série de recomendações disponíveis em guidelines internacionais (BEATON et al., 2000).

O termo "adaptação transcultural" indica o processo metodológico que se preocupa com a tradução e adaptação cultural de instrumentos que serão utilizados em situações diferentes daquelas para as quais havia sido desenvolvido. As etapas a serem seguidas incluem: tradução do questionário para a língua falada no país onde se pretende aplicá-lo, síntese da tradução, retrotradução para a língua original do questionário, revisão por um comitê de experts e teste da versão pré-final (BEATON et al., 2000; MAHER; LATIMER; COSTA, et al., 2007).

O teste das propriedades clinimétricas/psicométricas do instrumento traduzido e adaptado é importante para verificar se o questionário adaptado reteve as mesmas propriedades apresentadas pela versão original do instrumento. Esta metodologia facilita a comparação dos resultados obtidos pelo mesmo questionário em diferentes culturas (MAHER; LATIMER; COSTA, 2007).

Para determinar se um instrumento de pesquisa está adequado para aplicação clínica devese avaliar se determinados critérios foram seguidos para elaboração e validação deste, assegurando-se a confiabilidade dos dados coletados, portanto, essencialmente um instrumento de pesquisa tem que ser avaliado quanto à confiabilidade e à validade (BEATON et al, 2000; SWINKELS-MEEWISSE et al., 2003; ALEXANDRE; COLUCI, 2011). Para tal existem guidelines e consensos internacionais que podem fornecer parâmetros para os pesquisadores em 
diferentes partes do mundo como o COSMIN (COnsensus-based Standards for the selection of health Measurement INstruments) (MOKKINK et al., 2010).

Quando no processo de tradução e adaptação transcultural de uma ferramenta, observam-se boas propriedades psicométricas, é indicativo que esta pode ser utilizada na comparação em estudos internacionais e/ou multicêntricos, pois viabilizam a padronização e comparação dos resultados.

De acordo com Acquadro et al. (2008) muitos são os guias propostos na literatura para orientar os processos de tradução de uma ferramenta, dentre eles destacam-se os guias propostos por GUILLEMIN, BOMBARDIER e BEATON (1993) e por Beaton et al. (2000).

$\mathrm{Na}$ atualidade, o COnsensus-based Standards for the selection of health Measurement INstruments (COSMIN) (MOKKINK et al., 2012) contribuiu para padronizar aspectos na área de psicometria, disponibilizando um guia detalhado das etapas necessárias para validação, adaptação transcultural e avaliação crítica de estudos que empregaram tais processos. O COSMIN é um consenso baseado em padrões para a seleção de instrumentos de medida da área da saúde, consenso este proveniente de um estudo Delphi, com a participação de 43 experts internacionais (MOKKINK et al., 2010).

Dentro deste manual existem algumas definições importantes. Uma delas é a da validação transcultural, que corresponde ao grau em que o desempenho dos elementos de um instrumento traduzido ou adaptado transculturalmente é o reflexo adequado da versão original do instrumento (MOKKINK et al., 2012).

O processo de tradução e adaptação transcultural de acordo com o COSMIN recomenda ao menos dois tradutores a cada passo (tradução inicial e retrotradução), que devem executar as traduções individualmente e independentemente. Na tradução inicial, os tradutores devem: um ser leigo na temática em questão e o outro especialista sobre o assunto, já as exigências da 
retrotradução são em relação ao domínio da língua original da ferramenta e ao cegamento para a versão original do instrumento de ambos os tradutores.

Os membros do comitê de especialistas devem compor uma equipe multiprofissional, com especialistas no construto que devem ser caracterizados quanto ao domínio das línguas (língua original e lígua alvo) e membros da população que falem a língua para qual o instrumento está sendo traduzido (língua alvo) (MOKKINK et al., 2012).

O processo de tradução e retrotradução pode acontecer em etapas: tradução inicial para o português, síntese das traduções, reunião para consenso dos tradutores, retrotradução, comitê de especialistas e teste da versão pré-final do questionário (GUILLEMIN; BOMBARDIER; BEATON, 1993; BEATON et al., 2000; BEATON et al., 2002; MOKKINK et al., 2012).

Durante as reuniões os membros são instruídos a buscar equivalência entre a versão original e a versão pré-final em 4 áreas (GUILLEMIN; BOMBARDIER; BEATON, 1993): equivalência semântica, equivalência idiomática, conceitual e equivalência cultural (GUILLEMIN; BOMBARDIER; BEATON, 1993).

Um dos últimos passos a serem seguidos é o teste da versão pré-final. Nessa etapa o questionário (versão pré-final) deve ser aplicado na população-alvo. É importante destacar que se na versão pré-final ao ser aplicada a ferramenta, for identificada a necessidade de reformulações do instrumento, os questionários previamente aplicados devem ser excluídos e novos voluntários selecionados para completar a amostra final do estudo e responder à última versão do questionário.

Os voluntários devem ser convidados a completar o questionário e responder um formulário sobre sua impressão a respeito de cada item, opções de resposta, cabeçalhos dos itens, instruções e layout da ferramenta. Esta etapa do processo compreende aspectos de validação de face (BEATON et al., 2000).

Reconhece-se ainda, a necessidade de seguir protocolos aceitos internacionalmente para viabilizar a padronização dos processos de tradução e adaptação cultural, pois estudos sobre 
avaliação das propriedades de medida de um instrumento devem apresentar alta qualidade metodológica para garantir que o construto pretendido está sendo avaliado, devendo ainda preencher os requisitos referentes às análises estatísticas (DE VET et al., 2011; MOKKINK et al., 2012).

De acordo com o protocolo COSMIN (MOKKINK et al., 2012), dentro do domínio de reprodutibilidade da ferramenta (o grau no qual a medida é livre de erro aleatório e sistemático) se encaixam as propriedades de medida "Reprodutibilidade" e "Consistência Interna". A medida de reprodutibilidade é definida como a proporção de variância total da medida em relação às verdadeiras medidas provindas das respostas dos voluntários (MOKKINK et al., 2012). Já a consistência interna é definida como o grau de interrelações entre os itens (MOKKINK et al., 2012).

A validade de construto é outra propriedade de medida, definida como o grau em que as pontuações de um instrumento são consistentes com as hipóteses (MOKKINK et al., 2012). Esta é subdivida em teste de hipóteses, validade estrutural e validade transcultural. O teste de hipóteses é definido como o grau em que as pontuações de uma ferramenta de avaliação são consistentes com as hipóteses que geraram o construto em questão (por exemplo, a correlação entre pontuações de questionários que mensuram construtos similares), isso baseando-se na hipótese de que o construto mensura de maneira valida o construto a ser medido. A validade estrutural é o grau com o qual um instrumento mostra-se como um reflexo das dimensões do construto a ser mensurado. Já a validade transcultural é o grau com o qual a performance dos itens de um instrumento adataptado transculturalmente demonstra uma reflexão adequada dos itens da versão original do instrumento (MOKKINK et al., 2012).

A fim de que os dados forneçam uma base sólida para a tomada de decisão, a feramenta deve ser válida para o propósito alvo e o resultado deve ser reprodutível (TAKALA et al., 2010). Para tanto, as propriedades psicométricas devem mensuradas, como a validade de face e conteúdo, 
a reprodutibilidade do questionário, a consistência interna, a validade de construto e validade estrtutural (MOKKINK et al., 2012).

Assim, podemos destacar três aspectos que denotam a importância da realização do presente estudo: 1) A importância de se avaliar ambos os construtos incapacidade e funcionalidade na dor cervical; 2) As ferramentas disponíveis em português-brasileiro podem estar inadequadas em termos de adaptação transcultural ou validação (Schellingerhout et al., 2011) e 3) O ProFitMap-neck ser o único instrumento disponível na literatura que emgloba mais amplamente os aspectos de incapacidade e funcionalidade, mas estar disponível apenas em inglês/sueco.

Dentro deste contexto, a adaptação transcultural e validação do ProFitMap-neck para o português tornará disponível para utilização de pesquisadores e clínicos no Brasil, um instrumento que avalia aspectos de incapacidade e funcionalidade para indivíduos com dor cervical. 


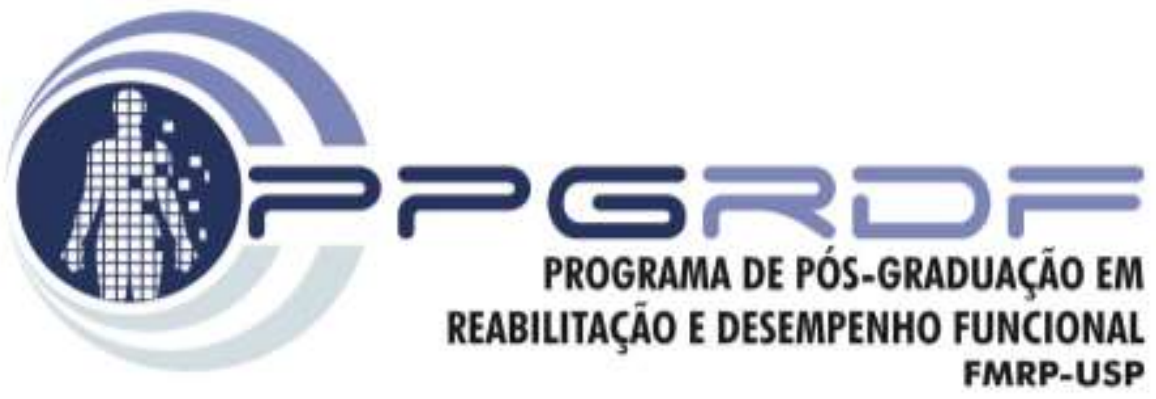

OBJETIVOS

"Se um dia tiver que escolher entre o amor e o mundo, escolha o amor. Se escolher o mundo ficará sem o amor, se escolher o amor poderá conquistar o mundo".

Albert Einstein 


\section{OBJETIVOS}

\subsection{Objetivo Geral}

O objetivo central deste estudo foi realizar a tradução e adaptação transcultural para o português brasileiro do Profile Fitness Mapping Neck (ProFitMap-neck) para pacientes com dor cervical crônica.

\subsection{Objetivos Específicos}

Avaliar as seguintes propriedades de medida da versão em português do Brasil do ProFitMap-neck: consistência interna dos itens, reprodutibilidade, validade de construto e validade estrutural.

Verificar diferenças nos níveis de incapacidade/funcionalidade entre subgrupos de pacientes com dor cervical e comorbidades associadas (DTM, Cefaléia e Fibromialgia). 


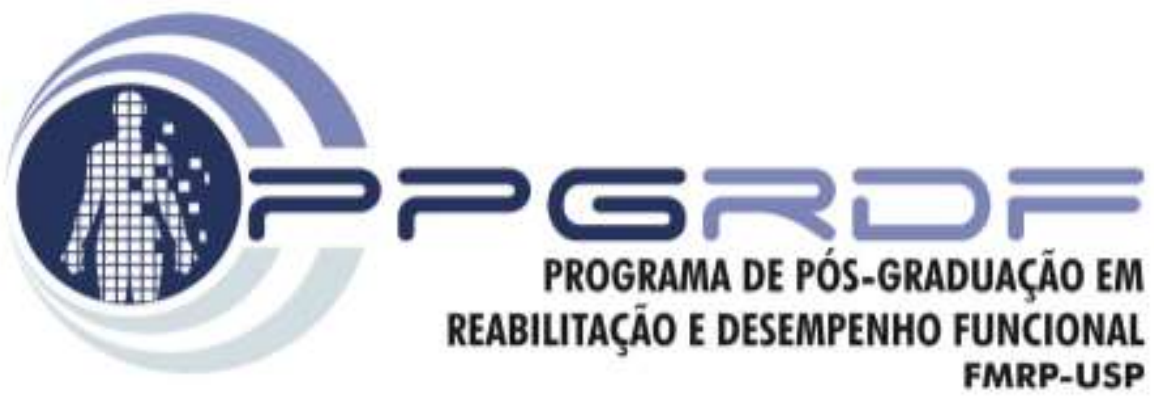

MÉTODOS

“A tarefa não é tanto ver aquilo

que ninguém viu, mas pensar o que ninguém ainda

pensou sobre aquilo que todo mundo vê."

Arthur Schopenhauer 


\section{MÉTODOS}

\subsection{Amostra, critérios de inclusão e exclusão}

Este trabalho foi coletado de setembro de 2014 a junho de 2015, contando com a participação de 180 pacientes, do sexo feminino, todas voluntárias e com queixa de dor cervical há pelo menos 3 meses. Para o teste da versão pré-final e validação de face e conteúdo, a amostra foi composta por 30 indivíduos com média de idade $33,44 \pm 10,32$ anos. Para a confiabilidade a amostra foi composta de 100 indivíduos com idade média de 38,89 \pm 10,84 anos, e para a validação de construto, consistência interna, análise fatorial e correlação do ProFitMap-neck com os demais questionários, a amostra foi composta por 180 indivíduos com idade média de 37,49 \pm 11,86 anos (TERWEE et al., 2012) (Tabela 1).

Tabela 1 - Caracterização da Amostra para cada Etapa de Validação do ProFitMap-Neck

\begin{tabular}{ccc}
\hline Etapas do estudo & Tamanho amostral & Média e Desvio Padrão de Idade \\
\hline Teste da versão Pré-Final & 30 & $33,44 \pm 10,32$ \\
Confiabilidade & 100 & $38,89 \pm 10,84$ \\
$\quad \begin{array}{l}\text { Validação e } \\
\text { Consistência Interna }\end{array}$ & 180 & $37,49 \pm 11,86$ \\
\hline
\end{tabular}

Foram incluídos, pacientes com dor cervical há mais de 3 meses durante o movimento ou o repouso. Foram excluídos deste estudo voluntários do sexo masculino, com idade inferior a 18 anos e superior a 55 anos, histórico de tumores na região craniofacial e cervical, traumas, fraturas, infecções agudas na região cervical, bem como doenças degenerativas sistêmicas e cirurgias recentes na região craniofacial e cervical. 


\subsection{Profile Fitness Mapping neck questionnaire (ProFitMap-neck)}

O Profile Fitness Mapping neck pain questionnaire é uma ferramenta auto-administrável utilizada para avaliação de sintomas e limitação funcional/incapacidade relacionada à dor cervical. O questionário é composto de 2 domínios: Escala de Sintomas/Frequência e Escala de Limitação Funcional.

A Escala de sintomas tem 26 questões e por sua vez é subdividida em escala de intensidade e frequência. A escala de intensidade questiona sobre a ocorrência dos sintomas em 6 itens: "Nothing/none at all", "Weak/little", "Rather weak/rather little”, "Rather strong/rather much", "Strong/much”, “Almost unbearable/ unbearable, all/maximally”. Já na escala de frequência os itens podem ser graduados com os seguintes descritores: "Never/very seldom", "Seldom", "Rather seldom", "Rather often", "Often” e "Very often/always". A escala de limitação funcional tem 18 questões com 6 opções de resposta: 1."Very good, no problem, very satisfying, very likely". 2. "Good, easily, satisfying, likely”. 3. "Rather good, rather easy, rather satisfying, rather likely". 4. "Rather bad, rather difficult rather dissatisfying, rather unlikely”. 5. "Bad, difficult, dissatisfying, unlikely". 6. "Very bad, very difficult/impossibly very dissatisfying, very unlikely” (ANEXO I) (BJORKLUND et al., 2012).

A pontuação do ProFitMap-neck na versão original é feita de forma individual para cada questão a partir de uma equação pré-determinada, logo após todos os escores das questões são somados chegando-se a um escore total para o domínio (ANEXO I). Por sua vez, o escore total é dividido pelo maior escore possível para o domínio, sendo 339 para as escalas de Sintomas/frequência e Sintomas/Intensidade, e 236 para a Escala de Limitação Funcional. Esse valor pode ser tratado como porcentagem (ao ser multiplicado por 100), sendo que quanto maior o escore final menor os níveis de incapacidade/funcionalidade (ANEXO I). 
As equações para o score individual de cada questão são $\left(6-\mathrm{f}_{\mathrm{x}}\right) * \mathrm{~W}_{\mathrm{x}}$ para a Escala de Sintomas/frequência e Escala de Funcionalidade e $\left(12-\mathrm{f}_{\mathrm{x}}\right) * \mathrm{~W}_{\mathrm{x}}$ para a escala de Sintomas/intensidade, sendo os valores de 6 e 12 as maiores pontuações para cada questão das escalas correspondentes, $\mathrm{f}_{\mathrm{x}}$ assinalado pelo indivíduo na questão, bem como $\mathrm{W}_{\mathrm{x}} \mathrm{o}$ valor de peso atribuído previamente para cada questão (ANEXO 1).

As questões disponíveis no domínio de sintomas versam sobre: 1) rigidez no pescoço, 2) dor, 3) tensão, 4) estalidos, 5) cansaço, 6) fraqueza, 7) adormecimento, 8) distúrbios de sensibilidade, 9) problemas orofaciais, 10) zumbido, 11) problemas de equilíbrio, 12) irritabilidade, 13) depressão, 14) estresse, 15) náusea, 16/17) sensibilidade a luz e ao som, 18) distúrbios da deglutição, 19) respiração, 20) deglutição, 21) distúrbios da concentração, 22) dor durante atividade, 23) dor durante repouso, 24) ansiedade, 25) problemas para dormir e 26) problemas de humor (BJORKLUND et al., 2012).

Já a escala de limitação funcional questiona sobre a interferência da dor cervical nos seguintes itens: 1) ficar em pé, 2) andar, 3) sentar, 4) deitar-se, 5) correr, 6) carregar algo, 7) levantar, 8) jogar, 9) colocar um suéter, 10) colocar meias, 11) inclinar a cabeça para trás, 12) inclinar a cabeça para frente, 13) inclinar a cabeça para direita, 14) inclinar a cabeça para esquerda, 15) rodar a cabeça para direita, 16) rodar a cabeça para esquerda, 17) interferência da dor cervical na sua saúde geral e 18) interferência da dor cervical no funcionamento do seu pescoço como um todo (BJORKLUND et al., 2012).

Todos os participantes assinaram um termo de consentimento livre e esclarecido que lhes foi fornecido de acordo com a resolução nº 466 de abril de 2012 do Conselho Nacional de Saúde e aprovado pelo Comitê de Ética em Presquisa do Hospital das Clínicas da Faculdade de Medicina de Ribeirão Preto número CAE: 24663514.0.0000.5440 (ANEXO II). 


\subsection{Adaptação transcultural do ProFitMap-neck para o português-brasileiro}

Realizar somente a tradução literal de um instrumento pode torná-lo incompreensível em outras línguas, devido à existência de nuances culturais (frases coloquiais, gírias, jargões e expressões idiomáticas) que, ao serem traduzidas para um contexto diferente perdem o significado original (BEATON et al., 2000; ALEXANDRE; COLUCI., 2011). Portanto, instrumentos desenvolvidos em outras línguas e culturas devem ser adaptados ou modificados até ficarem linguística e semanticamente compreensíveis, para um novo idioma, cultura e estilo de vida.

Neste estudo, os processos de tradução e retrotradução ocorreram em cinco etapas: tradução inicial para o português, síntese das traduções, a retrotradução ou back-translation, o Comitê de Especialistas e teste da versão pré-final do questionário (BEATON et al., 2002; BEATON et al., 2000; GUILLEMIN; BOMBARDIER, BEATON, 1993).

\subsubsection{Tradução inicial para o português}

Após contato com os autores da ferramenta ProFitMap-neck a tradução foi autorizada (ANEXO III). A versão original em sueco foi traduzida para o português por 1 tradutor expert brasileiro dominante da língua sueca, e a versão em inglês, por 1 tradutor leigo e 1 tradutor expert fluentes em ambas as línguas, cuja língua mãe era o português. Beaton et al. (2000) recomnedam que a tradução seja realizada a partir da versão original do questionário. Por outro lado, Guillemin, Bombardier e Beaton (1993) prevêm que em situações em que a língua original da ferramenta pode dificultar a operacionalização da participação de tradutores fluentes, é possível a realização da tradução a partir de uma versão inicial em inglês literal. Assim, realizamos o processo de tradução a partir de uma versão em inglês disponibilizada pelos autores da ferramenta original (2 tradutores e 2 retrotradutores) e a partir de uma versão em sueco (1 tradutor e 1 retrotradutor). 
Ao final do processo os tradutores foram convidados a preencher o item de "comentários adicionais" do formulário de tradução para que pudessem destacar frases ou incertezas originadas do processo de tradução, bem como, a razão para as escolhas feitas.

Os tradutores também foram convidados a traduzir os tópicos de conteúdo dos itens, opções de resposta e instruções, e tiveram que atender a dois diferentes perfis:

- Tradutores inglês/português: o tradutor 1-inglês (T1) deverá estar ciente dos conceitos do questionário que está sendo traduzido (Incapacidade e Funcionalidade relacionada à dor cervical). Presume-se que este tradutor tenha fornecido uma tradução mais adequada na perspectiva clínica e mais confiável na perspectiva de propriedades de medida. Este tradutor tinha o português como língua mãe. O tradutor 2-inglês (T2), pelo contrário, não estava ciente dos conceitos do questionário que estava sendo traduzido e não era profissional da saúde. O objetivo de incluir esse tradutor está relacionado ao fato de que este era menos influenciado pelas metas acadêmicas e possivelmente conseguiu de uma maneira mais adequada refletir a língua utilizada pela população. Este tradutor também tinha o português como língua mãe.

- Tradutor sueco/português: o tradutor 3-sueco (T3) estava ciente dos conceitos do questionário que está sendo traduzido (Incapacidade e Funcionalidade relacionada à dor cervical) e tinha domínio do sueco, além de ter o português como língua mãe. Este elaborou a versão T3 (APÊNDICE 2).

\subsubsection{Síntese das traduções e Consenso entre tradutores}

Ambas as traduções foram sintetizadas e as discrepâncias corrigidas a fim de se criar um documento único. Assim, os tradutores e um pesquisador relator/observador reuniram-se para sintetizar as versões obtidas como sugerido por Beaton et al. (2000). Esse processo foi realizado 
tendo em mãos as versões T1, T2 e T3 para o português do ProFitMap-neck. Essa versão sintética foi chamada T123 (APÊNDICE 1) e foi acompanhada de um documento resultante do processo de síntese escrito pelo pesquisador relator considerando todos os aspectos discutidos e o modo como foram resolvidos. O consenso foi favorecido em detrimento da percepção de um profissional envolvido.

\subsubsection{Retrotradução ou Backtranslation}

Nessa fase 2 tradutores, cuja língua mãe deveria ser o inglês, foram convidados a traduzir a versão T123 do questionário, em português, para o inglês. Esses tradutores eram totalmente “cegos" para a versão do questionário original, ou seja, era importante que nenhum desses tradutores tivessem tido acesso prévio ao conteúdo do ProFitMap-neck. Esse processo foi realizado para garantir que a versão traduzida estivesse contemplando e refletindo os mesmos conteúdos da versão original. Para que a versão pré-final ficasse ainda mais fidedigna a versão original, o autor da ferramenta foi convidado a participar do processo de backtranslation verificando se as questões, bem como o layout da ferramenta estavam de acordo com o objetivo inicial do desenvolvimento do questionário. Esse processo auxilia na amplificação de traduções incorretas, inconsistências grosseiras e erros conceituais e garante uma tradução consistente. As três versões originárias desse processo foram definidas RT1, RT2, RT3 (RT - retrotradução). A vesrão RT3 foi através da tradução da versão T123 para o sueco (APÊNDICE 3).

\subsubsection{Reunião do Comitê de Especialistas}

É uma etapa crucial para se alcançar a equivalência transcultural, sendo que a composição dos membros desse comitê deve contemplar profissionais da saúde, da área de reabilitação, os 
tradutores e tradutores de inglês e sueco. Os autores do ProFitMap-neck original foram informados sobre todas as etapas das reuniões via relatório de atividades e sobre as principais dificuldades durante esse processo, bem como por contato via e-mail e skype.

O papel desse comitê é consolidar todas as versões do questionário e conceber a versão pré-final a ser aplicada nos testes de campo. O comitê foi incumbido de revisar todas as traduções (T1, T2, T3, T123, RT1, RT2, RT3) e chegar a um consenso sobre possíveis discrepâncias. Os comentários adicionais feitos nos processos de tradução e retro tradução foram trazidos, bem como os relatórios escritos pelo pesquisador relator/observador. O pesquisador relator/observador novamente agrupou em um relatório os principais aspectos discutidos e as razões para a tomada de decisões específicas.

Os membros do comitê foram instruídos a buscar equivalência entre a versão original em sueco, inglês e a versão pré-final em 4 áreas:

- Equivalência semântica: o significado associado a cada item. As palavras apresentam o mesmo significado da versão original? É possível que existam múltiplos sentidos para um determinado item? Existem problemas gramaticais na tradução?

- Equivalência idiomática: coloquialismos e expressões idiomáticas são difíceis de traduzir, caso isso ocorra recomenda-se que o comitê formule uma expressão equivalente na versão pré-final.

- Equivalência de experiências/cultural: os itens devem contemplar as experiências de vida diária, considerando-se que em diferentes culturas ou países a carga emocional, e as características de dor são interpretadas de formas distintas, bem como as características quando traduzíveis. Recomenda-se, quando há discrepância, que o item seja substituído por um similar que de fato represente experiências reais na cultura alvo.

- Equivalência conceitual: Algumas vezes certas palavras possuem diferentes significados conceituais entre culturas. Um exemplo é o significado do termo família. 
O comitê avaliou as versões originais e retrotraduzidas para todas as equivalências. Na ausência de consenso era possível que as etapad de tradução e retrotradução tivessem que ser realizada novamente para verificar se outra expressão resolveria o problema, o que não ocorreu. Todos os tradutores estavam presentes na reunião de comitê para o caso da necessidade de uma nova tradução e retrotradução. A partir desta reunião do comitê foi obtida a versão RT12 (APÊNDICE 4) que foi enviada para o autor da ferramenta original para revisão e após as considerações do autor da ferramenta original está foi denominada de versão pré-final (APÊNDICE 5).

\subsubsection{Teste da versão pré-final}

A etapa final do processo de adaptação é o teste da versão pré-final. Beaton et al. (2000) recomendam uma amostra de 30 a 40 pessoas para esta fase da tradução transcultural, desta maneira, o ProFitMap-Neck foi aplicado em 30 pacientes com dor cervical crônica. É importante destacar que o questionário na sua versão final foi aplicado em 30 sujeitos, ou seja, ao longo da etapa de pré-teste, enquanto houvesse a necessidade de reformulações do questionário, os previamente aplicados deveriam ser excluídos, e novos voluntários deveriam ser selecionados para completar a amostra final do estudo e responder à última versão do questionário.

Os voluntários foram convidados a completar o questionário e foram entrevistados através da aplicação de um questionário semi-estruturado sobre sua impressão de cada item do questionário: opções de resposta, cabeçalhos dos itens, instruções e lay-out da ferramenta (APENDICE 6). O entrevistador também esteve atento para muitas respostas únicas para itens diferentes ou mesmo item sem reposta em diversas aplicações. Essa etapa do processo compreende aspectos de validação de face e conteúdo (BEATON et al., 2000). 


\subsection{Consistência interna e Validade de Construto}

De acordo com o checklist COSMIN (MOKKINK et al., 2010) a consistência interna é importante para homogeneizar os resultados de um questionário utilizando para tal avaliação a verificação do grau de consistência entre os itens que compõem a ferramenta, a consistência interna pode ser estabelecida, de preferência por meio do cálculo do alfa de Cronbach. Itens redundates sugerem a necessidade de revisão do item e até mesmo exclusão.

Recomenda-se a utilização de uma amostra de no mínimo 100 indivíduos para assegurar a estabilidade da matriz de covariância para verificação de validade e consistência interna (SCHOLTES; TERWEE; POOLMAN, 2011; MOKKINK et al., 2010).

Para a validade de construto formulou-se a hipótese de correlações de magnitude moderada a forte entre os escores do ProFitMap-neck e os escores das demais ferramentas consideradas: Neck Disability Index, Escala de Ansiedade e Depressão Hospitalar (HADS-A e -D), Escala Tampa de Cinesiofobia e Short Form - 36 Health Survey.

O Neck Disability Index (NDI) (VERNON; MIOR, 1991) apresenta 10 questões variando sua pontuação de 0 a 6 e o resultado da soma das questões é o seu score final. A versão em português-brasileiro foi disponibilizada por Cook et al. (2006). Pontuações de 10 a $28 \%$ ou 5 a 14 pontos demonstram incapacidade leve, de 3 a $48 \%$ ou 15 a 24 pontos, incapacidade moderada, de 50 a $68 \%$ ou 25 a 35 pontos, incapacidade severa e acima de $72 \%$ ou 36 pontos ou mais demonstram incapacidade completa.

O ProFitMap-neck também foi comparado a outras escalas como a Escala de Ansiedade e Depressão Hospitalar (ZIGMOND; SNAITH, 1983) versão português-brasil (PAIS-RIBEIRO et al., 2007) que é composta por 14 questões, 7 sobre ansiedade e 7 sobre depressão que variam de 0 a 3 como opção de respostas. Tanto para a pontação de ansiedade quanto de depressão de 0 a 8 considera-se que o paciente não apresenta sintomas de depressão e ansiedade, bem como pontuações iguais ou acima de 9 que sugerem a presença de ansiedade ou depressão. 
Também foi utilizada a versão em português-brasileiro da Escala Tampa de Cinesiofobia (SIQUEIRA; TEIXEIRA-SALMELA; MAGALHAES, 2007) originalmente elaborada por Vlaeyen et al. (1995). Esta é composta por 17 questões que variam sua pontuação de 1 a 4 sendo o score final apenas a soma comum das opções de escolha.

O Short Form - 36 Health Survey ou SF-36 (WARE; SHERBOURNE, 1992) versão português-brasileiro (CICONELLI et al., 1999) também foi utilizado, é composto por 11 questões sendo que a número 3 possui 10 itens, a questão número 4 possui 4 itens, a número 5 possui 3 itens, a número 9 possui 9 itens e a número 11 possui 4 itens. Sua pontuação foi feita seguindo as recomendações do artigo original que pré-determina substituições das pontuações obtidas por scores.

\subsection{Reprodutibilidade da medida}

Para os 100 voluntários que participaram do processo de reprodutibilidade do ProFitMapneck, o questionário foi reaplicado após um período de pelo menos duas horas para verificação dessa propriedade das respostas ao instrumento. Este período de tempo foi determinado considerando-se que pacientes com desordens de dor crônica apresentam alta variabilidade no sintoma (YAKUT et al., 2007) ao longo do mesmo dia (BELLAMY; SOTHERN; CAMPBELL, 2004) e entre dias diferentes (ZAUTRA et al., 2007).

\subsection{Análise dos resultados}

Para as comparações das pontuações do ProFitMap-neck nos subgrupos (amostras do teste da versão pré-final, reprodutibilidade e amostra total) foi utilizado a one-way analise de variância (ANOVA) $(\mathrm{p}<0.05)$. A ANOVA também foi utilizada para comparações dos subgrupos divididos quanto à presença de comorbidades. 
Para verificação da associação entre as variáveis dependentes (pontuação nas escalas do ProFitMap-neck) e a idade (variáveis independente) foi utilizada uma análise de regressão linear $(\mathrm{p}<0.05)$.

Para a análise fatorial exploratória foi utilizada a Análise de Componentes Principais com rotação Varimax para dividir os itens dos domínios do questionário em dois fatores. O número de fatores retidos considerou eigenvalues (ou autovalores: são as variâncias dos fatores que compõem um dado modelo) com valores superiores a 1 (KAISER, 1960), a proporção da variância extraída, o conteúdo do item, e a capacidade de interpretação dos fatores resultantes. As magnitudes das cargas fatoriais para cada variável foram analiasadas de acordo com a contribuição do item para o modelo. Quanto à carga fatorial, após a rotação Varimax, os itens com carga fatorial inferior a 0,2 deveriam ser excluídos, exceto itens que traduzem questões relevantes do construto avaliado. Além disso, os domínios poderiam apresentar até dois fatores e caso a análise demonstrasse mais de 2 fatores, seria realizada uma análise forçada de dois fatores. A variância extraída de cada item também foi avaliada e valores próximos de 50\% foram considerados aceitáveis (BEAVERS et al., 2013).

Para análise dos resultados da validação estrutural também foi considerada a análise do teste de Kaiser-Meyer-Olkin (KMO). Este teste, também conhecido como índice de adequação da amostra, é utilizado para identificar se um modelo de análise fatorial que está sendo utilizado é adequadamente ajustado aos dados. O KMO é calculado por meio do quadrado das correlações totais dividido pelo quadrado das correlações parciais, das variáveis analisadas (FIELD, 2005). Portanto, um teste estatístico que sugere a proporção de variância dos itens que pode estar sendo explicada por uma variável latente (LORENZO-SEVA; TIMMERMAN; KIERS, 2011). Valores altos (entre 0,5 e 1,0) indicam que a análise fatorial é apropriada, enquanto abaixo de 0,5 indicam que a análise pode ser inadequada. Já Hair et al. (2006) sugerem 0,50 como patamar aceitável. Por 
fim, o Teste de Esfericidade de Bartelett (TEB) deve ser estatisticamente significativo considerando-se $\mathrm{p}<0,05$.

O teste de esfericidade de Bartlett, por sua vez, avalia em que medida a matriz de (co) variância é similar a uma matriz-identidade, ou seja, avalia se os elementos da diagonal principal tem valor igual a um, e os demais elementos da matriz são aproximadamente zero, ou seja, não apresentam correlações entre si (FIELD, 2005). Segundo Hair et al. (2005), esse teste avalia, também, a significância geral de todas as correlações em uma matriz de dados. Valores do teste de esfericidade de Bartlett com níveis de significância $\mathrm{p} \leq 0,05$ indicam que a matriz é fatorial (TABACHNICK; FIDELL, 2007) rejeitando a hipótese nula de que a matriz de dados é similar a uma matriz-identidade.

Para a análise da consistência interna foi utilizado o coeficiente de $\alpha$ de Cronbach, com resultados esperados entre 0,7 e 0,95 (TERWEE et al., 2007). A variável de Correlação Total do Item (CTI) mensura a correlação entre um item de uma escala e a pontuação total desta excluindose aquele item. Valores entre 0,2 e 0,8 foram considerados aceitáveis, pois a correlação entre os itens maior que 0,2 indica que os itens se correlacionam mais fortemente com o domínio a que pertencem, e valores não muito maiores que 0,5 são desejáveis (CLARK; WATSON, 1998). Omitem-se valores inferiores a 0,2 como indicação de uma correlação inexistente com o construto (CLARK; WATSON, 1998). O CTI foi calculado utilizando o Coeficiente de Correlação de Pearson, utilizado para distribuições assimétricas (PICON et al., 2006). O alpha de Cronbach se o item for excluído, representa o coeficiente de confiabilidade alpha (GLIEM; GLIEM, 2003). Entretanto, quando o item é removido da escala, verifica-se se os mesmos aumentariam significativamente o valor do coeficiente alpha (PICON et al., 2006).

A confiabilidade/reprodutibilidade foi avaliada utilizando-se o Coeficiente de Correlação Intraclasse ( $\mathrm{CCI}_{2,1}$ ) e seus respectivos intervalos de confiança (IC) a 95\%. O CCI é interpretado da seguinte maneira: menor do que 0,40: baixa reprodutibilidade; entre 0,40 e 0,75: 
reprodutibilidade moderada; entre 0,75 e 0,90: reprodutibilidade substancial e maior do que 0,90: reprodutibilidade excelente (MAHER; LATIMER; COSTA, 2007).

O índice de alfa de Cronbach será utilizado para avaliação da consistência interna e será calculado para cada item, para identificar se existem itens do questionário redundantes ou heterogêneos. Os valores do alfa de Cronbach são considerados adequados entre 0,70 e 0,95 (MAHER; LATIMER; COSTA, 2007).

Para análise do Erro Padrão da Medida (SEM - Standard Error of Measurement) foi utilizada a fórmula descrita por Weir (2005): EPM = DP $\sqrt{ }$ CCIx(1 - CCI) (WEIR, 2005) na qual DP = desvio padrão. Já a Mínima Diferença Detectável foi calculada considerando-se: MDD = $1,96 \times \sqrt{ } 2 \times \operatorname{EPM}($ WEIR, 2005).

O coeficiente de correlação de Pearson foi utilizado para comparação das pontuações da escala ProFitMap-Neck e do NDI. A força da correlação foi graduada da seguinte maneira: R < 0,29: pobre; 0,3 < R < 0,69: moderada; R>0,7: forte (DANCEY; REIDY, 2004).

Todas as análises foram realizadas através do software estatístico Statistical Package for Social Science for Windows (SPSS) versão 220 (ARMONK, NY: IBM CORP, 2013). 


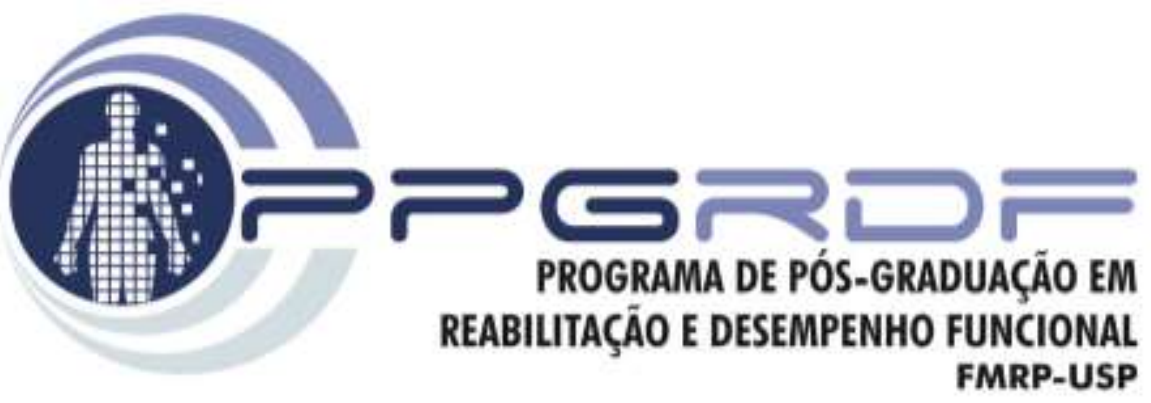

"Disse a flor para o Pequeno Príncipe: é preciso que eu suporte duas ou três larvas para que eu conheça as borboletas". (Antoine de Saint-Exupéry) 


\section{RESULTADOS}

\subsection{Diferenças entre subgrupos de dor cervical e Teste da versão pré-final}

Neste estudo foram avaliados 180 pacientes com dor cervical nas etapas de validação, 100 pacientes na etapa de reprodutibilidade e 30 participnates na etapa de teste da versão pré-final (Tabela 2). Foi observada média de idade significativamente menor no grupo da etapa de teste da versão pré-final em relação ao grupo da etapa de validação (n=180) (Tabela 2). Entretanto, uma análise de regressão linear não mostrou associação entre idade e a pontuação total das escalas de Sintomas/Frequência, Sintomas/Intensidade e Limitação Funcional do ProFitMap-neck versão português brasileiro, respectivamente $\left(\mathrm{R}^{2}=0,001, \mathrm{p}=0,667 ; \mathrm{R}^{2}<0,001, \mathrm{p}=0,94 ; \mathrm{R}^{2}<0,001, \mathrm{p}=0,98\right)$.

A versão pré-final do ProFitMap-neck foi aplicada em 30 pacientes, do sexo feminino com média de idade de 33,44 \pm 10,32 anos, escolaridade mínima da $4^{\text {a }}$ série do ensino fundamental e máxima de ensino superior (Tabela 2). Seguindo as recomendações de Beaton et al. (2000), durante a aplicação da versão pré-final, as voluntárias foram questionadas quanto à satisfação com o layout do questionário, bem como quanto ao entendimento dos itens componentes ou sugestões caso entendessem que o conteúdo não atendia aos sintomas e características funcionais da mesma. Nenhuma sugestão ou queixa sobre o entendimento e conteúdo do ProFitMap-neck foi feita durante a aplicação da versão pré-final do questionário. 
Tabela 2. Dados antropométricos e escolaridade da amostra completa $(n=180)$, da etapa de reprodutibilidade $(\mathrm{n}=100)$ e teste da versão pré-final $(\mathrm{n}=30)$.

\begin{tabular}{|c|c|c|c|c|}
\hline Escolaridade & $\begin{array}{l}\text { Tamanho } \\
\text { Amostral }\end{array}$ & $\begin{array}{c}\text { Idade (Média } \pm \text { DP) } \\
\text { Anos }\end{array}$ & $\begin{array}{c}\text { Peso (Média } \pm \text { DP) } \\
\text { Kg }\end{array}$ & $\begin{array}{c}\text { Altura (Média } \pm \\
\text { DP) Metros }\end{array}$ \\
\hline $\begin{array}{c}\text { Amostra Completa - } \\
\text { etapa de validação }\end{array}$ & 180 & $38,84 \pm 11,36$ & $63,81 \pm 11,76$ & $1,65 \pm 0,10$ \\
\hline $1^{\circ}$ grau incompleto & 28 & $42,82 \pm 8,03$ & $63,43 \pm 12,55$ & $1,65 \pm 0,08$ \\
\hline $1^{\circ}$ grau complete & 12 & $49,25 \pm 6,25$ & $63,83 \pm 11,82$ & $1,63 \pm 0,06$ \\
\hline $\begin{array}{l}2^{\circ} \text { grau completo e } \\
\text { incompleto }\end{array}$ & 46 & $30,03 \pm 10,86$ & $60,76 \pm 11,55$ & $1,64 \pm 0,09$ \\
\hline Técnico & 11 & $42,81 \pm 11,16$ & $63,81 \pm 10,36$ & $1,63 \pm 0,10$ \\
\hline Superior & 83 & $38,65 \pm 10,72$ & $64,47 \pm 11,85$ & $1,65 \pm 0,10$ \\
\hline $1^{\circ}$ grau & $\mathrm{n}=40(23 \%)$ & & & \\
\hline $\begin{array}{l}\text { Amostra teste da versão } \\
\text { pré-final }\end{array}$ & 30 & $33,43 \pm 10,32 *$ & $62,93 \pm 11,32$ & $1,63 \pm 0,10$ \\
\hline $1^{\circ}$ grau incompleto & 5 & $43,80 \pm 6,49$ & $68,40 \pm 14,39$ & $1,65 \pm 0,04$ \\
\hline $1^{\circ}$ grau complete & 2 & $41,50 \pm 10,50$ & $80,50 \pm 2,50$ & $1,59 \pm 0,40$ \\
\hline $\begin{array}{l}2^{\circ} \text { grau completo e } \\
\text { incompleto }\end{array}$ & 8 & $30,25 \pm 9,13$ & $63,01 \pm 11,69$ & $1,65 \pm 0,04$ \\
\hline Técnico & 2 & $31,50 \pm 13,50$ & $71,50 \pm 5,50$ & $1,55 \pm 0,03$ \\
\hline Superior & 13 & $30,46 \pm 7,62$ & $59,84 \pm 9,13$ & $1,64 \pm 0,09$ \\
\hline $1^{\circ}$ grau & $\mathrm{n}=7(23 \%)$ & & & \\
\hline $\begin{array}{l}\text { Amostra da } \\
\text { Reprodutibilidade }\end{array}$ & 100 & $38,89 \pm 10,84$ & $62,58 \pm 11,45$ & $1,64 \pm 0,09$ \\
\hline $1^{\circ}$ grau incompleto & 13 & $42,84 \pm 8,47$ & $63,84 \pm 13,08$ & $1,63 \pm 0,07$ \\
\hline $1^{\circ}$ grau complete & 10 & $44,90 \pm 8,29$ & $60,10 \pm 7,80$ & $1,63 \pm 0,06$ \\
\hline $\begin{array}{l}2^{\circ} \text { grau completo e } \\
\text { incompleto }\end{array}$ & 15 & $38,70 \pm 10,21$ & $60,20 \pm 12,01$ & $1,62 \pm 0,07$ \\
\hline Técnico & 13 & $43,01 \pm 10,21$ & $64,03 \pm 9,48$ & $1,61 \pm 0,09$ \\
\hline Superior & 49 & $38,81 \pm 9,99$ & $63,10 \pm 11,68$ & $1,66 \pm 0,09$ \\
\hline $1^{\circ}$ grau & $\mathrm{n}=23(23 \%)$ & & & \\
\hline ANOVA & & $F=3,23, p=0,04$ & $\mathrm{~F}=0,37, \mathrm{p}=0,68$ & $\mathrm{~F}=0,25, \mathrm{p}=0,77$ \\
\hline
\end{tabular}

$\mathrm{n}$ - número de indivíduos da amostra; DP - desvio padrão

* Diferença significativa em relação ao grupo $\mathrm{n}=180$ (ANOVA, post hoc Bonferroni)

Os participantes da etapa de validação foram subdivididos em grupos quanto à presença de comorbidades. Assim, foram analisadas diferenças nos dados entre os subgrupos quanto aos dados antrompométricos e pontuação das escalas do ProFitMapneck. Não foram verificadas diferenças significativas para os dados antropométricos (Tabela 3) e para nenhum dos construtos avaliados entre os subgrupos (Tabela 4). 
Tabela 3. Dados antropométricos dos subgrupos de pacientes com Dor cervical, Dor cervical + Cefaléia, Dor cervical + DTM e Dor cervical + Fibromialgia.

Dor cervical

$(n=47)$

Dor cervical + Cefaléia

$(\mathbf{n}=\mathbf{7 5})$

Dor cervical + DTM

$(\mathbf{n}=\mathbf{2 3})$

Dor cervical + Fibromialgia

$(\mathbf{n}=35)$
Idade

(Média \pm DP)

Anos

Peso

(Média \pm DP)

Quilos

$37,00 \pm 11,85$

$37,69 \pm 10,79$

$40,48 \pm 12,70$

$43,16 \pm 10,04$

$\mathrm{F}=2,40, \mathrm{p}=0,07$
$61,36 \pm 11,80$

$63,36 \pm 11,91$

$65,96 \pm 11,49$

$66,87 \pm 11,06$

$1,65 \pm 0,09$

ANOVA

$\mathrm{n}=$ número de indivíduos da amostra; DP - desvio padrão da amostra; DTM - Disfunção

Temporomandibular

ANOVA, $\mathrm{p}<0,05$ (post hoc Bonferroni) 


\section{Resultados 48}

Tabela 4. Valores médios e intervalos de confiança 95\% para as pontuações das escalas do ProFitMap-neck, Neck Disability Index (NDI), Escala de Ansiedade e Depressão Hospitalar (HADS-A e HADS-D), Escala Tampa de Cinesiofobia (TSK) e Short Form-36 (SF-36) nos subgrupos de pacientes com Dor cervical, Dor cervical + Cefaléia, Dor cervical + Disfunção Temporomandibular (DTM) e Dor cervical + Fibromialgia $(\mathrm{n}=180)$.

\begin{tabular}{|c|c|c|c|c|c|c|}
\hline Instrumentos & $\begin{array}{c}\text { Dor cervical } \\
(\mathrm{n}=47)\end{array}$ & $\begin{array}{l}\text { Dor cervical + Cefaléia } \\
(\mathrm{n}=77)\end{array}$ & $\begin{array}{c}\text { Dor cervical + DTM } \\
(\mathrm{n}=25)\end{array}$ & $\begin{array}{c}\text { Dor cervical + Fibro } \\
(\mathrm{n}=31)\end{array}$ & $\begin{array}{c}\text { Grupo total } \\
(\mathrm{n}=180)\end{array}$ & $\begin{array}{c}\text { ANOVA } \\
\text { F/P } \\
\end{array}$ \\
\hline $\begin{array}{l}\text { ProFitMap-neck } \\
\text { Sintomas Frequencia }\end{array}$ & $240,84(229,60-252,41)$ & $232,72(224,63-240,81)$ & $242,26(226,75-257,78)$ & $242,54(229,59-255,48)$ & $237,86(232,44-243,28)$ & $0,88 / \mathrm{p}=0,45$ \\
\hline $\begin{array}{l}\text { ProFitMap-neck } \\
\text { Sintomas Intensidade }\end{array}$ & $223,54(214,51-232,57)$ & $220,04(212,55-227,53)$ & $229,46(214,46-244,45)$ & $228,00(215,65-240,35)$ & $223,63(218,79-228,48)$ & $0,74 / \mathrm{p}=0,53$ \\
\hline ProFitMap-neck & & & & & & \\
\hline $\begin{array}{l}\text { Sintomas Limitação } \\
\text { Funcional }\end{array}$ & $224,54(215,51-233,57)$ & $222,04(214,55-229,53)$ & $232,46(217,46-247,45)$ & $232,00(219,65-244,35)$ & $225,86(230,71-230,70)$ & $1,06 / \mathrm{p}=0,37$ \\
\hline NDI & $11,00(8,93-13,07)$ & $11,70(9,86-13,55)$ & $11,56(8,50-14,62)$ & $9,90(8,51-11,29)$ & $11,19(10,15-12,23)$ & $0,50 / \mathrm{p}=0,69$ \\
\hline HADS-A & $10,98(9,83-12,13)$ & $10,96(10,08-11,84)$ & $10,44(8,55-11,06)$ & $9,94(8,82-11,06)$ & $10,72(10,16-11,28)$ & $0,63 / \mathrm{p}=0,60$ \\
\hline HADS-D & $7,81(6,72-8,90)$ & $8,53(7,63-9,43)$ & $8,24(6,13-10,35)$ & $6,97(5,99-7,95)$ & $8,03(7,46-8,60)$ & $1,27 / \mathrm{p}=0,28$ \\
\hline TSK & $27,32(24,15-30,49)$ & $28,17(26,04-30,30)$ & $26,32(22,47-30,17)$ & $28,39(25,78-31,00)$ & $27,73(24,36-29,10)$ & $0,32 / \mathrm{p}=0,81$ \\
\hline SF-36 & & & & & & \\
\hline Capacidade funcional & $91,17(88,02-94,32)$ & $88,90(85,50-92,29)$ & $91,20(85,75-96,64)$ & $93,87(91,66-96,08)$ & $90,67(88,84-92,50)$ & $1,23 / \mathrm{p}=0,30$ \\
\hline $\begin{array}{l}\text { Limitação por Aspectos } \\
\text { Físicos }\end{array}$ & $76,60(69,03-84,16)$ & $71,43(65,07-77,79)$ & $77,00(66,29-87,71)$ & $77,42(69,44-85,40)$ & $74,58(70,78-78,38)$ & $0,66 / \mathrm{p}=0,58$ \\
\hline Dor & $72,36(67,75-76,98)$ & $69,05(64,39-73,71)$ & $74,48(66,86-82,10)$ & $73,13(67,36-78,90)$ & $71,37(68,71-74,03)$ & $0,79 / \mathrm{p}=0,50$ \\
\hline Estado Geral de Saúde & $65,43(62,72-68,13)$ & $63,27(61,08-65,46)$ & $65,04(60,67-69,41)$ & $66,65(64,07-69,22)$ & $64,66(63,31-66,61)$ & $1,17 / \mathrm{p}=0,32$ \\
\hline Vitalidade & $54,04(51,24-56,84)$ & $53,12(50,85-55,38)$ & $55,80(51,82-59,78)$ & $55,00(51,75-58,25)$ & $54,06(52,66-55,46)$ & $0,62 / \mathrm{p}=0,60$ \\
\hline Aspectos Sociais & $50,00(0-50,00)$ & $50,32(49,68-50,97)$ & $50,00(50,00-50,00)$ & $50,00(50,00-50,00)$ & $50,14(49,87-50,41)$ & $0,44 / \mathrm{p}=0,72$ \\
\hline $\begin{array}{l}\text { Limitação por Aspectos } \\
\text { Emocionais }\end{array}$ & $84,40(77,68-91,12)$ & $78,36(74,17-93,83)$ & $84,00(74,17-93,83)$ & $89,25(83,44-95,06)$ & $82,59(81,85-86,34)$ & $1,50 / \mathrm{p}=0,22$ \\
\hline
\end{tabular}


Na primeira reunião de tradução, as versões dos tradutores leigo e expert do Inglês e o expert do Sueco foram sintetizadas em um único documento (APÊNDICE 1). Para o consenso da versão T123 houve alguns pontos de discussão. Todos foram devidamente discutidos com o autor da ferramenta original via e-mail e Skype, de modo, a saber, qual a intenção semântica para o termo usado, para, dessa forma, não fugir da construção primária do questionário. Para a Escala de Limitação Funcional não foram verificadas grandes divergências nas traduções devido à simplicidade e clareza estrutural do questionario. Para as graduações de intensidade, frequência e percepção de funcionalidade, a questão foi adaptar um vocabulário simples e direto, usado no questionário original para a população sueca, para uma população com hábitos e cultura de comunicação diferentes. No questionário original, o autor oferece várias opções de resposta para uma mesma questão, no entanto preferimos deixar apenas uma opção para cada de modo a evitar dificuldades na interpretação. Todas as mudanças foram discutidas com o autor da ferramenta com o intuito de não modificar semanticamente qualquer questão ou opção de resposta do questionário original. 


\section{Processo de Adaptação Transcultural}
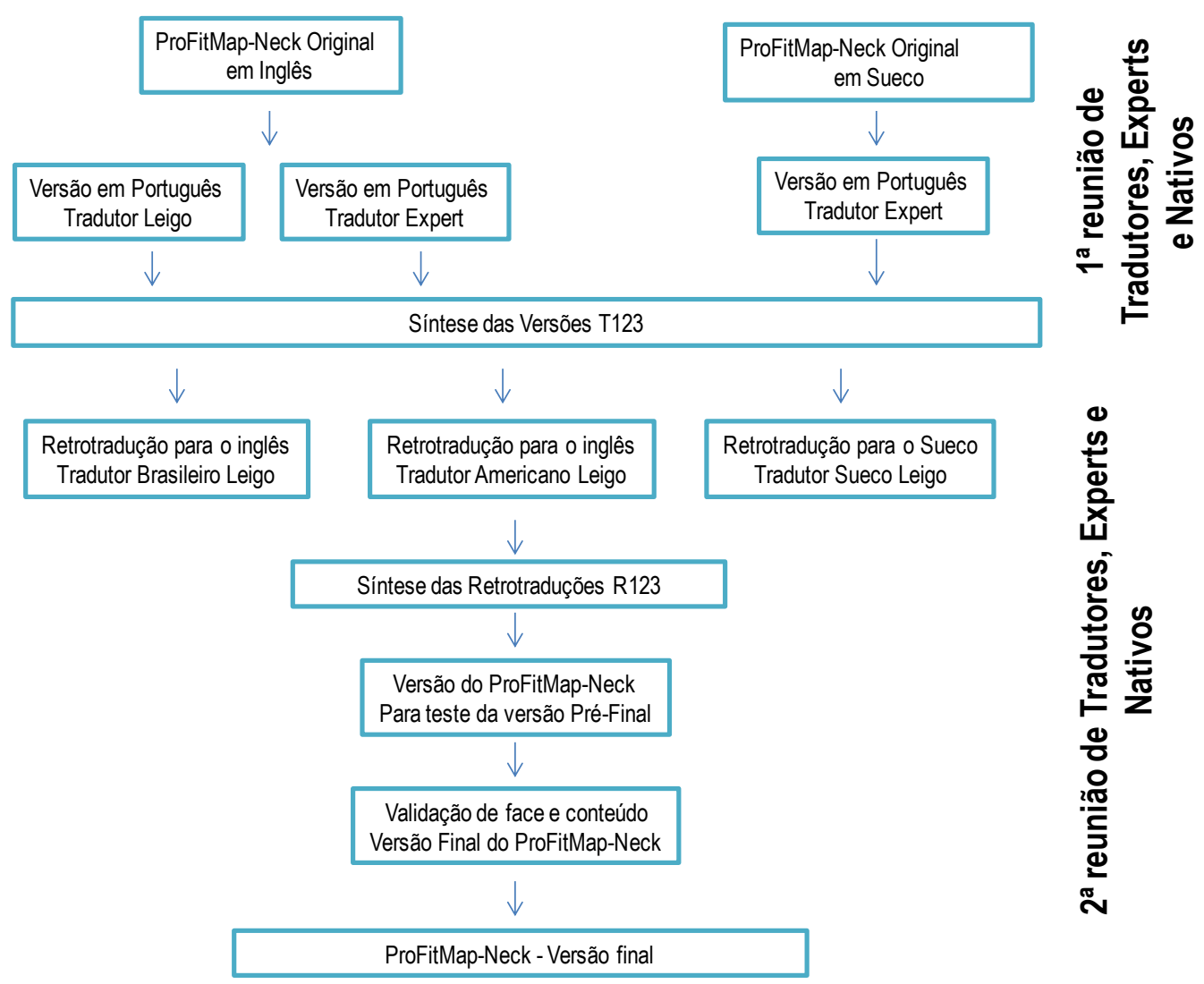

Figura 1. Etapas do processo de adaptação transcultural realizadas no estudo conforme preconizado por Beaton et al. (2000).

O layout da ferramenta também foi modificado, ainda durante a fase de tradução. Devido a experiências com a adaptação de outros questionários na população brasileira, observamos a necessidade de repetir o formato da frase em cada questão, bem como as opções de respostas para que os pacientes com menor nível cognitivo não se perdesse ao longo do preenchimento. O Questionário passou de 2 páginas em posicionamento da folha em retrato, para 7 páginas em paisagem. Durante a aplicação do questionário os pacientes parecem ter se familiarizado com o layout utilizado, não houve questões sem preenchimento, nem o preenchimento indevido de 2 questões na mesma linha. 
Participaram do comitê de especialistas 14 profissionais de saúde, sendo, 4 estudantes de graduação na área de fisioterapia, 2 médicos (sendo um deles o tradutor expert que domina o sueco), 1 enfermeira, 7 fisioterapeutas e 1 tradutor leigo que tinham o objetivo de encontrar equivalências semântica, idiomática, cultural e conceitual mantendo um fácil entendimento, ou seja, compreensíveis para uma criança de 12 anos (TERWEE et al., 2007), e que ao mesmo tempo atendessem as equivalências de conteúdo do questionário original.

As principais dúvidas que surgiram durante o processo de tradução/retrotradução e nas reuniões do comitê de especialistas foram:

- Q2 da escala de sintomas - A palavra "Soreness" em português foi traduzida como dor/desconforto após orientação do autor da ferramenta original;

- Q8 da escala de sintomas - A expressão "fumblingness in the hands" foi traduzida inicialmente como fraqueza/adormecimento. Após conversa com o autor da ferramenta optamos por falta de habilidade/fraqueza nas mãos;

- Q9 da escala de sintomas - A expressão "sensory disturbance" foi traduzida inicialmente como "problemas sensoriais", mas após contato com o autor chegamos ao consenso de que seria interessante explicar acrescebtabdo entre parênteses (formigamento/dormência);

- Q21 da escala de sintomas - A expressão "disturbance of breathing" foi motivo de debate durante a reunião de tradução/retrotradução, mas o grupo em consenso decidiu traduzir por dificuldade para respirar. O autor concordou com a tradução/adaptação; 
- Q19 e Q21 da escala de sintomas - A frase "por causa do seu problema no pescoço..." foi inserida para tentar estabelecer relação mais estreita entre a capacidade de concentração e dificuldade para respirar com a dor cervical;

- Q1 e Q3 da escala de limitação funcional - houve uma dúvida sobre o sentido da expressão "manage to stand" e "manage to sit". A dúvida referiu-se a permanecer em pé ou sentado ou o ato de ficar de pé ou sentar-se. A dúvida foi sanada com o autor e o consenso de tradução definiu que ficaria "permanecer em pé" e "permanecer sentado".

- Q9 da escala de limitação funcional - a palavra "sweater" (fazendo alusão à blusa de frio) foi adaptada/substituída por camiseta devido as características do clima quente no Brasil, isso para facilitar o relato do paciente, já que é provável que o uso de camisetas seja mais comum do que o de blusas de frio. $\mathrm{O}$ autor nos orientou de que o sentido da questão era fazer referência aos movimentos de abdução de ombro, elevação do membro superior, flexão, extensão e inclinação da coluna cervical necessários para colocação da vestimenta.

Como questão geral do processo de tradução os membros do grupo de consenso sugeriram que o uso apenas de descritores numéricos poderia facilitar o entendimento das alternativas de resposta. Entretanto, o autor da ferramenta sugeriu que destacássemos os descritores verbais, já que para obtenção do escore das escalas da ferramenta é necessário um cálculo matemático e não a simples a somatória das pontuações ("Do you mean to substitute the verbal anchors with only numbers (but keeping the verbal anchors for 0 and 5), or do you mean to add the numbers to each 
verbal answer? I think you need to keep the wordings of each response alternative, but feel free to add the numbers.")

\subsection{Validade Estrutural das Escalas do ProFitMap-neck}

Previamente as análises de consistência interna e reprodutibilidade a estrtutura fatorial/validade fatorial das escalas do ProFitMap-neck foi testada através da análise fatorial exploratória. Está análise foi testada por que a versão original não foi analisada em termos da estrututura em domínios (BJORKLUND et al., 2012).

Para a escala de Sintomas/Intensidade do ProFitMap-Neck versão português brasileiro foram verificados dois fatores/domínios com porcentagem de variância cumulativa de 57,33\%, índice de Kaiser-Meyer-Olkin adequado (KMO=0,66) e autovalores (eigen values) maior que 5. A análise das cargas fatoriais demonstrou que as questões tontura e eequilibrio se enquadraram em um domínio específico (domínio Sintomas/Intensidade Equilíbrio) e as demais questões no domínio Sintomas/Intensidade Geral (Tabela 5). Todos os itens apresentaram carga fatorial superior a 0,4, considerada adequada (Tabela 5). Apesar de todos os itens apresentarem carga fatorial superior a 0,3 quando a escala foi testada apenas com um fator/domínio, a taxa de variância cumulativa apresentou valor abaixo do recomendado na estrutura unifatorial $(36,98 \%)$. Por isso, a estrutura em dois fatores foi preconizada.

Para a escala de Sintomas/Frequência do ProFitMap-neck versão português brasileiro foi verificado apenas 1 fator/domínio com porcentagem de variância cumulativa de 56,20\%, índice $\mathrm{KMO}=0,84$ e auto-valor (eigen value) 14 . Todos os itens apresentaram carga fatorial superior a 0,2 , considerada adequada (Tabela 6). 
Para a escala de Limitação Funcional do ProFitMap-neck versão português brasileiro foram verificados 2 fatores/domínios com porcentagem de variância cumulativa de $56,28 \%$, índice $\mathrm{KMO}=0,57$ e e auto-valores (eigen values) maior que 5 . A melhor solução obtida através da análise fatorial foi a divisão em dois fatores/domínios. As questões de 1-10 sobre aspectos posturais e atividades de vida diária (AVD) se enquadraram no domínio "postura e AVD” e as demais questões sobre dor aos movimentos cervicais e avaliação sobre saúde se enquadraram em outro domínio denominado "Movimentos e percepção sobre saúde" (Tabela 7). Todos os itens apresentaram carga fatorial maior que 0,42 em seus respectivos domínios (Tabela 7). Novamente, a estrutura unifatorial não foi privilegiada, uma vez que taxa de variância cumulativa apresentou valor abaixo do recomendado na estrutura unifatorial $(37,16 \%)$. 
Tabela 5. Dados da Análise Fatorial Exploratória: valores de carga fatorial, Eigenvalues e \% de variância cumulativa dos itens e domínios da Escala de Sintomas/Intensidade $(\mathrm{n}=180)$.

Escala de Sintomas/Intensidade

\begin{tabular}{llll}
\hline \multicolumn{3}{c}{ Domínio Sintomas/Intensidade Geral } & \\
\hline Questões & Fator 1 & Fator 2 \\
1 & Você sente rigidez no pescoço? & 0,58 & 0,69 \\
2 & Você sente dor leve/desconforto no pescoço? & 0,61 & 0,61 \\
3 & Você sente tensão no pescoço? & 0,82 & 0,23 \\
4 & Você tem estalos no pescoço? & 0,66 & 0,39 \\
5 & Você sente cansaço no pescoço? & 0,68 & $-0,64$ \\
6 & Você sente fraqueza no pescoço? & 0,79 & $-0,47$ \\
7 & Você sente seu pescoço travar? & 0,72 & $-0,62$ \\
8 & Você sente falta de habilidade/ fraqueza nas mãos? & 0,72 & $-0,50$ \\
9 & Você sente formigamento/dormência nos braços, pescoço e mãos? & 0,38 & $-0,36$ \\
10 & Você tem problemas na mandíbula? & 0,33 & 0,02 \\
13 & Você se sente irritado ou tem pouca paciência? & 0,42 & 0,01 \\
14 & Você se sente deprimido? & 0,56 & 0,06 \\
15 & Você se sente estressado? & 0,63 & 0,04 \\
16 & Você sente náuseas? & 0,60 & $-0,08$ \\
17 & Você tem sensibilidade à luz? & 0,47 & 0,37 \\
18 & Você tem sensibilidade ao som? & 0,66 & $-0,41$ \\
19 & Por causa do seu problema no pescoço, você tem dificuldades & de & 0,59 \\
& concentração? & $-0,54$ \\
20 & Você tem dificuldades de engolir? & 0,61 & \\
21 & Por causa do seu problema no pescoço, você tem dificuldades & de & 0,51 \\
& respirar? & & 0,36 \\
22 & Você se sente ansioso? & 0,74 & 0,46 \\
23 & Você tem dor durante as atividades? & $-0,23$ \\
24 & Você tem dor durante o repouso? & 0,62 & $-0,52$ \\
25 & O seu problema no pescoço afeta o seu sono? & 0,68 & $-0,25$ \\
26 & O seu problema no pescoço afeta seu humor? & 0,60 & 0,31 \\
\hline & & 0,68 & 0,49 \\
\hline
\end{tabular}

Domínio Sitomas/Eequilibrio

\begin{tabular}{lll}
\hline $11 \quad$ Você sente tontura? & 0,41 & 0,73 \\
$12 \quad$ Você sente falta de equilíbrio? & 0,38 & 0,81 \\
\hline Estatísticas descritivas do modelo & & \\
\hline Eigenvalue & 9,61 & 5,29 \\
\% de Variancia cumulativa & 57,33 & \\
Medida Kaiser-Meyer-Olkin & 0,66 & \\
Teste de esfericidade de Bartlett & $9295,26 / \mathrm{p}<0,001$ & \\
\hline
\end{tabular}


Tabela 6. Dados da Análise Fatorial Exploratória: valores de carga fatorial, Eigenvalues e \% de Variância Explicada dos itens e domínios da Escala de Sintomas/Frequência $(\mathrm{n}=180)$.

\begin{tabular}{|c|c|c|}
\hline \multicolumn{3}{|c|}{ Escala de Sintomas/Frequência } \\
\hline \multicolumn{2}{|c|}{ Questões } & Fator 1 \\
\hline 1 & Você sente rigidez no pescoco? & 0,21 \\
\hline 2 & Você sente dor leve/desconforto no pescoço? & 0,76 \\
\hline 3 & Você sente tensão no pescoço? & 0,76 \\
\hline 4 & Você tem estalos no pescoço? & 0,72 \\
\hline 5 & Você sente cansaço no pescoço? & 0,89 \\
\hline 6 & Você sente fraqueza no pescoço? & 0,64 \\
\hline 7 & Você sente seu pescoço travar? & 0,33 \\
\hline 8 & Você sente falta de habilidade/ fraqueza nas mãos? & 0,77 \\
\hline 9 & Você sente formigamento/dormência nos braços, pescoço e mãos? & 0,60 \\
\hline 10 & Você tem problemas na mandíbula? & 0,76 \\
\hline 11 & Você sente tontura? & 0,82 \\
\hline 12 & Você sente falta de equilíbrio? & 0,87 \\
\hline 13 & Você se sente irritado ou tem pouca paciência? & 0,88 \\
\hline 14 & Você se sente deprimido? & 0,81 \\
\hline 15 & Você se sente estressado? & 0,82 \\
\hline 16 & Você sente náuseas? & 0,84 \\
\hline 17 & Você tem sensibilidade à luz? & 0,75 \\
\hline 18 & Você tem sensibilidade ao som? & 0,79 \\
\hline 19 & $\begin{array}{l}\text { Por causa do seu problema no pescoço, você tem dificuldades de } \\
\text { concentração? }\end{array}$ & 0,83 \\
\hline 20 & Você tem dificuldades de engolir? & 0,90 \\
\hline 21 & $\begin{array}{l}\text { Por causa do seu problema no pescoço, você tem dificuldades de } \\
\text { respirar? }\end{array}$ & 0,85 \\
\hline 22 & Você se sente ansioso? & 0,74 \\
\hline 23 & Você tem dor durante as atividades? & 0,63 \\
\hline 24 & Você tem dor durante o repouso? & 0,71 \\
\hline 25 & O seu problema no pescoço afeta o seu sono? & 0,72 \\
\hline 26 & O seu problema no pescoço afeta seu humor? & 0,75 \\
\hline \multicolumn{3}{|c|}{ Estatísticas descritivas do modelo } \\
\hline \multicolumn{2}{|c|}{ Eigenvalue } & 14,61 \\
\hline \multicolumn{2}{|c|}{$\%$ de Variancia cumulativa } & 56,20 \\
\hline \multicolumn{2}{|c|}{ Medida Kaiser-Meyer-Olkin } & 0,84 \\
\hline \multicolumn{2}{|c|}{ Teste de esfericidade de Bartlett } & $6863,47 / \mathrm{p}<0.001$ \\
\hline
\end{tabular}


Tabela 7. Dados da Análise Fatorial Exploratória: valores de carga fatorial, Eigenvalues e \% de Variância cumulativa dos itens e domínios da Escala de Limitação Funcional $(\mathrm{n}=180)$.

\begin{tabular}{|c|c|c|c|}
\hline \multicolumn{4}{|c|}{ Escala de Limitação Funcional } \\
\hline \multicolumn{4}{|c|}{ Domínio Postura e AVDs } \\
\hline \multicolumn{2}{|c|}{ Questões } & Fator 1 & Fator 2 \\
\hline 1 & Como é, para você, permanecer em pé? & 0,42 & 0,03 \\
\hline 2 & Como é, para você, caminhar? & 0,77 & $-0,04$ \\
\hline 3 & Como é, para você, permanecer sentado? & 0,71 & 0,01 \\
\hline 4 & Como é, para você, permanecer deitado? & 0,94 & $-0,14$ \\
\hline 5 & Como é, para você, correr? & 0,86 & 0,08 \\
\hline 6 & Como é, para você, carregar algo? & 0,62 & 0,61 \\
\hline 7 & Como é, para você, levantar algo? & 0,55 & 0,62 \\
\hline 8 & Como é, para você, arremeçar algo? & 0,65 & 0,29 \\
\hline 9 & Como é, para você, vestir e tirar camisetas? & 0,55 & 0,31 \\
\hline 10 & Como é, para você, calçar e tirar meias? & 0,66 & 0,51 \\
\hline \multicolumn{4}{|c|}{ Domíno movimentos e percepção sobre saúde } \\
\hline 11 & Como é, para você, inclinar a cabeça para frente? & $-0,24$ & 0,69 \\
\hline 12 & Como é para você, inclinar a cabeça para trás? & 0,24 & 0,48 \\
\hline 13 & Como é, para você, inclinar a cabeça para a direita? & 0,48 & 0,46 \\
\hline 14 & Como é, para você, inclinar a cabeça para a esquerda? & 0,44 & 0,63 \\
\hline 15 & Como é, para você, virar a cabeça para a direita? & 0,16 & 0,62 \\
\hline 16 & Como é, para você, virar a cabeça para a esquerda? & $-0,30$ & 0,83 \\
\hline 18 & Como você avalia seu problema no pescoço? & $-0,43$ & 0,66 \\
\hline 19 & Como você avalia a sua saúde em geral? & 0,23 & 0,63 \\
\hline \multicolumn{4}{|c|}{ Estatísticas descritivas do modelo } \\
\hline \multicolumn{2}{|c|}{ Eigenvalue } & 6,69 & 3,44 \\
\hline \multicolumn{2}{|c|}{$\%$ de Variancia cumulativa } & \multicolumn{2}{|l|}{$56,28 \%$} \\
\hline \multicolumn{2}{|c|}{ Medida Kaiser-Meyer-Olkin } & \multicolumn{2}{|l|}{0,57} \\
\hline \multicolumn{2}{|c|}{ Teste de esfericidade de Bartlett } & \multicolumn{2}{|c|}{$3704,61 / \mathrm{p}<0,001$} \\
\hline
\end{tabular}




\subsection{Erro padrão da medida, Mínima Diferença Detectável e Reprodutibilidade das Escalas do ProFitMap-neck}

Também foram analisados os valores de Erro Padrão da Medida (EPM) e Mínima Diferença Detectável (MDD) para todas as escalas e subescalas do ProFitMapNeck (Tabelas 8-10). Para a escala Sintomas/Intensidade, o EPM variou entre 0 - 1,21 e MDD entre 0 e 3,35 (Tabela 8). Para o domínio Sintomas/Intensidade Geral o EPM foi de 6,17 e a MDD de 17,06 e para o domínio Sintomas/Equilíbrio o EPM foi de 1,74 e a MDD foi de 4,82 (Tabela 9). Para a pontuação total da escala de Intensidade o EPM foi de 11,23 e a MDD foi de 31,02 (Tabela 8).

Já para a escala Sintomas/Frequencia o EPM variou entre 0 - 1,5 e MDD entre 0 e 4,13 (Tabela 8). Para a pontuação total da escala de Sintomas/Frequencia o EPM foi de 5,21 e a MDD foi de 14,40 (Tabela 9).

Para a escala de Limitação Funcional, o EPM variou entre 0 - 2,21 e MDD entre 0 e 6,12 (Tabela 10). Para o domínio Postura e AVD, o EPM foi de 6,17 e a MDD de 17,06 e para o domínio Movimentos e Percepção de Saude, o EPM foi de 2,21 e a MDD foi de 6,12 (Tabela 10). Para a pontuação total da escala de Limitação Funcional, o EPM foi de 6,24 e a MDD foi de 17,25 (Tabela 10). 
Tabela 8. Valores médios das pontuações de cada questão, Erro Padrão da Medida (EPM) e Mínima Mudança Detectável (MMD) do ProFitMap-neck para a Escala de Sintomas/Intensidade $(\mathrm{n}=180)$.

\section{Questões}

Você sente rigidez no pescoço?

Você sente dor leve/desconforto no pescoço?

Você sente tensão no pescoço?

Você tem estalos no pescoço?

Você sente cansaço no pescoço?

Você sente fraqueza no pescoço?

Você sente seu pescoço travar?

Você sente falta de habilidade/ fraqueza nas mãos?

Você sente formigamento/dormência nos braços,

pescoço e mãos?

Você tem problemas na mandíbula?

Você se sente irritado ou tem pouca paciência?

Você se sente deprimido?

Você se sente estressado?

Você sente náuseas?

Você tem sensibilidade à luz?

Você tem sensibilidade ao som?

Por causa do seu problema no pescoço, você tem

dificuldades de concentração?

Você tem dificuldades de engolir?

Por causa do seu problema no pescoço, você tem

dificuldades de respirar?

Você se sente ansioso?

Você tem dor durante as atividades?

Você tem dor durante o repouso?

O seu problema no pescoço afeta o seu sono?

O seu problema no pescoço afeta seu humor?

Pontuação total Dominio Sintomas/Intensidade

Geral

Você sente tontura?

Você sente falta de quilíbrio?

Pontuação total Dominio Sintomas/Eequilibrio

Pontuação Total da Escala de

Sintomas/Intensidade

\section{Pontuação Média (IC 95\%)}

\begin{tabular}{|c|c|c|}
\hline $7,40(7,25-7,55)$ & 0,23 & 0,64 \\
\hline $7,01(6,72-7,30)$ & 0,45 & 1,24 \\
\hline $6,20(5,92-6,48)$ & 0,43 & 1,20 \\
\hline $3,21(3,06-3,37)$ & 0,24 & 0,66 \\
\hline $3,53(3,28-3,79)$ & 0,39 & 1,07 \\
\hline $6,07(5,73-6,40)$ & 0,72 & 1,99 \\
\hline $6,52(6,00-7,04)$ & 1,07 & 2,96 \\
\hline $7,09(6,73-7,45)$ & 0,70 & 1,93 \\
\hline $7,79(7,52-8,06)$ & 0,45 & 1,25 \\
\hline $7,19(6,85-7,52)$ & 0,89 & 2,47 \\
\hline $6,23(6,01-6,46)$ & 0,49 & 1,35 \\
\hline $6,19(5,97-6,40)$ & 0,00 & 0,00 \\
\hline $6,16(5,97-6,34)$ & 0,22 & 0,61 \\
\hline $12,64(12,31-12,98)$ & 0,40 & 1,11 \\
\hline $4,25(4,09-4,42)$ & 0,30 & 0,82 \\
\hline $3,08(2,83-3,33)$ & 0,59 & 1,62 \\
\hline $8,10(7,52-8,68)$ & 1,19 & 3,29 \\
\hline $7,49(7,26-7,71)$ & 0,27 & 0,74 \\
\hline $7,44(7,25-7,63)$ & 0,26 & 0,72 \\
\hline $7,01(6,81-7,22)$ & 0,35 & 0,95 \\
\hline $29,33(28,54-30,12)$ & 1,21 & 3,35 \\
\hline $28,40(27,47-29,33)$ & 1,11 & 3,06 \\
\hline $13,94(13,59-14,29)$ & 0,67 & 1,86 \\
\hline $13,32(12,87-13,77)$ & 0,75 & 2,08 \\
\hline $215,60(210,39-220,81)$ & 6,17 & 17,06 \\
\hline $9,63(9,16-10,11)$ & 1,42 & 3,93 \\
\hline $7,36(6,96-7,76)$ & 0,82 & 2,26 \\
\hline $16,99(16,14-17,84)$ & 1,74 & 4,82 \\
\hline $232,59(227,13-238,06)$ & 11,23 & $\begin{array}{c}\mathbf{3 1 , 0 2} \\
(13,34 \%)\end{array}$ \\
\hline
\end{tabular}

n = número de indivíduos da amostra; DP - desvio padrão da amostra, CCI: Coeficiente de Correlação Intraclasse

$* \mathrm{EPM}=\mathrm{DP} \lambda 1-\mathrm{CCI}$

$* * \mathrm{MMD}_{95}=1.96 \times$ EPM $\mathrm{x} 72$

$* * * \mathrm{MMD}_{\%}=\left(\mathrm{MMD}_{95} /\right.$ média $) \mathrm{x} 100$ 
Tabela 9. Valores médios das pontuações de cada questão, Erro Padrão da Medida (EPM) e Mínima Mudança Detectável (MMD) do ProFitMap-neck para a Escala de Sintomas/Frequência $(\mathrm{n}=180)$.

\section{Escala de Sintomas/Frequência}

\section{Questões}

Você sente rigidez no pescoço?

Você sente dor leve/desconforto no pescoço?

Você sente tensão no pescoço?

Você tem estalos no pescoço?

Você sente cansaço no pescoço?

Você sente fraqueza no pescoço?

Você sente seu pescoço travar?

Você sente falta de habilidade/ fraqueza nas mãos?

Você sente formigamento/dormência nos

braços, pescoço e mãos?

Você tem problemas na mandíbula?

Você sente tontura?

Você sente falta de equilíbrio?

Você se sente irritado ou tem pouca paciência?

Você se sente deprimido?

Você se sente estressado?

Você sente náuseas?

Você tem sensibilidade à luz?

Você tem sensibilidade ao som?

Por causa do seu problema no pescoço, você tem dificuldades de concentração?

Você tem dificuldades de engolir?

Por causa do seu problema no pescoço, você tem dificuldades de respirar?

Você se sente ansioso?

Você tem dor durante as atividades?

Você tem dor durante o repouso?

O se problema no pescoço afeta o seu sono?

O seu problema no pescoço afeta seu humor?

Pontuação Total da Escala de

Sintomas/Frequencia

\section{Pontuação}

Média (IC 95\%)

$7,41(7,27-7,55)$

$6,82(6,62-7,03)$

$6,89(6,68-7,10)$

$3,31(3,20-3,41)$

$4,06(3,89-4,23)$

$6,48(6,23-6,72)$

$7,70(7,44-7,95)$

$7,92(7,63-8,20)$

$8,25(8,03-8,48)$

$8,11(7,91-8,31)$

$10,55(10,24-10,86)$

$8,00(7,76-8,24)$

$6,73(6,52-6,95)$

$6,96(6,75-7,17)$

$6,88(6,67-7,09)$

$13,54(13,12-13,95)$

$4,18(4,07-4,29)$

$4,13(3,98-4,27)$

$10,53(10,20-10,86)$

$6,74(6,53-6,96)$

$6,71(6,48-6,94)$

$6,90(6,69-7,11)$

$27,69(26,87-28,51)$

$26,71(25,82-27,60)$

$11,96(11,60-12,32)$

$12,70(12,41-12,99)$

$237,86(232,47-243,24)$

EPM*

0,36

0,31

0,21

0,18

0,20

0,38

0,35

0,43

1,19

0,34

0,94

0,31

0,85

0,42

1,16

0,65

0,23

0,33

0,92

0,20

0,56

0,36

0,28

0,00

0,00

0,45

0,15

0,22

0,21

0,80

1,50

0,69

0,28

5,21
1,25

0,41

0,62

0,98

0,79

0,00

0,00

0,57

2,20

4,13

1,92

0,76

$14,40(6,05 \%)$

n = número de indivíduos da amostra; DP - desvio padrão da amostra, CCI: Coeficiente de Correlação

Intraclasse

* EPM = DP $11-\mathrm{CCI}$

$* * \mathrm{MMD}_{95}=1.96 \times \mathrm{EPM} \times 72$

$* * * \mathrm{MMD}_{\%}=\left(\mathrm{MMD}_{95} /\right.$ média $) \mathrm{x} 100$ 
Tabela 10. Valores médios das pontuações de cada questão, Erro Padrão da Medida (EPM) e Mínima Mudança Detectável (MMD) do ProFitMap-neck para a Escala de Limitação Funcional $(\mathrm{n}=180)$

\begin{tabular}{|c|c|c|c|}
\hline \multicolumn{4}{|c|}{ Escala de Limitação Funcional } \\
\hline Questões & $\begin{array}{c}\text { Pontuação } \\
\text { Média (IC 95\%) }\end{array}$ & EPM & MMD \\
\hline Como é, para você, permanecer em pé? & $8,20(7,64-8,76)$ & 0,55 & 1,51 \\
\hline Como é, para você, caminhar? & $10,77(10,01-11,53)$ & 0,90 & 2,49 \\
\hline Como é, para você, permanecer sentado? & $8,19(7,71-8,66)$ & 0,46 & 1,27 \\
\hline Como é, para você, permanecer deitado? & $11,13(10,51-11,76)$ & 0,74 & 2,05 \\
\hline Como é, para você, correr? & $6,92(6,49-7,35)$ & 0,41 & 1,14 \\
\hline Como é, para você, carregar algo? & $3,81(3,61-4,01)$ & 0,14 & 0,38 \\
\hline Como é, para você, levantar algo? & $3,75(3,52-3,98)$ & 0,35 & 0,97 \\
\hline Como é, para você, arremeçar algo? & $4,19(3,94-4,43)$ & 0,38 & 1,04 \\
\hline Como é, para você, vestir e tirar camisetas? & $7,63(7,04-8,21)$ & 1,45 & 4,00 \\
\hline Como é, para você, calçar e tirar meias? & $8,69(8,26-9,13)$ & 0,30 & 0,82 \\
\hline Pontuação Total Escala Postura e AVDs & $73,28(69,99-76,57)$ & 2,25 & 6,23 \\
\hline Como é, para você, inclinar a cabeça para frente? & $11,48(10.94-12,03)$ & 0,99 & 2,73 \\
\hline Como é para você, inclinar a cabeça para trás? & $10,27(9,70-10,84)$ & 0,00 & 0,00 \\
\hline Como é, para você, inclinar a cabeça para a direita? & $10,10(9,53-10,67)$ & 0,68 & 1,88 \\
\hline Como é, para você, inclinar a cabeça para a esquerda? & $10,48(9,97-10,99)$ & 0,70 & 1,93 \\
\hline Como é, para você, virar a cabeça para a direita? & $9,92(9,31-10,53)$ & 1,78 & 4,91 \\
\hline Como é, para você, virar a cabeça para a esquerda? & $11,07(10,43-11,70)$ & 1,15 & 3,17 \\
\hline Como você avalia seu problema no pescoço? & $13,47(12,70-14,23)$ & 1,17 & 3,24 \\
\hline Como você avalia a sua saúde em geral? & $13,44(12,67-14,22)$ & 1,30 & 3,61 \\
\hline Pontuação Total Escala Movimentos e Saúde & $90,23(86,99-93,46)$ & 2,21 & 6,12 \\
\hline Pontuação Total da Escala de Limitação Funcional & $163,51(158,25-168,77)$ & 6,24 & $\begin{array}{c}17,25 \\
(10,55 \%)\end{array}$ \\
\hline
\end{tabular}

n = número de indivíduos da amostra; DP - desvio padrão da amostra, CCI: Coeficiente de Correlação Intraclasse

$* \mathrm{EPM}=\mathrm{DP} \pi 1-\mathrm{CCI}$

$* * \mathrm{MMD}_{95}=1.96 \times \mathrm{EPM} \times \mathrm{x} 2$

$* * * \mathrm{MMD}_{\%}=\left(\mathrm{MMD}_{95} /\right.$ média $) \times 100$ 
Para todas as escalas e domínios das escalas do ProFitMap-neck os valores médios de CCI variaram entre 0,81 e 1 , indicando níveis excelentes de confiabilidade para a reprodutibilidade das pontuações do ProFitMap-neck Sintomas/Intensidade (Tabela 11), ProFitMap-neck Sintomas/Frequencia (Tabela 12) e ProFitMap-neck Limitação Funcional (Tabela 13). 
Tabela 11. Valores médios de CCI e IC 95\% para a reprodutibilidade $(n=100)$ das pontuações dos domínios da Escala de Sintotomas/Intensidade

\section{Escala de Sintomas/Intensidade}

\section{Domínio Intensidade Geral}

Questões

\section{CCI (IC 95\%)}

Você sente rigidez no pescoço?

Você sente dor leve/desconforto no pescoço?

Você sente tensão no pescoço?

Você tem estalos no pescoço?

Você sente cansaço no pescoço?

Você sente fraqueza no pescoço?

Você sente seu pescoço travar?

Você sente falta de habilidade/ fraqueza nas mãos?

Você sente formigamento/dormência nos braços, pescoço e mãos?

Você tem problemas na mandíbula?

13 Você se sente irritado ou tem pouca paciência?

14 Você se sente deprimido?

15 Você se sente estressado?

16 Você sente náuseas?

17 Você tem sensibilidade à luz?

18 Você tem sensibilidade ao som?

19 Por causa do seu problema no pescoço, você tem dificuldades de concentração?

20 Você tem dificuldades de engolir?

21 Por causa do seu problema no pescoço, você tem dificuldades de respirar?

22 Você se sente ansioso?

23 Você tem dor durante as atividades?

24 Você tem dor durante o repouso?

25 O seu problema no pescoço afeta o seu sono?

26 O seu problema no pescoço afeta seu humor?

Pontuação total Domínio Intensidade Geral
$0,95(0,92-0,97)$

$0,95(0,92-0,96)$

$0,95(0,92-0,97)$

$0,95(0,92-0,96)$

$0,95(0,93-0,97)$

$0,90(0,84-0,94)$

$0,91(0,86-0,95)$

$0,92(0,87-0,95)$

$0,94(0,90-0,96)$

$0,85(0,77-0,91)$

$0,90(0,84-0,94)$

1,00

$0,97(0,96-0,98)$

$0,97(0,95-0,98)$

$0,93(0,89-0,95)$

$0,88(0,80-0,92)$

$0,91(0,85-0,94)$

$0,97(0,96-0,98)$

$0,96(0,95-0,98)$

$0,94(0,91-0,96)$

$0,95(0,93-0,97)$

$0,97(0,95-0,98)$

$0,92(0,88-0,95)$

$0,94(0,92-0,96)$

0,97 (0,96 - 0,98)

\section{Domínio Equilíbrio}

11 Você sente tontura?

$0,81(0,79-0,93)$

12 Você sente falta de equilíbrio?

Pontuação total Domínio Equilíbrio

$0,91(0,86-0,94)$

Pontuação total da Escala

$0,97(0,97-0,98)$

n - número de indivíduos da amostra; CCI - Coeficiente de Correlação Intraclasse; IC 95\% - Intervalo de Confiança de $95 \%$ 
Tabela 12. Valores médios de CCI e IC 95\% para a reprodutibilidade $(n=100)$ das pontuações dos domínios da Escala de Sintomas/Frequência.

\section{Escala de Sintomas/Frequência}

\section{Domínio de Frequência dos Sintomas}

Questões

$1 \quad$ Você sente rigidez no pescoço?

2 Você sente dor leve/desconforto no pescoço?

CCI (IC 95\%)

$0,88(0,80-0,92)$

Você sente tensão no pescoço?

$0,95(0,93-0,97)$

$4 \quad$ Você tem estalos no pescoço?

$0,98(0,97-0,98)$

$0,94(0,91-0,96)$

Você sente cansaço no pescoço?

$0,97(0,96-0,98)$

Você sente fraqueza no pescoço?

$0,95(0,92-0,96)$

Você sente seu pescoço travar?

$0,96(0,93-0,97)$

Você sente falta de habilidade/ fraqueza nas mãos?

$0,95(0,92-0,97)$

Você sente formigamento/dormência nos braços, pescoço e mãos?

$0,95(0,92-0,96)$

Você tem problemas na mandíbula?

$0,95(0,93-0,97)$

Você sente tontura?

Você sente falta de equilíbrio?

Você se sente irritado ou tem pouca paciência?

$0,97(0,95-0,98)$

$0,96(0,98-0,99)$

14 Você se sente deprimido?

$0,98(0,98-0,99)$

14 Você se sente deprimido?

$0,95(0,92-0,97)$

$0,98(0,97-0,99)$

Você sente náuseas?

$0,94(0,91-0,96)$

17 Você tem sensibilidade à luz?

$0,99(0,98-0,99)$

Por causa do seu problema no pescoço, você tem dificuldades de

concentração?

20 Você tem dificuldades de engolir?

21 Por causa do seu problema no pescoço, você tem dificuldades de

$0,96(0,94-0,97)$ respirar?

22 Você se sente ansioso?

$\mathbf{2 3}$ Você tem dor durante as atividades?

$0,98(0,97-0,99)$

$0,98(0,98-0,99)$

$24 \quad$ Você tem dor durante o repouso?

$0,98(0,97-0,98)$

25 O se problema no pescoço afeta o seu sono?

$0,94(0,91-0,96)$

26 O seu problema no pescoço afeta seu humor?

$0,92(0,82-0,95)$

Pontuação total da Escala de Sintomas/Frequencia

$0,98(0,98-0,99)$

n - número de indivíduos da amostra; CCI - Coeficiente de Correlação Intraclasse; IC 95\% - Intervalo de Confiança de $95 \%$ 
Tabela 13. Valores médios de CCI e IC 95\% para a reprodutibilidade $(n=100)$ das pontuações dos domínios da Escala de Limitação Funcional.

\section{Escala de Limitação Funcional}

\section{Domínio Função Postura e AVDs}

\section{Questões}

1 Como é, para você, permanecer em pé?

2 Como é, para você, caminhar?

3 Como é, para você, permanecer sentado?

4 Como é, para você, permanecer deitado?

$5 \quad$ Como é, para você, correr?

6 Como é, para você, carregar algo?

7 Como é, para você, levantar algo?

8 Como é, para você, arremeçar algo?

9 Como é, para você, vestir e tirar camisetas?

10 Como é, para você, calçar e tirar meias?

Pontuação total Domínio Função Postura e AVDs

\section{Domínio Movimento e Saúde}

11 Como é, para você, inclinar a cabeça para frente?

12 Como é para você, inclinar a cabeça para trás?

13 Como é, para você, inclinar a cabeça para a direita?

14 Como é, para você, inclinar a cabeça para a esquerda?

15 Como é, para você, virar a cabeça para a direita?

16 Como é, para você, virar a cabeça para a esquerda?

18 Como você avalia seu problema no pescoço?

19 Como você avalia a sua saúde em geral?

Pontuação total Domínio Movimento e Saúde Pontuação Total Escala
CCI (IC 95\%)

$0,98(0,97-0,99)$

$0,97(0,96-0,98)$

$0,98(0,96-0,99)$

$0,97(0,96-0,98)$

$0,98(0,97-0,99)$

$0,99(0,99-1,00)$

$0,95(0,92-0,97)$

$0,95(0,92-0,97)$

$0,87(0,78-0,92)$

$0,99(0,98-0,99)$

$0,99(0,98-0,99)$

$0,93(0,89-0,95)$

1,00

$0,97(0,95-0,98)$

$0,96(0,93-0,97)$

$0,82(0,71-0,89)$

$0,93(0,89-0,95)$

$0,95(0,93-0,97)$

$0,94(0,91-0,96)$

$0,99(0,98-0,99)$

$0,97(0,98-0,99)$

n - número de indivíduos da amostra; CCI - Coeficiente de Correlação Intraclasse; IC 95\% - Intervalo de Confiança de $95 \%$ 


\subsection{Consistência Interna das Escalas do ProFitMap-neck}

O alpha de Cronbach foi superior a 0,74 para todas as escalas do ProFitMapneck e a Correlação Total do Item (CTI) de cada domínio entre 0,23 e 0,95 (Tabela 1416). Para a escala de Sintomas/Intensidade Geral, o alpha de cronbach médio foi de 0,75 e para a escala Sintomas/Intensidade Equilibrio foi de 0,92 (Tabela 14). Já para a Escala Sintomas/Frequência, o alpha de cronbach médio foi de 0,75 (Tabela 15) e para as escalas de Limitação Funcional Postura e AVD e Movimentos e Percepção de Saúde foram de 0,76 (Tabela 16).

Os valores de alpha de Cronbach se o item for deletado variaram entre 0,71 e 0,91 (Tabelas 14-16). Assim, para o alpha de Chonbach se o item for excluído não foram observados aumentos no alpha de cronbach médio quando os itens foram excluídos (Tabelas 14-16). Exceto para a escala Sintomas/Intensidade, com a exclusão do item "rigidez no pescoço", houve um aumento de 0,75 para 0,76 no alpha de cronbach médio da escala (Tabela 14). 
Tabela 14. Descrição dos valores de $\alpha$ de Cronbach e Correlação Total do Item de cada domínio e questão da Escala se Sintomas/Intensidade (n=180).

\section{Escala de Sintomas/Intensidade}

\section{Domínio Sintomas/Intensidade Geral \\ Questões}

1 Você sente rigidez no pescoço?

2 Você sente dor leve/desconforto no pescoço?

3 Você sente tensão no pescoço?

4 Você tem estalos no pescoço?

5 Você sente cansaço no pescoço?

6 Você sente fraqueza no pescoço?

7 Você sente seu pescoço travar?

8 Você sente falta de habilidade/ fraqueza nas mãos?

9 Você sente formigamento/dormência nos braços, pescoço e mãos?

10 Você tem problemas na mandíbula?

13 Você se sente irritado ou tem pouca paciência?

14 Você se sente deprimido?

15 Você se sente estressado?

16 Você sente náuseas?

17 Você tem sensibilidade à luz?

18 Você tem sensibilidade ao som?

19 Por causa do seu problema no pescoço, você tem dificuldades de concentração?

20 Você tem dificuldades de engolir?

21 Por causa do seu problema no pescoço, você tem dificuldades de respirar?

22 Você se sente ansioso?

23 Você tem dor durante as atividades?

24 Você tem dor durante o repouso?

25 O seu problema no pescoço afeta o seu sono?

26 O seu problema no pescoço afeta seu humor?
Correlação

Total do Item Corrigido

0,42

0,45

0,72

0,50

0,78

0,82

0,79

0,76

0,44

0,35

0,44

0,50

0,55

0,52

0,29

0,63

0,61

0,50

0,39

0,78

0,75

0,77

0,58

0,57
Alpha de

Chonbach se

o item for excluído

0,76

0,74

0,74

0,74

0,74

0,73

0,73

0,73

0,74

0,74

0,74

0,74

0,74

0,74

0,75

0,74

0,73

0,74

0,74

0,74

0,72

0,71

0,74

0,73

Alpha de Cronbach médio $=\mathbf{0 , 7 5}$

\section{Domínio Sintomas/Intensidade Equilíbrio}

11 Você sente tontura?

0,95

0,85

12 Você sente falta de equilíbrio?

Alpha de Cronbach médio $=0,92$ 
Tabela 15. Descrição dos valores de $\alpha$ de Cronbach e Correlação Total do Item de cada domínio e questão da Escala se Sintomas/Frequência $(n=180)$.

\section{Escala de Sintomas/Frequência}

Questões

1 Você sente rigidez no pescoço?

2 Você sente dor leve/desconforto no pescoço?

3 Você sente tensão no pescoço?

4 Você tem estalos no pescoço?

5 Você sente cansaço no pescoço?

6 Você sente fraqueza no pescoço?

7 Você sente seu pescoço travar?

8 Você sente falta de habilidade/ fraqueza nas mãos?

9 Você sente formigamento/dormência nos braços, pescoço e mãos?

10 Você tem problemas na mandíbula?

11 Você sente tontura?

12 Você sente falta de equilíbrio?

13 Você se sente irritado ou tem pouca paciência?

14 Você se sente deprimido?

15 Você se sente estressado?

16 Você sente náuseas?

17 Você tem sensibilidade à luz?

18 Você tem sensibilidade ao som?

19 Por causa do seu problema no pescoço, você tem dificuldades de concentração?

20 Você tem dificuldades de engolir?

21 Por causa do seu problema no pescoço, você tem dificuldades de respirar?

22 Você se sente ansioso?

23 Você tem dor durante as atividades?

$\begin{array}{cc}\begin{array}{c}\text { Correlação } \\ \text { Total do } \\ \text { Item } \\ \text { Corrigido } \\ 0,23\end{array} & \begin{array}{c}\text { Alpha de } \\ \text { Chonbach se } \\ \text { o item for } \\ \text { excluído }\end{array} \\ 0,71 & 0,75 \\ 0,69 & 0,75 \\ 0,64 & 0,75 \\ 0,82 & 0,75 \\ 0,62 & 0,75 \\ 0,32 & 0,75 \\ 0,69 & 0,75 \\ 0,51 & 0,74 \\ 0,69 & 0,75 \\ 0,75 & 0,75 \\ 0,80 & 0,74 \\ 0,78 & 0,74 \\ 0,77 & 0,75 \\ 0,78 & 0,75 \\ 0,79 & 0,75 \\ 0,73 & 0,74 \\ 0,72 & 0,75 \\ 0,81 & 0,75 \\ & 0,74 \\ 0,90 & 0,74 \\ 0,87 & 0,74 \\ & \end{array}$

24 Você tem dor durante o repouso?

$\begin{array}{ll}0,82 & 0,75 \\ 0,71 & 0,73 \\ 0,78 & 0,72 \\ 0,80 & 0,74 \\ 0,78 & 0,74\end{array}$

26 O seu problema no pescoço afeta seu humor? 
Tabela 16. Descrição dos valores de $\alpha$ de Cronbach e Correlação Total do Item de cada domínio e questão da Escala de Limitação Funcional $(n=180)$.

\section{Escala de Limitação Funcional}

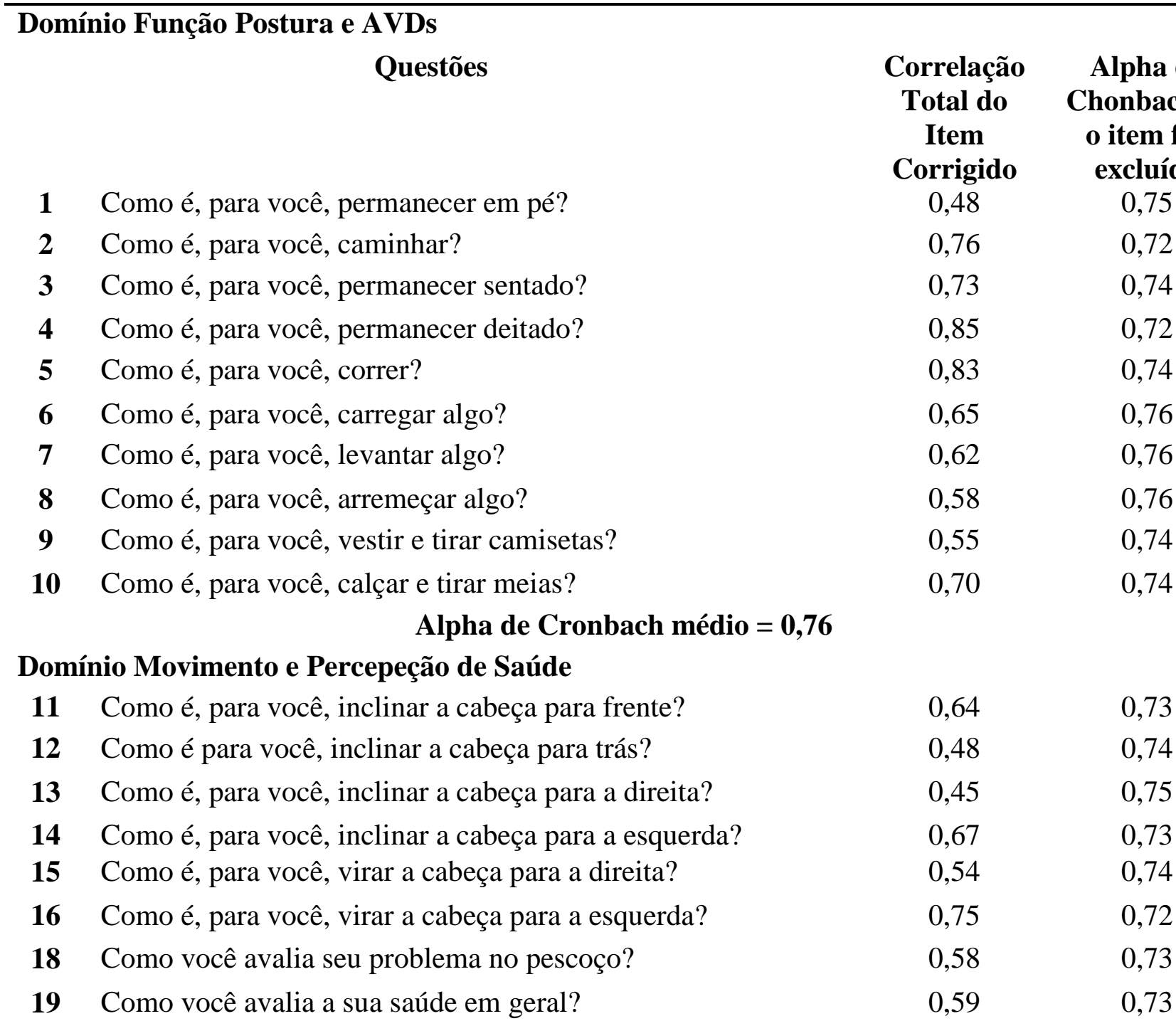

Alpha de Cronbach médio = 0,76 


\subsection{Validade de Construto}

Para verificação da validade de construto a pontuação total das escalas do ProFitMap-neck e dos domínios das escalas foram correlacionadas com as pontuações totais das seguintes escalas: Neck Disability Index, Domínios do questionário de qualidade de vida Short Form-36, Escala de Ansiedade e Depressão Hospitalar (HADSA e -D) e Escala Tampa de Cinesiofobia (Tabela 17). Maiores níveis de magnitude de correlação indicam maiores níveis de validade de construto entre as escalas.

$\mathrm{Na}$ comparação entre os construtos Sintomas e Funcionalidade da coluna cervical (Escalas do ProFitMap-neck) e Incapacidade cervical (Neck Disability Index NDI) foi pré-estabelecida uma hipótese de correlação moderada/forte entre os construtos. Foram verificadas correlações moderadas e negativas entre a pontuação total do NDI e as pontuações dos domínios e escalas do ProFitMap-neck, exceto para a pontuação total da escala de Limitação Funcional que obteve uma correlação negativa e forte, confirmando a hipótese inicial (Tabela 17).

A segunda validação de construto foi executada através da comparação entre as pontuações das Escalas do ProFitMap-neck e o construto qualidade de vida, considerando-se a hipótese inicial de correlação moderada entre estes construtos.

Assim, foram verificadas correlações positivas e fortes $(R>0,7)$ entre o domínio “capacidade funcional” do SF-36 vs. pontuação total da Escala Sintomas/Intensidade, Dominio Movimento e Percepção de Saúde da escala Limitação Funcional e a pontuação da Escala de Limitação Funcional. As demais correlações entre o domínio capacidade funcional vs. domínio equilíbrio da escala de Sintomas/Intensidade, pontuação total da escala Sintomas/Frequência e do domínio Postura e AVDs da Escala de Limitação Funcional foram positivas e moderadas (entre 0,39 a 0,55) (Tabela 17). 
Para o domínio "Limitação por aspectos Físicos” do SF-36 foram observadas correlações de forte magnitude e positivas entre este domínio e as escalas Sintomas/ Intensidade Geral, pontuação total da Escala Sintomas/Intensidade e a Pontuação da Escala de Limitação Funcional (Tabela 17). As correlações entre o domínio "Limitação por aspectos Físicos” vs. pontuação total de Sintomas/Frequencia, pontuação total da escala Sintomas/Frequencia e dos domínios Movimento e Percepção de Saúde e Postura e AVDs da Escala de Limitação Funcional foram positivas e moderadas (entre 0,48 a 0,66) (Tabela 17). Já para a correlação entre "Limitação por aspectos Físicos" e o domínio Sintomas/Intensidade equilíbrio foi observada correlação positiva e pobre $(\mathrm{R}=0,28)$ (Tabela 17).

Para o "domínio dor" do SF-36, foram observadas correlações positivas e fortes vs. Escala de Sintomas/Intensidade Geral, pontuação total das Escalas Sintomas/Intensidade, Sintomas/Frequencia e Limitação Funcional (Tabela 17). Já para as correlações com o domínio Sintomas/Intensidade equilíbrio, e os domínios Movimento e percepeção de saúde e postura e AVDs da escala de Limitação Funcional foram observadas correlações positivas e moderadas $(0,34$ a 0,66) (Tabela 17).

Para o domínio do SF-36 "Estado Geral de Saúde", foram verificadas correlações de positivas e forte magnitude entre todos os domínios e pontuações totais do ProFitMap-neck, exceto para o domínio Sintomas/Intensidade equilíbrio e postura e AVDs da escala de Limitação Funcional que apresentaram correlações positivas e moderadas $(0,43$ e 0,61 , respectivamente) (Tabela 17).

Para o domínio do SF-36 "Vitalidade", foram verificadas correlações de moderada magnitude e positivas entre todos os domínios e pontuações totais do ProFitMap-neck, exceto para a correlação entre este domínio e para o domínio 
Sintomas/Intensidade equilíbrio, que demonstrou magnitude positiva e pobre $(R=0,26)$ (Tabela 17).

O domínio "Aspectos Sociais" do SF-36 demonstrou correlações negativas moderadas e pobres apenas com os domínios e pontuação total da Escala de Limitação Funcional (Tabela 17).

O domínio "Limitação por Aspectos Emocionais" do SF-36 demonstrou correlações positivas e moderadas quando analisado em relação a todos os domínios e pontuações totais de todas as escalas do ProFitMap-neck, exceto para o domínio Sintomas/Intensidade equilíbrio, que demonstrou magnitude positiva e pobre $(R=0,24)$ (Tabela 17).

O domínio "Saude Mental” do SF-36 demonstrou correlações positivas e de forte magnitude quando comparado à pontuação do domínio Sintomas/Intensidade geral, pontuações totais da escala Sintomas/Frequencia e Limitação Funcional e domínio Postura e AVD da escala de Limitação Funcional. Já as demais correlações foram positivas e moderadas (Tabela 17).

Para a validação de construto contranstando os construtos de aspectos psicoemocionais (Ansiedade, Despressão e Cinesiofobia através das escalas de Ansiedade e Depressão Hospitalar: HADS-A e -D e Escala Tampa de Cinesiofobia: TSK) versus Sintomas e Funcionalidade da coluna cervical (Escalas do ProFitMapneck) foram verificadas correlações negativas e fortes entre ansiedade (HADS-A) e pontuação total das escalas de Sintomas/Intensidade, Sintomas/Frequencia e Limitação Funcional do ProFitMap-neck, bem como entre o domínio de Sintomas/Intensidade Geral (Tabela 16). Já em relação ao construto depressão (HADS-D) foram verificadas correlações negativas e de forte magnitude apenas para com as pontuações do domínio Sintomas/Intensidade Geral e pontuação total da escala de Sintomas/Intensidade do 
ProFitMap-Neck, as demais correlações foram negativas e moderadas e a correlação com o domínio Sintomas/Intensidade Equilibrio foi pobre $(\mathrm{R}=-0,27)$ (Tabela 17).

A correlação com o construto psicoemocional Cinesiofobia (TSK) demonstrouse negativa e moderada para a maior parte das comparações, exceto para a correlação entre TSK vs. domínio Sintomas/Intensidade Equilibrio $(\mathrm{R}=-0,26)$ e para o domínio Postura e AVD da Escala de Limitação Funcional $(\mathrm{R}=-0,28)$ que se mostraram negativas e de pobre magnitude (Tabela 17). Correlações moderadas foram hipopeticamente pré-estabalecidas entre as escalas do ProFitMap-neck e os construtos psicoemocionais. 


\section{Resultados 74}

Tabela 17. Tabela de Valores de Correlação entre as pontuações totais e domínios do ProFitMap-neck e os instrumentos Short Form - 36 (SF36), o Neck Disability Index (NDI), Escala de Ansiedade e Depressão Hospitalar (HADS) e Escala Tampa de Cinesiofobia (TSK) para n = 180.

\begin{tabular}{|c|c|c|c|c|c|c|c|c|}
\hline \multirow[b]{2}{*}{ Escalas } & \multirow[b]{2}{*}{ Domínios } & \multicolumn{2}{|c|}{ Escala de Sintomas - Intensidade } & \multirow[t]{2}{*}{$\begin{array}{l}\text { Total - } \\
\text { Escala } \\
\text { Sintomas/ } \\
\text { Intensidade } \\
\end{array}$} & \multirow[t]{2}{*}{$\begin{array}{l}\text { Total - } \\
\text { Escala de } \\
\text { Sintomas/ } \\
\text { Frequencia } \\
\end{array}$} & Escala de Lin & ç̧ão Funcional & \multirow[t]{2}{*}{$\begin{array}{l}\text { Total - Escala } \\
\text { de Limitação } \\
\text { Funcional }\end{array}$} \\
\hline & & Intensidade Geral & $\begin{array}{l}\text { Intensidade } \\
\text { Equilíbrio }\end{array}$ & & & $\begin{array}{l}\text { Movimento e } \\
\text { percepção de } \\
\text { saúde } \\
\end{array}$ & Postura e AVDs & \\
\hline \multirow[t]{7}{*}{ SF- 36} & $\begin{array}{c}\text { Capacidade funcional } \\
\text { Limitação por } \\
\text { Aspectos Físicos }\end{array}$ & $\begin{array}{l}0,71^{*} \\
0,78^{*}\end{array}$ & $\begin{array}{l}0,39^{*} \\
0,28^{*}\end{array}$ & $\begin{array}{l}0,73^{*} \\
0,77^{*}\end{array}$ & $\begin{array}{l}0,55^{*} \\
0,56^{*}\end{array}$ & $\begin{array}{l}0,75^{*} \\
0,66^{*}\end{array}$ & $\begin{array}{l}0,48^{*} \\
0,48^{*}\end{array}$ & $\begin{array}{l}0,76^{*} \\
0,77^{*}\end{array}$ \\
\hline & Dor & $0,74 *$ & $0,34 *$ & $0,75^{*}$ & $0,72 *$ & $0,66^{*}$ & $0,52 *$ & $0,74 *$ \\
\hline & Estado Geral de Saúde & $0,81 *$ & $0,43^{*}$ & $0,84 *$ & $0,71 *$ & $0,70 *$ & $0,61 *$ & $0,85^{*}$ \\
\hline & Vitalidade & $0,64 *$ & $0,26 *$ & $0,65^{*}$ & $0,30 *$ & $0,45^{*}$ & $0,69 *$ & $0,68 *$ \\
\hline & Aspectos Sociais & $-0,13$ & -0.15 & $-0,14$ & $-0,07$ & $-0.30 *$ & $-0,31 *$ & $-0,21^{*}$ \\
\hline & $\begin{array}{c}\text { Limitação por } \\
\text { Aspectos Emocionais }\end{array}$ & $0,60 *$ & $0,24 *$ & $0,60 *$ & $0,37 *$ & $0,59 *$ & $0,46^{*}$ & $0,66^{*}$ \\
\hline & Saúde Mental & $0,81 *$ & $0,36^{*}$ & $0,83 *$ & $0,55^{*}$ & $0,64 *$ & $0,73^{*}$ & $0,85^{*}$ \\
\hline NDI & & $-0,63 *$ & $-0,32 *$ & $-0,65^{*}$ & $-0,56^{*}$ & $-0,62 *$ & $-0,51 *$ & $-0,71^{*}$ \\
\hline HADS & Ansiedade & $-0,81 *$ & $-0,32 *$ & $-0,82 *$ & $-0,71 *$ & $-0,57 *$ & $-0,67 *$ & $-0,76^{*}$ \\
\hline & Depressão & $-0,72 *$ & $-0,27 *$ & $-0,73^{*}$ & $-0,61 *$ & $-0,53^{*}$ & $-0,59 *$ & $-0,68^{*}$ \\
\hline TSK & & $-0,45^{*}$ & $-0,26^{*}$ & $-0,46^{*}$ & $-0,50 *$ & $-0,47 *$ & $-0,28 *$ & $-0,47 *$ \\
\hline
\end{tabular}

$* \mathrm{p}<0,05$, Correlação de Pearson

$\mathrm{n}$ - número de indivíduos da amostra; NDI - Neck Disability Index; HADS - Escala de Ansiedade e Depressão Hospitalar, TSK - Escala Tampa de Cinesiofobia 


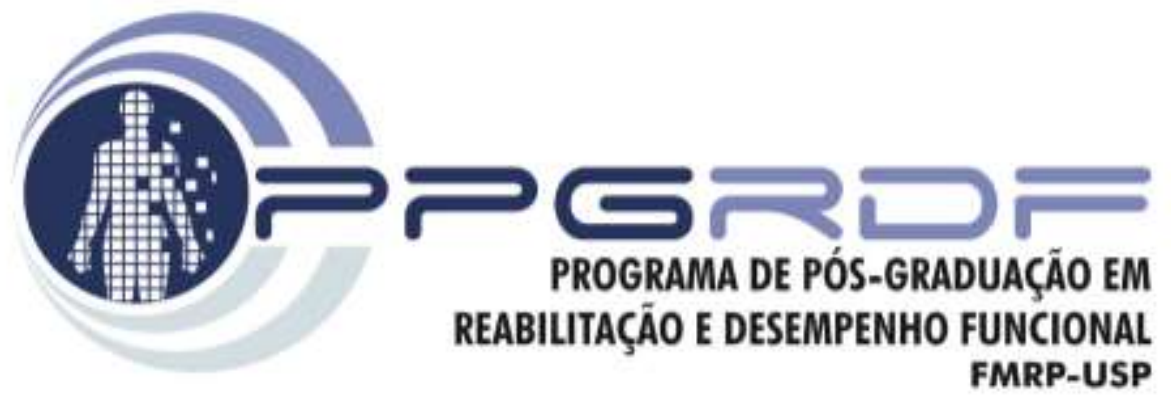

DISCUSSÃO

O Ser Humano é falho, hoje mesmo eu falhei, ninguém nasce sabendo, então me deixe tentar...

(O Homem que não tinha nada - Emicida) 


\section{DISCUSSÃO}

O objetivo inicial deste trabalho foi realizar a adaptação transcultural para o português brasileiro do Profile Fitness Mapping Neck Questionaire (ProFitMap-neck), originalmente elaborado em sueco. A adaptação seguiu as recomendações internacionais do COSMIN e Beaton et al. (2000), como já descrito anteriormente, e foi realizada concomitantemente a partir do questionário em inglês e sueco com o objetivo de tornar o processo o mais fidedigno possível.

O COSMIN considera três grandes esferas na avaliação de psicometria de instrumentos de avaliação em saúde: confiabilidade, validade e responsividade. A confiabilidade engloba consistência interna, confiabilidade e medida de erro, a validade considera as validades de construto, critério e conteúdo e a responsividade que constitui sozinha uma das esferas (MOKKINK et al., 2010). Em estudos de adaptações transculturais, é recomendado que alguns itens sejam considerados como demonstrado na tabela 18. Ao longo desta discussão vamos demonstrar quais recursos foram empregados e que resultados foram obtidos para alcançar cada um dos itens recomendados pelo COSMIM no processo de validação transcultural. Na tabela 18 os itens que foram contemplados neste estudo estão marcados com $\mathrm{X}$ e nos itens não abordados estão marcados com asterisco. 
Tabela 18. Itens do COSMIN que foram considerados no estudo de adaptação transcultural e validação do ProFitMap-Neck versão português Brasil.

1. A porcentagem de itens "perdidos" foi mencionada?

2. Houve uma descrição de como os itens perdidos foram manipulados?

3. O tamanho da amostra incluído foi adequado?

$*$

$*$

$\mathrm{X}$

4. Estavam descritas ambas as línguas: a original em que o instrumento foi desenvolvido e a $\mathrm{X}$ que o instrumento foi traduzido?

5. Foi descrito adequadamente a experiência das pessoas envolvidas no processo de tradução? Por exemplo: experiência na(s) doença(s) envolvida(s), experiência no construto a ser medido e experiência em ambas as línguas.

6. Os tradutores trabalharam de forma independente um do outro?

7. Os itens foram traduzidos e retrotraduzidos?

8. Foi descrito de forma adequada como as diferenças entre as versões original e traduzida foram resolvidas?

9. A tradução foi revista por um comitê? (Por exemplo: Desenvolvedores originais)

10. O instrumento foi pré-testado (Por exemplo: entrevistas cognitivas) para verificar a interpretação, a relevância cultural da tradução, e facilidade de compreensão?

11. A amostra utilizada no pré-teste foi descrita adequadamente?

12. As amostras foram semelhantes para todas as características, exceto Língua e / ou aspectos culturais?

13. Houve falhas importantes no projeto ou nos métodos de estudo?

Não

\section{Métodos estatísticos}

14. Para TCT: Foi realizada análise fatorial confirmatória?

Ou

15. Para TRI: A função diferencial do item (FDI) entre grupos linguísticos foi avaliada?

* Nenhum item foi perdido.

**Foi realizada análise fatorial exploratória, uma vez que na versão original do ProFitMap-neck a

exploratória não foi analisada 


\subsection{Amostras do estudo e Diferenças entre os subgrupos de dor cervical}

As amostras dos três estudos realizados (teste da versão pré-final $/ \mathrm{n}=30$, estudo de reprodutibilidade/n=100 e estudo de validação/n=180) não demonstraram diferenças significativas para os dados antropométricos, exceto para a idade. Entretanto, não foi verificada associação entre idade e incapacidade cervical através de uma análise de regressão linear.

Pelo menos $20 \%$ da amostra total de nossa pesquisa, apresentou menos de 8 anos de escolaridade. Esses dados estão em concordância com os dados do último senso do Instituto de Pesquisa Econômica Aplicada (IPEA) que demonstra que $20 \%$ da população brasileira tem menos de 4 anos de escolaridade e taxa de analfabetismo funcional de $10,7 \%$. Assim, é possível ressaltar que os participantes do estudo são representativos do universo sócio-cultural brasileiro em termos de escolaridade. E, portanto, o ProFitMap-neck versão português-Brasil pode ser compreensível para públicos de diferentes níveis socioeconômico e educacional (IPEA, 2010).

No presente estudo incluímos participantes com dor cervical e diferentes comorbidades, considerando a amostra recrutada por Bjorklund et al. (2012) e a dificuldade de se triar pacientes com dor crônica musculoesquelética que não possuam nenhuma comorbidade associada. Além disso, a literatura traz evidência da associação entre dor cervical e outras desordens (HOGG-JOHNSON et al., 2008).

Não verificamos diferenças entre os subgrupos com dor cervical e Disfunção Temporomandibular, dor cervical e cefaleia, dor cervical e fibromialgia e dor cervical apenas para nenhum dos itens avaliados neste estudo: incapacidade cervical, qualidade de vida, ansiedade, depressão e cinesiofobia. Não foram encontrados na literatuta consultada estudos que tenham verificado diferenças nesses aspectos em indivíduos 
com dor cervical e diferentes comorbidades associadas. Esses resultados sugerem que independente da presença de condições associadas, os pacientes conseguem direcionar suas respotas para os aspectos relativos à incapacidade/funcionalidade relacionada à dor cervical.

\subsection{Adaptação Transcultural do ProFitMap-neck versão português-Brasil}

No processo de tradução e adaptação transcultural do ProFitMap-neck para o português brasileiro, foram necessárias algumas adaptações culturais mas não foram necessárias alterações da ferramenta ao longo do teste da versão pré-final, sugerindo

que o processo de tradução foi realizado de maneira adequada. É possível que a expertise dos profissionais $(n=14)$ envolvidos no processo de tradução, retrotradução e reuniões do comitê de especialistas sobre o construto incapacidade/funcionalidade relacionada à dor cervical pode ter contribuído para que o conteúdo original traduzido para o idioma Português-Brasil mantivesse os itens que representavam o construto na versão no idioma sueco. Durante as reuniões de tradução ficaram claras as diferenças culturais entre as duas nacionalidades, e o quanto isso pode ter influenciado na semântica de algumas palavras, bem como nos vícios de linguagem, distinção na noção de graduação da percepção aos itens do questionário. Esses ascpectos enfatizam de maneira clara e inequívoca, a necessidade do processo de adaptação transcultural seguindo critérios e recomendações descritos na literatura (MOKKINK et al., 2010; BEATON et al., 2000).

É recomendado que ao longo do processo de teste da versão pré-final, caso a ferramenta apresente um alto nível de incompreensão para o mesmo item, que este seja reformulado e nova amostra seja recrutada para responder ao questionário reformulado 
(BEATON et al., 2000). Entretanto, em nosso estudo, para nenhuma das questões do ProFitMap-neck foi relatada incompreensão, o que não levou à necessidade de novo recrutamento na etapa de teste da versão pré-final e reaplicação do questionário em nova amostra. Orfale et al. (2005) sugerem que um índice de incompreensão de até 20\% é aceitável, minimizando à necessidade de reaplicação do instrumento reformulado em nova amostra. A possível explicação para a ausência de relatos de dúvidas ou incompreensão na aplicação do ProFitMap-neck pode estar relacionado ao fato da estrututura das perguntas do questionário ser simples e direta, não favorecendo o surgimento de dúvidas.

Além disso, todo o processo de elaboração e construção da ferramenta foi realizado com a ativa participação do público-alvo da ferramenta (BJORKLUND et al., 2012) o que pode ter contribuído para a disponibilização de uma ferramenta final adequada ao entendimento dos pacientes com dor cervical. Assim, é possível considerar que o ProFitMap-neck apresente níveis adequados de validade de conteúdo devido à contribuição da perspectiva dos pacientes no desenvolvimento do questionário. Apesar de ser altamente recomendado, este procedimento é raramente seguido (BJORKLUND et al., 2012). Wiitavaara et al. (2009) em uma revisão sobre o processo de desenvolvimento de questionários utilizados para avaliação da incapacidade cervical verificaram que apenas dois questionários utilizaram esse procedimento: o ProFitMapNeck e o Extended Aberdeen Back Pain Scale (WILLIAMS; WILKINSON; RUSSELL 2001). Não há versões em outras línguas do ProFitMap-neck e, dessa forma, não foi possível comparar se em outras línguas houve necessidade de grandes adaptações linguísticas no questionário. 


\subsection{Confiabilidade e Erro Padrão da Medida do ProFitMap-neck versão português-Brasil}

Quanto à reprodutibilidade da ferramenta, segundo o COSMIN (MOKKINK et al., 2010) o tamanho amostral considerado em nosso estudo para análise da reprodutibilidade do ProFitMap-Neck é classificado como excelente ( $n=100$, TERWEE et al., 2012). Os valores de reprodutibilidade da pontuação total e das questões das escalas de Frequência dos sintomas, Intensidade dos sintomas e Limitação Funcional demonstraram nível de reprodutibilidade excelente - CCI>0,75 (FLEISS; LEVIN; PAIK, 2003; TERWEE et al., 2007) atestando, portanto, a reprodutibilidade do ProFitMap-neck português brasileiro e suas subescalas. Nossos achados, concordam com os valores de reprodutibilidade obtidos por Bjorklund et al. (2012) que relataram valores de CCI maiores que 0,80 para todas as escalas que constituem o ProFitMapNeck.

Bons níveis de reprodutibilidade de ferramentas que avaliam o construto incapacidade na dor cervical têm sido observados na literatura (MACDERMID et al., 2009; SCHELLINGERHOUT et al., 2011). O Neck Disability Index tem demonstrado bons resultados quando o teste-reteste é efetuado em curtos intervalos de tempo (0-3 dias), já que os curtos períodos de tempo favorecem o controle da estabilidade clínica dos pacientes e pode resultar em maior estabilidade dos escores obtidos (MACDERMID et al., 2009). Dessa forma, o uso de um período de tempo curto para a realização do reteste do ProFitMap-neck (em nosso estudo pelo menos duas horas entre avaliações) neste estudo pode ser justificado pela necessidade de se controlar a estabilidade do quadro clínico, especificamente considerando que recrutamos apenas pacientes com dores crônicas. Este período de tempo foi determinado considerando-se que pacientes 
com desordens de dor crônica podem apresentar alta variabilidade no sintoma (YAKUT et al., 2007), ao longo do mesmo dia (BELLAMY; SOTHERN; CAMPBELL, 2004) e entre dias diferentes (ZAUTRA et al., 2007).

Alguns estudos se utilizam de intervalos de até cinco semanas para verificação da confiabilidade teste-reteste (MACDERMID et al., 2009). Embora seja importante para compreender a estabilidade da medida em longo prazo, é necessário considerar que outros fatores podem contribuir aumentado o nível de viés dos resultados obtidos no teste-reteste. Mesmo se a severidade da dor de um paciente ou dificuldade ao realizar uma tarefa permaneça consistente ao longo de várias semanas, a experiência de dor e incapacidade pode ser influenciada por aspectos psicossociais e referencias múltiplas externas e internas. Assim, as mudanças nos fatores enfrentamento, auto-eficácia, ou suporte social podem contribuir para alterações na incapacidade percebida ao longo de um período de cinco semanas. Entretanto, cabe destacar a importância de teste-reteste com períodos longos e curtos: estudos de confiabilidade com intervalos de teste-reteste mais longos são necessários para a determinação de intervalos de tempo adequados no delineamente experimental de ensaios clínicos, por outro lado, estudos realizados em intervalos mais curtos são mais apropriados para adequada estimativa de erro real da medida (MACDERMID et al., 2009).

Ainda dentro dos aspectos recomendados pelo consenso COSMIM (MOKKINK et al., 2010) faz-se necessária a avaliação do erro padrão da medida (Standard Error of Measurement - SEM). Para a pontuação total da escala de Sintomas/Intensidade o EPM foi de 11,23 e a Mínima Diferença Detectável (MDD) foi de 31,02, já para a escala Sintomas/Frequencia o EPM foi de 5,21 e a MDD foi de 14,40 e para a pontuação total da escala de Limitação Funcional, o EPM foi de 6,24 e a MDD foi de 17,25. Bjorklund et al. (2012) relataram valores bem inferiores com valor de EPM entre 0,04 e 0,06, com 
MDD de 0,15 e 0,18 para as subescalas de sintomas e 0,15 para a escala de Limitação Funcional. Nossos resultados não estão em concordância com os relatados por Bjorklund et al. (2012) o que pode ser explicado pela diferença no cálculo do EPM, já que Bjorklund et al. (2012) utilizaram a raiz quadrada do erro médio ao quadrado e em nosso estudo utilizamos a cálculo recomendado por Weir (2003) EPM = DP オ1 - CCI, na qual $\mathrm{DP}=$ desvio padrão e $\mathrm{CCI}=$ Coeficiente de Correlação Intraclasse. Assim, para o ProFitMap-neck versão português-Brasil as alterações minimante relevantes na pontuação do escore total das subescalas devem ser de 31,02, para o ProFitMap-neck sintomas/intensidade, 14,40 para o ProFitMap-Neck sintomas/frequência e 17,25 para o ProFitMap-neck Limitação Funcional.

\subsection{Validade Estrutural e Consistência Interna do ProFitMap-neck versão português-Brasil}

Como já mencionado de acordo com o COSMIN, a análise fatorial é parte da validade de construto (DE VET et al., 2011; MOKKINK et al., 2010) e pode ser definida como o grau em que os escores da ferramenta são um reflexo adequado da dimensionalidade do construto a ser mensurado (MOKKINK et al., 2010), ou seja, verifica a organização dos itens da escala em domínios/fatores.

Previamente, à análise de consistência interna foi avaliada a validade estrutural das escalas do ProFitMap-neck, uma vez que se faz necessário definir a estrutura em domínios da feramenta antes de se testar o grau de interrelação entre os itens em um domínio. Apesar de o COSMIN recomendar a utilização da análise fatorial confirmatória em processos de adaptação transcultural, como a versão original do 
ProFitMap-neck não foi testada em termos de sua estrutura (BJORKLUND et al., 2012), realizamos a análise fatorial exploratória da versão ProFitMap-neck português-Brasil.

Diferentemente da estrutura empírica proposta na versão original da ferramenta (BJORKLUND et al., 2012), a análise fatorial exploratório demonstrou que o ProFitMap-neck português-Brasil escala de Sintomas/Intensidade apresentou dois domínios: Sintomas/Intensidade Equilíbrio (composto pelas questões tontura e equilíbrio) e as demais questões no domínio Sintomas/Intensidade Geral. Essa estrutura em dois domínios também foi verificada para o ProFitMap-neck português-Brasil escala de limitação funcional. No qual, as questões de 1-10 sobre aspectos posturais e atividades de vida diária (AVD) se enquadraram no domínio "postura e AVD” e as demais questões sobre dor aos movimentos cervicais e avaliação sobre saúde se enquadraram em outro domínio denominado "Movimentos e percepção sobre saúde".

Apenas a escala ProFitMap-neck versão português-brasil escala de Sintomas/Frequência demonstrou uma estrutura organizada em um único fator.

São comums relatos divergentes sobre a estrututura fatorial de ferramentas amplamente utilizadas na literatura como o Neck Disability Index (VAN DER VELDE et al., 2009; WALTON; MACDERMID, 2013; GABEL et al., 2014; HUNG et al., 2015). Possíveis explicações para essas diferenças podem estar relacionadas aos procedimentos estatísticos adotados, bem como características e tamanhos de amostras de pesquisa consideradas (HOGG-JOHNSON et al., 2009).

Não foi necessária a remoção de itens da ferramenta, já que todos apresentaram carga fatorial maior que 0,2 considerada adequada (BEAVERS et al., 2013). Há autores que recomendam que apenas itens com carga fatorial superior a 0,4 sejam considerados (MAINLY, 1994). Se tal valor de referência fosse considerado teríamos que excluir 4 itens do Kit ProFitMap-neck: 2 itens da escala sintomas/intensidade ("Você sente 
formigamento/dormência nos braços, pescoço e mãos?" e "Você tem problemas na mandíbula?") e 2 itens da escala de sintomas/frequência ("Você sente rigidez no pescoço?" e "Você sente seu pescoço travar?"). Entretanto, excetuando-se o item sobre dor na mandíbula, todos os itens parecem ter relações diretas com o construto incapacidade/funcionalidade relacionada à dor cervical. Além disso, o objetivo deste estudo foi realizar uma adaptação transcultural e, dessa forma, exclusões de itens da ferramenta original não são recomendadas (BEATON et al., 2000).

Como a ferramenta original não havia sido testada em relação à sua solução fatorial não é possível determinar se aspectos do processo de adaptação transcultural podem ter levado a essas diferenças na organização das escalas do Kit ProFitMap-neck. Futuros estudos em que a estrutura fatorial de outras versões do ProFitMap-neck sejam testadas precisam ser conduzidas para confirmar nosso achados.

Para a análise de consistência interna do ProFitMap-neck versão portuguêsBrasil escala de intensidade e frequencia dos sintomas e ProFitMap-neck escala de Limitação Funcional, o alpha de Cronbach foi superior a 0,74 para todas as escalas do ProFitMap-neck e a Correlação Total do Item (CTI) de cada domínio entre 0,23 e 0,95. Assim, foram observados valores adequados de alpha de Cronbach ( $\alpha$ cronbach $>0,70$ TERWEE et al., 2007) e CTI (>0,2 - [CLARK; WATSON, 1998]) para as escalas do ProFitMap-neck versão português-Brasil.

Os valores de alpha de Cronbach se o item for deletado variaram entre $0,71 \mathrm{e}$ 0,91. Dessa forma, a exclusão de itens da escala não levou a grandes alterações no alpha de Cronbach médio. Apenas para a escala Sintomas/Intensidade, com a exclusão do item "rigidez no pescoço", houve um aumento de 0,75 para 0,76 no alpha de cronbach médio da escala. Entretanto, ambos os valores se encontram dentro do valor recomendado por Terwee et al. (2007) $(\alpha$ cronbach $>0,70)$. 
Nossos resultados estão em concordância com os achados de Bjorklund et al. (2012) já que os autores relataram valores entre 0,88-0,96 para todos os itens do ProFitMap-neck versão original. Entretanto, os autores não verificaram os valores de alpha de Cronbach se o item for deletado e o CTI, o que impossibilita comparações entre os estudos. De qualquer forma, nossos resultados demonstram a interelação entre os itens dos diferentes domínios obtidos na análise de validade estrutural da ferramenta em sua versão português-brasileiro.

Em relação ao tamanho amostral, de acordo com Terwee et al. (2012) para a análise fatorial, o tamanho da amostral deve ser de pelo menos cinco a sete vezes o número de itens da escala com um tamanho mínimo de 100 sujeitos. Como a consistênca interna é dependente da análise fatorial, em decorrência da investigação prévia dos domínios do construto, é importante realizá-la posteriomente à análise dos fatores. Assim, o tamanho amostral utulizado para validade estrutural e consistência interna deste pode ser considerada adequada.

\subsection{Validade de Construto do ProFitMap-neck versão português-Brasil}

Como já mencionado, a validade de construto é o grau com que escores de um instrumento se mostram consistentes com hipóteses prévias (exemplos: inter-relações internas da ferramenta, relações com escores de outros instrumentos ou diferenças entre grupos relevantes), baseando-se na suposição de que o instrumento em questão realmente mensura o construto específico (MOKKINK et al., 2010). Neste estudo adotamos a análise de validade de construto baseada na verificação de relação entre os escores do ProFitMap-neck versão português-Brasil e os escores das seguintes 
ferramentas: Neck Disability Index, SF-36 (qualidade de vida), Escala Tampa de Cinesiofobia e Escala de Ansiedade e Depressão Hospitalar.

Assim, foram estabelecidas hipóteses prévias de correlação entre os instrumentos. Para o Neck Disability Index - NDI vs. ProFitMap-neck versão português-Brasil foi pré-estabelecida uma hipótese de correlação moderada/forte entre os construtos. Nossos achados confirmaram nossa hipótese inicial, já que foram verificadas correlações moderadas/fortes e negativas entre a pontuação total do NDI e as pontuações dos domínios e escalas Sintomas/Intensidade, Sintomas/Frequencia e Limitação Funcional do ProFitMap-neck ( $R=-0,65, \quad R=-0,56$ e $R=-0,71$, respectivamente). No artigo da versão original do ProFitMap-Neck, Bjorklund et al (2012) relataram valores similiares de valor de $\mathrm{R}$ de correlação para as escalas do ProFitMap-neck $(\mathrm{R}=0,66$ para a escala Sintomas/Intensidade, $\mathrm{R}=0,74$ para a escala Sintomas/Frequencia e $\mathrm{R}=0,74$ para a escala de Limitação Funcional). Assim, nossos resultados sugerem que o ProFitMap-neck versão português-brasileiro atingiu caracerísticas psicométricas similares a da versão em sueco, e que adequadamente comtempla o construto incapacidade relacionada à dor cervical.

Para a relação entre os construtos qualidade de vida (SF-36) e incapacidade cervical (ProFitMap-neck versão português-Brasil) foi estipulada uma hipótese inicial de correlação moderada. Foram verificadas correlações no geral moderadas/fortes e positivas entre os escores das ferramentas SF-36 e ProFitMap-neck versão portuguêsBrasil, exceto para a pontuação do domínio "Aspectos Sociais" do SF-36 e a pontuação total de todas as subescalas do ProFitMap-Neck versão português-Brasil. Nossos resultados estão em concordância com os achados de Bjorklund et al. (2012) que verificaram correlações similares entre os domínios do SF-36 e a pontuação total das subescalas do ProFitMap-Neck versão português-Brasil, com valor de R variando entre 
0.30-0.59. Entretanto, nossos achados estão em discordância dos resultados relatados por Bjorklund et al (2012) quanto à ausência de correlação/fraca correlação entre a pontuação do domínio de "Aspectos Sociais" do SF-36 e pontuação total das subescalas do ProFitMap-Neck versão português-Brasil. Concordando com nossos achados, Cook et al (2006) verificaram correlação pobre entre o NDI e o domínio de aspectos sociais do SF-36 ( $\mathrm{R}=-0,29)$. Nolet et al. (2015) também não verificaram associação entre dor cervical e o componente mental SF-36 (que neste estudo incluíu o componente social) em um estudo longitudinal.

Uma possível explicação para esses achados sejam diferenças culturais na percepção de influência da doença/disfunção nos aspectos sociais da vida entre brasileiros e suecos. É possível que latinos ou nativos de países com nível piores níveis de desenvolvimento sócio-econômico, não identifiquem os sintomas e incapacidade relacionada à dor cervical como potencilamente capazes de influenciar suas atividades sociais, recreacionais e de lazer. Por outro lado, Hogg-Johnson et al. (2008) relataram ausência de evidência para a associação entre dor cervical e status sócio-econômico.

Para a validação de construto, também verificamos a relação entre construtos psicoemocionais (Ansiedade, Despressão e Cinesiofobia através das escalas de Ansiedade e Depressão Hospitalar: HADS-A e -D e Escala Tampa de Cinesiofobia: TSK) e as Escalas do ProFitMap-neck versão português brasileiro. Também hipoteticamente postulamos correlações moderadas entre os construtos.

Assim, foram verificadas correlações negativas e fortes entre ansiedade (HADSA) e todas as escalas do ProFitMap-neck versão português brasileiro e moderadas/fortes entre o construto depressão (HADS-D) e as subescalas do ProFitMap-neck versão português brasileiro. Já para a correlação com o construto Cinesiofobia (TSK) foram verificadas correlações negativas e moderadas $(-0,46<\mathrm{R}<-0,50)$. 
Nossos achados estão em concordância com os achados de Dimitriadis et al. (2015) já que os autores verificaram correlações entre ansiedade e depressão e incapacidade cervical em pacientes com dor cervical crônica. Monticone et al. (2012) também verificaram correlações moderadas entre os construtos ansiedade e depressão e incapacidade cervical mensurada através do NDI.

Entretanto, Dimitriadis et al. (2015) não verificaram correlação entre incapacidade cervical (NDI) e Cinesiofobia. Por outro lado, valores de correlação fraca, porém positiva entre Cinesiofobia e incapacidade cervical (NDI) foram observados no estudo de Saavedra-Hernández et al. (2012) $(\mathrm{R}=0,23)$ em pacientes com dor cervical crônica mecânica. Dessa forma, podemos observar que nossos achados dão suporte para as relações entre os construtos psicoemocionais e Cinesiofobia vs. incapacidade cervical, demonstrando que o ProFitMap-neck versão português brasileiro foi capaz de demonstrar as relações já descritas previamnete na literatura.

É reconhecido na literatura que a Cinesiofobia pode exercer papel importante no desenvolvimento e persistência da dor na coluna cervical (NEDERHAND et al., 2004; LANDERS et al., 2008; MONTICONE, 2015). De acordo com o modelo de medoevitação, é possível que percepções negativas tais como ansiedade e catastrofização levem ao medo-evitação que por sua vez pode levar a comportamentos deletérios e prejuízo da performance física. Estes aspectos podem contribuir para prejuízos na realização das atividades de vida diárias ou para adoção de estratégias adaptativas de enfrentamento (VLAEYEN et al., 1995). Assim, é possível verificar que a literatura estabelece relações entre incapacidade, aspectos psicoemocionais e cinesiofobia. 


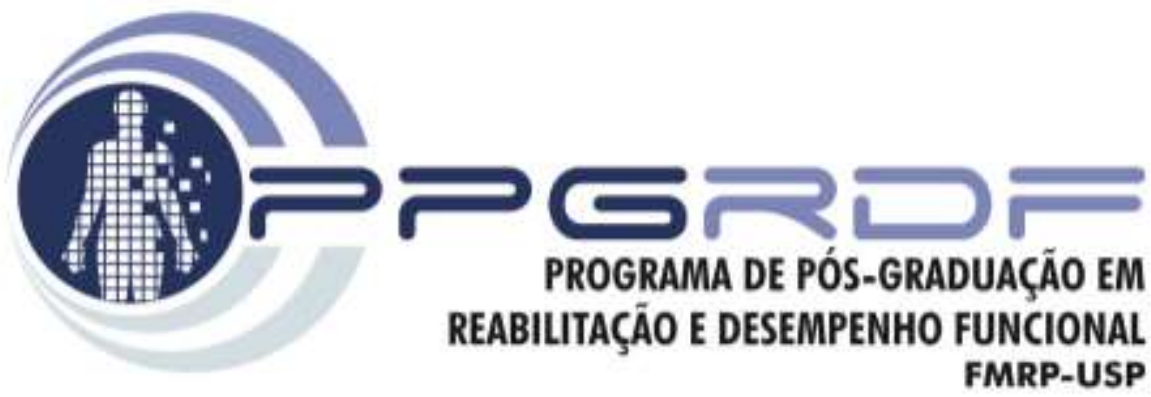

CONCLUSÃO

“Descobrir consiste em olhar para o que todo mundo está vendo e pensar uma coisa diferente.'

Roger Von Oech 


\section{CONCLUSÃO}

O Profile Fitness Mapping neck Questionnaire foi devidamente adaptado transculturalmente segundo as recomendações internacionais do COSMIN e da Beaton et al. (2000). Aprentou bons níveis nos índices de reprodutibildade e correlação moderadas e fortes com os questionários Neck Disability Index (NDI), SF-36, Escala de Ansiedade e Depressão Hospitalar e a Escala Tampa de Cinesiofobia.

Também foi verificada validade estrututural do Profile Fitness Mapping Neck Questionnaire tendo sido verificada a seguinte solução fatorial:

- Dois fatores para a escala de Sintomas/Intensidade do ProFitMap-neck versão português brasileiro: domínio Sintomas/Intensidade Equilíbrio e Domínio Sintomas/Intensidade Geral;

- Um domínio para a escala Sintomas/Frequencia do ProFitMap-neck versão português brasileiro;

- E para a escala de Limitação Funcional do ProFitMap-neck versão português brasileiro foram verificados dois domínios: domínio "postura e AVD” e domínio "Movimentos e percepção sobre saúde".

O Profile Fitness Mapping neck Questionnaire também demonstrou consistência interna entre os itens dos domínios das subescalas.

Assim, o Profile Fitness Mapping neck Questionnaire versão português-Brasil apresentou índices psicométricos adequados e, dessa forma, seu uso pode ser realizado na prática clínica e pesquisa em pacientes com dor cervical crônica. 


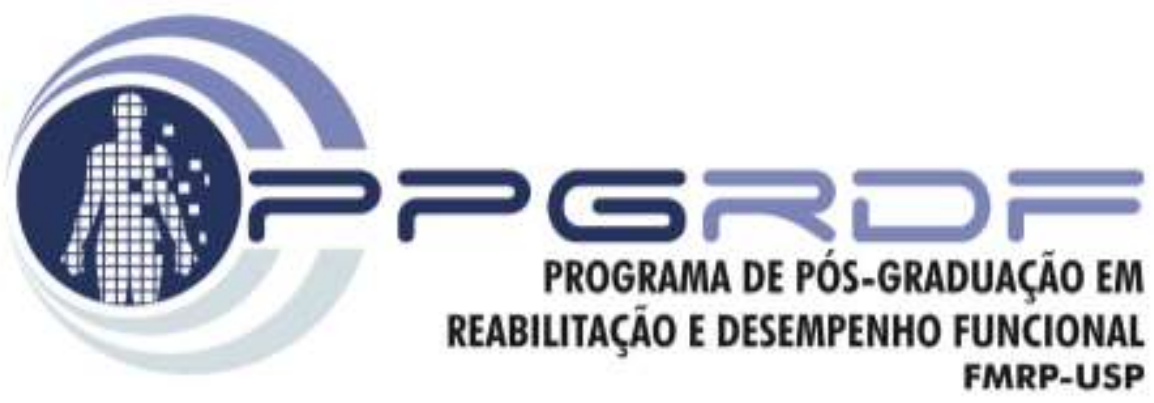

REFERÊNCIAS

"O pensamento constrói o futuro."

Alziro Zarur 


\section{REFERÊNCIAS}

ACQUADRO, C. et al. European Regulatory Issues and Quality of Life Assessment (ERIQA) Group. Literature review of methods to translate health-related quality of life questionnaires for use in multinational clinical trials. Value in Health. New York. v.11, n.3, p.509-21, 2008.

AKER, P.D. et al. Conservative management of mechanical neck pain: systematic overview and meta-analysis. British Medical Journal. London. v.23, n. 313(7068), p.1291-6, 1996.

ALEXANDRE, N.M.C.; COLUCI, M.Z.O. Validade de conteúdo nos processos de construção e adaptação de instrumentos de medidas. Ciência \& Saúde Coletiva. Rio de Janeiro. 2011, v. 16, n.7, p. 3061-3068, 2011.

BEATON, D. et al. Guidelines for the Process of Cross-Cultural Adaptation of SelfReport Measures. Spine. Philadelphia. v.25, n. 24, p.3186-91, 2000.

BEATON, D. et al. Recommendations for the Cross-Cultural Adaptation of Health Status Measures. American Academy of Orthopaedic Surgeons Institute for Work $\boldsymbol{\&}$ Health. p. $1-36$.

http://www.ortho.umn.edu/prod/groups/med/@pub/@med/@ ortho/documents/asset/me d_asset_360072.pdf. 2002. Acesso em 15/12/2015.

BEAVERS, A. S. et al. Practical Considerations for Using Exploratory Factor Analysis in Educational Research. Practical Assessment, Research \& Evaluation. Chicago. v. 18, n. 6, p. 2, 2013. 
BELLAMY, N.; SOTHERN, R.B.; CAMPBELL, J. Aspects of diurnal rhythmicity in pain, stiffness, and fatigue in patients with fibromyalgia. The Journal of Rheumatology. Toronto. v. 31, n.2, p.379-89, 2004.

BENDEBBA, M. et al. Cervical spine outcomes questionnaire - Its development and psychometric properties. Spine. Philadelphia. v. 27, n.19, p. 2116-2123, 2002.

BJÖRKLUND M, et al. The ProFitMap-neck - reliability and validity of a questionnaire for measuring symptoms and functional limitations in neck pain. Disability and Rehabilitation. Abingdon, Oxford. v. 34, p. 1096-1107, 2012.

BOGDUK, N. Neck pain: an update. Australian Family Physician. Sidney. v.17, p.7580, 1988.

BOGDUK, N. The anatomy and pathophysiology of neck pain. Physical Medicine \& Rehabilitation Clinics of North America. London. v.14, n.3, p.455-72, 2003.

BOLTON, J.E.; HUMPHREYS, B.K. The Bournemouth Questionnaire. A short-form comprehensive outcome measure. II. Psychometric properties in neck pain patients. Journal of Manipulative and Physiological Therapeutics. Lombard. v. 25, n. 3, p.141-148, 2002.

CHAN, Y.H. Correlational Statistics. Singapore Medical Journal. Singapore. v.44, n. 12, p. 614-619, 2003.

CHILDS, J.D. et al. American Physical Therapy Association. Neck pain: Clinical practice guidelines linked to the International Classification of Functioning, Disability, and Health from the Orthopedic Section of the American Physical Therapy Association. 
Journal of Orthopedics \& Sports Physical Therapy. Washington. v. 38, n.9:A1-A34, 2008.

CICONELLI, R.M. et al. Tradução para a língua portuguesa e validação do questionário genérico de avaliação de qualidade de vida SF-36 (Brasil SF-36). Revista Brasileira Reumatologia. São Paulo. v.39, n.3, p.143-50, 1999.

CIEZA, A. et al. ICF Core Sets for low back pain. Journal of Rehabilitation Medicine. Sweden. v. 36, p.69-74, 2004.

CLARK, L. A.; WATSON, D. Constructing validity: basic issues in objective scale development. In: KAZDIN, A. E. (Org.). Methodological Issues and Strategies in Clinical Research. Washington (DC): 2nd ed. American Psychological Association, p. 215-239, 1998.

COOK, C. et al. Cross-cultural adaptation and validation of the Brazilian Portuguese version of the Neck Disability Index and Neck Pain and Disability Scale. Spine (Phila Pa 1976). v.31, n.14, p.1621-7, 2006.

DANCEY, C.P.; REIDY, J. Statistics without maths for psychology: Using SPSS for Windows. New York: Prentice Hall, 2004.

DE VET , H. C. et al. Measurement in Medicine: a practical guide. Cambridge: University Press, 2011.

DIMITRIADIS, Z. et al. Do psychological states associate with pain and disability in chronic neck pain patients? Journal of Back and Musculoskeletal Rehabilitation. Amsterdam, 2015. [Epub ahead of print]. 
EVANS, G. Identifying and treating the causes of neck pain. The Medical Clinics of North America. Philadelphia. v. 98, n.3, p.645-61, 2014.

FEJER, R.; HARTVIGSEN, J. Neck pain and disability due to neck pain: whatis the relation? European Spine Journal. Heidelberg. v.17, p.80-88, 2008.

FERREIRA, M.L. et al. Are neck pain scales and questionnaires compatible with the international classification of functioning, disability and health? A systematic review. Disability and Rehabilitation. London. v. 32, n.19, p. 1539-46, 2010.

FIELD, A. P. Discovering statistics using SPSS (2nd edition). London: Sage, 2005.

FLEISS J.L., LEVIN B., PAIK M.C. Statistical Methods for Rates and Proportions. Hoboken, New Jersey: John Wiley \& Sons, Inc., 2003.

GABEL, C.P. et al. Confirmatory factory analysis of the Neck Disability Index in a general problematic neck population indicates a one-factor model. The Spine Journal. New York. v. 14, n.8, p.1410-6, 2014.

GABEL, C.P. et al. The Spine Functional Index: development and clinimetric validation of a new whole-spine functional outcome measure. The Spine Journal. New York. 25. pii: S1529-9430(13)01598-2, 2013.

GLIEM, J. A.; GLIEM, R. R. Calculating, interpreting, and reporting Cronbach's alpha reliability coefficient for Likert-type scales. Midwest Research-to-Practice Conference in Adult, Continuing, and Community Education, 2003.

GUILlEMIN, F.; BOMBARDIER, C.; BEATON, D. Cross-Cultural Adaptation of Health-Related Quality of Life Measures: Literature Review and Proposed Guidelines. J Clinical Journal of Epidemiology. Oxford. v. 6, n. 12, p. 1417-1432, 1993. 
HAIR, J. et al. Multivariate Data Analysis (6th edition). Upper Saddle River, NJ: Prentice-Hall. 2006.

HOGG-JOHNSON, S., et al. Bone and Joint Decade 2000-2010 Task Force on Neck Pain and Its Associated Disorders. The burden and determinants of neck pain in the general population: results of the Bone and Joint Decade 2000-2010 Task Force on Neck Pain and Its Associated Disorders. Spine Journal. New York. v.33, p.S39-S51, 2008.

HOGG-JOHNSON, S. et al. Differences in reported psychometric properties of the Neck Disability Index: patient population or choice of methods? Spine Journal. New York. v.9, n.10, p. 854-6, 2009.

HOY, D. et al. The global burden of neck pain: estimates from the global burden of disease 2010 study. Annuals of the Rheumatic Diseases. London. v.73, n.7, p.1309$15,2014$.

HUNG, M. et al. Challenging the norm: further psychometric investigation of the neck disability index. Spine Journal. New York. v.15, n.11, p. 2440-5, 2015.

IMRIE R. Demystifying disability: a review of the International Classification of Functioning, Disability and Health. Sociology of health \& illness. Henley-on-Thames. v. 26, p.287-305, 2004.

IPEA. Instituto de Pesquisa Econômica. Secretaria de Assuntos Estratégicos da Presidência da República. Evolução do analfabetismo e do analfabetismo funcional no Brasil Período 2004-2009. Comunicados IPEA. Brasília, 2010. http://www.ipea.gov.br/portal/images/stories/PDFs/comunicado/101209_comunicadoip ea70.pdf. Acesso em 15/12/2015. 
JORDAN, A. et al. The Copenhagen neck functional disability scale: A study of reliability and validity. Journal of Manipulative and Physiological Therapeutics. Lombard. v. 21, n.8, p. 520-527, 1998.

KAISER, H. F. The application of eletronic computers to factor analysis. Educational and Psychological Measurement. Thousand Oaks. v. 20, p. 141-151, 1960.

LANDERS, M.R. et al. The use of fear avoidance beliefs and nonorganic signs in predicting prolonged disability in patients with neck pain. Manual Therapy. Edinburgh. 2008, v.13, p.239-248, 2008.

LEAK, A.M. et al. The Northwick Park Neck Pain Questionnaire, devised to measure neck pain and disability. British Journal of Rheumatology. London. v.33, p.469-474, 1994.

LORENZO-SEVA, U.; TIMMERMAN, M. E.; KIERS, H. A. The hull method for selecting the number of common factors. Multivariate Behavioral Research. Fort Worth. v.46, n.2, p.340-364, 2011.

MACDERMID, J.C.; et al. Measurement properties of the neck disability index: a systematic review. Journal of Orthopedics \& Sports Physical Therapy. Washington. v. 39, n.5, p.400-17, 2009.

MAHER, C.G.; LATIMER, J. COSTA, L.O.P. The relevance of cross-cultural adaptation and clinimetrics for physical therapy instruments. Revista Brasileira de Fisioterapia. São Carlos. v.11, p.245-52, 2007.

MANLY, B.F.J. Factor analysis. In: MANLY B.F.J, editor. Multivariate statistical methods. A primer. London, United Kingdom: Chapman \& Hall, 1994. p. 93-106. 
MAROUFI, N. et al. A comparative investigation of flexion relaxation phenomenon in healthy and chronic neck pain subjects. European Spine Journal. Heidelberg. v. 22, n.1, p. 162-8, 2013.

MOKKINK, L. B. et al. COSMIN checklist manual. Amsterdam: VU University Medical Center. 2012.

MOKKINK, L. B. et al. The COSMIN checklist for evaluating the methodological quality of studies on measurement properties: a clarification of its content. BMC Medical Research Methodology. London. v. 18, p. 10-22, 2010.

MONTICONE, M. et al. Development of the Italian Version of the Neck Disability Index: cross-cultural adaptation, factor analysis, reliability, validity, and sensitivity to change. Spine (Phila Pa 1976), v.37, n.17, p.E1038-44, 2012.

MONTICONE, M. et al. Reliability, validity and responsiveness of the cross-culturally adapted Italian version of the core outcome measures index (COMI) for the neck. European Spine Journal. Heidelberg. v.23, n. 4, p. 863-72, 2014.

MONTICONE, M. The NeckPix(C): development of an evaluation tool for assessing kinesiophobia in subjects with chronic neck pain. European Spine Journal. Heidelberg. v.24, n.1, p.72-9, 2015.

MÜLLER, U.; RÖDER, C.; GREENOUGH, C.G. Back related outcome assessment instruments. European Spine Journal. Heidelberg, v.15, Suppl 1:S25-S31, 2006.

NEDERHAND, M.J. et al. Predictive value of fear avoidance in developing chronic neck pain disability: consequences for clinical decision making. Archives of Physical Medicine and Rehabilitation. Philadelphia. v.85, n.3, p.496-501, 2004. 
NOLET, P.S. et al. Is neck pain associated with worse health-related quality of life 6 months later? A population-based cohort study. Spine Journal. New York. 2015, v.15, n. 4, p.675-84.

ORFALE, A. G. et al. Translation into Brazilian Portuguese, cultural adaptation and evaluation of the reliability of the Disabilities of the Arm, Shoulder and Hand Questionnaire. Brazilian Journal of Medical and Biological Research. São Paulo. v. 38, n. 2, p. 293-302, 2005.

PAIS-RIBEIRO, J. et al. Validation study of a Portuguese version of the Hospital Anxiety and Depression Scale. Psychology, Health \& Medicine. Pavia. v.12, n.2, p. $225-237,2007$

PICON, P. et al. The Portuguese language version of social phobia and Anxiety Inventory: analysis of items and internal consistency in a Brazilian sample of 1,014 undergraduate students. Jornal Brasileiro de Psiquiatria. Rio de Janeiro. v. 55, n. 2, p. 114-119, 2006.

POLLARD, C.A. Preliminary validity study of the pain disability index. Perceptual and Motor Skills. Louisville. v.59, n.3, p.974, 1984.

SAAVEDRA-HERNÁNDEZ, M. et al. The contribution of previous episodes of pain, pain intensity, physical impairment, and pain-related fear to disability in patients with chronic mechanical neck pain. American Journal of Physical and Medicine Rehabilitation. Hagerstown. v.91, n.12, p.1070-6, 2012.

SAMPAIO, R.F.; LUZ, M.T. Human functioning and disability: exploring the scope of the World Health Organization's international classification. Cadernos de Saúde Pública. Rio de Janeiro. v. 25, n.3, p. 475-83, 2009. 
SCHELLINGERHOUT, J.M. et al. Measurement properties of translated versions of neck-specific questionnaires: a systematic review. BMC Medical Research Methodology. London. v.6, n.11, p.87, 2011.

SCHOLTES, V.A.; TERWEE, C.B.; POOLMAN, R.W. What makes a measurement instrument valid and reliable? Injury. Amsterdam. v.42, p.236-240, 2011.

SIQUEIRA, F.B.; TEIXEIRA-SALMELA, L,F.; MAGALHAES, LC. Análise das propriedades psicométricas da versão brasileira da escala tampa de cinesiofobia. Acta Ortopédica Brasileira. São Paulo. v. 15, n. 1, p. 19-24, 2007.

TABACHNICK, B.; FIDELL, L. Using multivariate analysis. Needham Heights: Allyn \& Bacon, 2007.

TAKALA, E. P. et al. Systematic evaluation of observational methods assessing biomechanical exposures at work. Scandinavian Journal of Work, Environment \& Health. Helsinki. v. 36, n. 1, p. 3-24, 2010.

TERWEE, C. B. et al. Quality criteria were proposed for measurement properties of health status questionnaires. Journal of Clinical Epidemiology. Oxforf, v. 60, p. 3442, 2007.

TERWEE, C. B. et al. Rating the methodological quality in systematic reviews of studies on measurement properties: a scoring system for the COSMIN checklist. Quality of Life Research. Oxford. v. 21, n. 4, p. 651-657, 2012.

VAN DER VELDE, G. et al. Rasch analysis provides new insights into the measurement properties of the neck disability index. Arthritis and Rheumatism. Hoboken. v. 61, n.4, p. 544-551, 2009. 
VERNON, H.; MIOR, S. The Neck Disability Index: a study of reliability and validity.

Journal of Manipulative and Physiological Therapeutics. Lombard. v.14, p.409-415, 1991.

VLAEYEN J.W.S. et al. The role of fear of movement/(re)injury in pain disability. Journal of Occupational Rehabilitation. Dordrecht. v.5, p.235-252, 1995.

VLAEYEN, J.W. et al. Fear of movement/(re)injury in chronic low back pain and its relation to behavioral performance. Pain. Hagerstown. v. 62, p.363-72, 1995.

WALTON, D.M.; MACDERMID, J.C. A brief 5-item version of the Neck Disability Index shows good psychometric properties. Health Quality of Life Outcomes. London. v.1, n.11, p.108, 2013.

WARE JE, JR.; SHERBOURNE, C.D. The MOS 36-item short-form health survey (SF36). I. Conceptual framework and item selection. Medical Care. Philadelphia. v.30, n.6, p.473-83, 1992.

WEIR, J.P. Quantifying test-retest reliability using the intraclass correlation coefficient and the SEM. Journal of Strength Conditioning Research. Champaign. v. 19, n.1, p.231-40, 2005.

WESTAWAY, M.D.; STRATFORD, P.W.; BINKLEY, J.M. The patient-specific functional scale: Validation of its use in persons with neck dysfunction. Journal of Orthopaedic \& Sports Physical Therapy. Washington. v.27, n.5, p.331-338, 1998.

WHEELER, A.H. et al. Development of the neck pain and disability scale - Item analysis, face, and criterion-related validity. Spine. New York. v.24, n.13, p.1290-1294, 1999. 
WHITE, P.; LEWITH, G.; PRESCOTT, P. The core outcomes for neck pain: Validation of a new outcome measure. Spine. New York. v. 29, n.17, p.1923-1930, 2004.

WIITAVAARA. B, et al. How well do questionnaires on symptoms in neck-shoulder disorders capture the experiences of those who suffer from neck-shoulder disorders? A content analysis of questionnaires and interviews. BMC Musculoskeletal Disorders. London. v.9, n.10, p. 30, 2009.

WILLIAMS, N.H.; WILKINSON, C.; RUSSELL, I.T. Extending the Aberdeen Back Pain Scale to include the whole spine: a set of outcome measures for the neck, upper and lower back. Pain. Hagerstown. v. 94, p.261-274, 2001.

WORLD HEALTH ORGANIZATION (WHO). The International Classification of Functioning, Disability and Health (ICF). 2001; Available from: http://www.who.int/classifications/icf/en/ $\quad$ or http://apps.who.int/classifications/icfbrowser/. Acesso em 15/12/2015.

YAKUT, Y.; et al. Reliability and validity of the Turkish version short-form McGill pain questionnaire in patients with rheumatoid arthritis. Clinical Rheumatology. Heidelberg. v.26, n.7, p. 1083-7, 2007.

YAO, M. et al. A systematic review of cross-cultural adaptation of the neck disability index. Spine (Phila Pa 1976). 2015 1; 40(7):480-90.

ZAUTRA, A.J.; et al. Daily fatigue in women with osteoarthritis, rheumatoid arthritis, and fibromyalgia. Pain. Hagerstown. v.128, n.1-2, p.128-35, 2007.

ZIGMOND, A.S.; SNAITH, R.P. The hospital anxiety and depression scale. Acta Psychiatrica Scandinavica. Malden. v.67, p.361-370, 1983. 


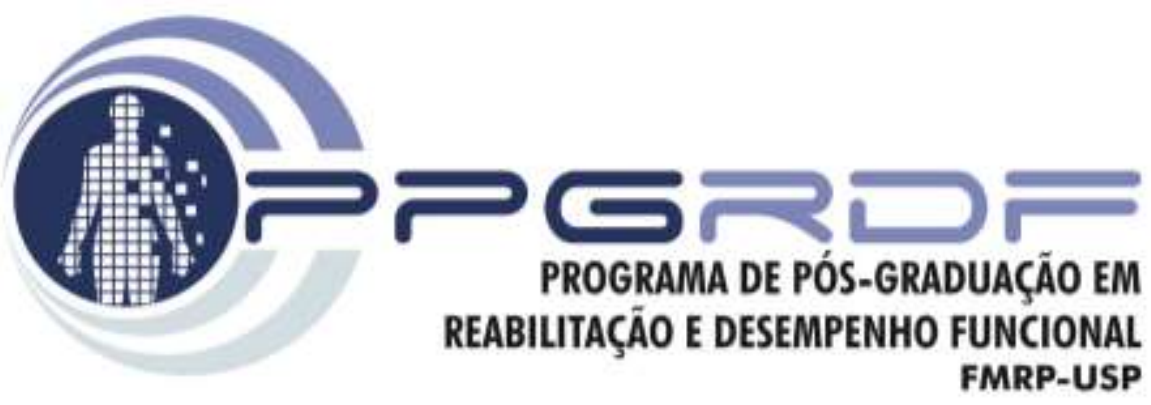

ANEXOS E APÊNDICES

"Por vezes sentimos que aquilo que fazemos não é senão uma gota de água no mar.

Mas o mar seria menor se lhe faltasse uma gota."

Madre Teresa de Calcuta 


\section{ANEXO 1 - Profile Fitness Mapping Neck}

\section{Profile Fitness Mapping questionnaires}

\section{T1} ProFitMap-neck, revised version

The symptom scale

\begin{tabular}{|c|c|}
\hline \multicolumn{2}{|c|}{ Do you feel/experience: } \\
\hline 1 & Stiffness in the neck? \\
\hline 2 & Soreness in the neck? \\
\hline 3 & Tension in the neck? \\
\hline 4 & Cracks in the neck? \\
\hline 5 & Tiredness in the neck? \\
\hline 6 & Weakness in the neck? \\
\hline 7 & Lockings in the neck? \\
\hline 8 & Fumblingness in the hands? \\
\hline 9 & Sensory disturbance? \\
\hline 10 & Jaw problems? \\
\hline 11 & Dizziness? \\
\hline 12 & Disturbance of balance? \\
\hline 13 & Irritability, short tempered? \\
\hline 14 & Depressed? \\
\hline 15 & Stressed? \\
\hline 16 & Nausea? \\
\hline 17 & Sensitivity to light? \\
\hline 18 & Sensitivity to sound? \\
\hline 19 & Disturbance of concentration? \\
\hline 20 & Disturbance of swallowing? \\
\hline 21 & Disturbance of breathing? \\
\hline 22 & Anxiety? \\
\hline 23 & Pain in the neck during activity? \\
\hline 24 & Pain in the neck during rest? \\
\hline \multicolumn{2}{|r|}{ Does your neck problems affect: } \\
\hline 25 & Your sleep? \\
\hline 26 & Your mood? \\
\hline
\end{tabular}

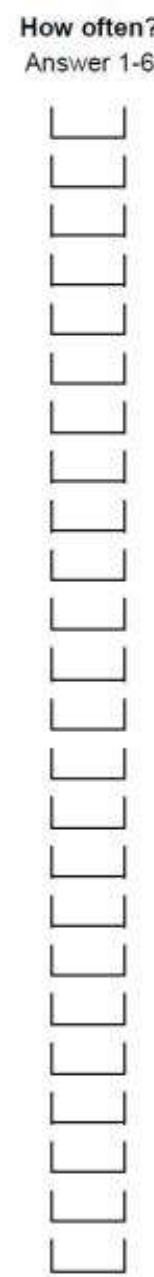

How much?

Answer 7-12

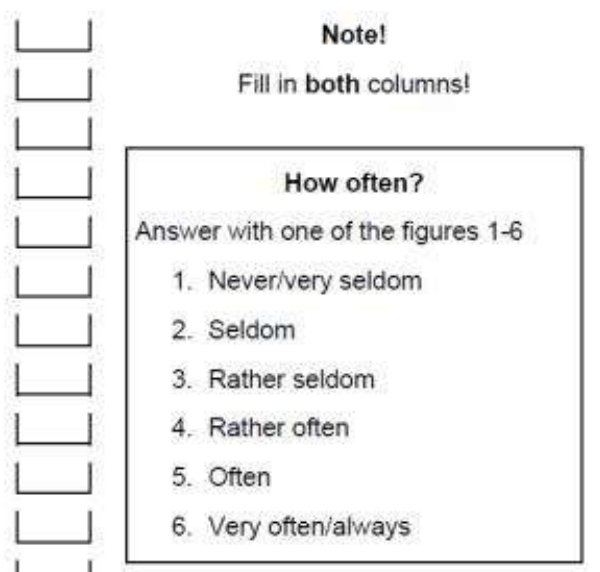

\section{How much?}

Answer with one of the figures 7-12

7. Nothing/none at all

8. Weak/little

9. Rather weak/rather little

10. Rather strong/rather much

11. Strong/much

12. Almost unbearable/

unbearable, all/maximally 
Anexos e 106

Apêndices

Profile Fitness Mapping questionnaires

ProFitMap-neck, revised version

The functional limitation scale

Because of your neck problems, $\quad$ How?

how do you manage to:

1 Stand?

2 Walk?

3 Sit?

4 Lay down?

5 Run?

6 Carry?

$7 \quad$ Lift?

8 Throw?

9 Put on and take off a sweater?
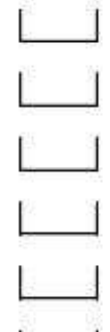
satisfying.

likely.

3. Rather good, rather easy, rather satisfying, rather likely.

4. Rather bad, rather difficult rather dissatisfying. rather unlikely.

10 Put on and take off socks?

11 Bend the head forward?

12 Bend the head backward?

13 Bend the head to the right?

14 Bend the head to the left?

15 Turn the head to the right?

16 Turn the head to the left?

What do you say about:

17 The condition of your neck?

18 Your general health? 
Anexos e

Method of score calculation for The Profile Fitness Mapping scales.

The table shows the weighting and maximum score of each item in the Profile Fitness Mapping scales, and the calculation of scores for each index.

Frequency ( $f$ ) is the answer on how often the symptom is felt (6-point scale from $1=$ never/very seldom, to $6=$ very often/always). Intensity (i) is the answer on how much the symptom is felt (6-point scale from $7=$ nothing/none at all, to $12=$ almost unbearable/unbearable, all/maximally). The answers of the functional limitation scale (fl) range from 1 = very good, no problem, very satisfying, very likely, to 6 = very bad, very difficultimpossible, very dissatisfying, very unlikely.

The result of each index is expressed as the percentage of the maximum score, where $100 \%$ is the best possible result. Adjustments due to omitted questions are done by removing the maximum score for those questions from the denominator before calculating the percentage.

\begin{tabular}{|c|c|c|c|c|c|c|c|c|}
\hline \multicolumn{5}{|c|}{ The symptom scale (s) } & \multicolumn{4}{|c|}{ The functional limitation scale (fl) } \\
\hline Item $_{5}$ & $\begin{array}{l}\text { Weight } \\
\left(W_{5}\right)\end{array}$ & $\begin{array}{l}\text { Score } \\
\text { frequency } \\
\text { index }\end{array}$ & $\begin{array}{l}\text { Score } \\
\text { intensity } \\
\text { index }\end{array}$ & $\begin{array}{l}\text { Max } \\
\text { score }\end{array}$ & Item $_{\text {rd }}$ & $\begin{array}{l}\text { Weight } \\
\left(W_{f i}\right)\end{array}$ & $\begin{array}{l}\text { Score } \\
\text { function } \\
\text { index }\end{array}$ & $\begin{array}{l}\text { Max } \\
\text { score }\end{array}$ \\
\hline 1 & 2 & $\left(6-f_{1}\right)^{*} W_{s}$ & $\left(12-i_{1}\right) * W_{s}$ & 10 & 1 & 2,4 & $\left(6-f_{1}\right)^{*} W_{n}$ & 12 \\
\hline 2 & 2 & $\left(6-f_{2}\right)^{*} W_{s}$ & $\left(12-\mathrm{i}_{2}\right)^{*} \mathrm{~W}_{\mathrm{s}}$ & 10 & 2 & 3 & $\left(6-\mathrm{fl}_{2}\right)^{*} \mathrm{~W}_{\mathrm{n}}$ & 15 \\
\hline 3 & 2 & $\left(6-f_{3}\right) * W_{5}$ & $\left(12-i_{3}\right)^{*} W_{5}$ & 10 & 3 & 2,4 & $\left(6-f_{3}\right)^{*} W_{n}$ & 12 \\
\hline 4 & 1 & $\left(6-f_{4}\right)^{*} W_{5}$ & $\left(12-i_{4}\right)^{*} W_{5}$ & 5 & 4 & 3 & $\left(6-\mathrm{fl}_{4}\right)^{*} \mathrm{~W}_{\pi}$ & 15 \\
\hline 5 & 1,2 & $\left(6-f_{5}\right)^{*} W_{s}$ & $\left(12-\mathrm{i}_{5}\right)^{*} \mathrm{~W}_{\mathrm{S}}$ & 6 & 5 & 2 & $\left(6-f_{5}\right)^{*} W_{\pi}$ & 10 \\
\hline 6 & 2 & $\left(6-f_{6}\right)^{*} W_{s}$ & $\left(12-i_{6}\right)^{*} W_{5}$ & 10 & 6 & 1,2 & $\left(6-f l_{6}\right)^{*} W_{f}$ & 6 \\
\hline 7 & 2.4 & $\left(6-f_{7}\right)^{*} W_{5}$ & $\left(12-i_{7}\right)^{*} W_{5}$ & 12 & 7 & 1,2 & $\left(6-f_{7}\right)^{x} W_{f}$ & 6 \\
\hline 8 & 2,4 & $\left(6-f_{B}\right) * W_{S}$ & $\left(12-\mathrm{i}_{8}\right)^{*} \mathrm{~W}_{\mathrm{s}}$ & 12 & 8 & 1,2 & $\left(6-f_{8}\right)^{*} W_{n}$ & 6 \\
\hline 9 & 2,4 & $\left(6-f_{g}\right)^{*} W_{s}$ & $\left(12-i_{9}\right)^{*} W_{s}$ & 12 & 9 & 2,4 & $\left(6-f_{9}\right)^{*} W_{f}$ & 12 \\
\hline 10 & 2,4 & $\left(6-f_{10}\right)^{x} W_{s}$ & $\left(12-i_{10}\right)^{\star} W_{5}$ & 12 & 10 & 2,4 & $\left(6-\mathrm{fl}_{10}\right)^{*} \mathrm{~W}_{\mathrm{f}}$ & 12 \\
\hline 11 & 3 & $\left(6-f_{11}\right)^{*} W_{s}$ & $\left(12-i_{11}\right)^{\star} W_{s}$ & 15 & 11 & 3 & $\left(6-\mathrm{fl}_{11}\right)^{*} W_{n}$ & 15 \\
\hline 12 & 2,4 & $\left(6-f_{12}\right)^{*} W_{s}$ & $\left(12-\mathrm{i}_{12}\right)^{*} \mathrm{~W}_{\mathrm{s}}$ & 12 & 12 & 3 & $\left(6-f_{12}\right)^{*} W_{f}$ & 15 \\
\hline 13 & 2 & $\left(6-f_{13}\right)^{*} W_{s}$ & $\left(12-i_{13}\right)^{*} W_{s}$ & 10 & 13 & 3 & $\left(6-f_{13}\right)^{2} W_{f}$ & 15 \\
\hline 14 & 2 & $\left(6-f_{14}\right)^{*} W_{s}$ & $\left(12-i_{14}\right)^{\star} W_{s}$ & 10 & 14 & 3 & $\left(6-\mathrm{fl}_{14}\right)^{*} W_{n}$ & 15 \\
\hline 15 & 2 & $\left(6-f_{15}\right)^{*} W_{5}$ & $\left(12-i_{15}\right)^{\star} W_{s}$ & 10 & 15 & 3 & $\left(6-f_{15}\right)^{*} W_{\mathrm{f}}$ & 15 \\
\hline 16 & 4 & $\left(6-f_{16}\right)^{*} W_{s}$ & $\left(12-i_{16}\right)^{\star} W_{s}$ & 20 & 16 & 3 & $\left(6-f_{16}\right)^{*} W_{n}$ & 15 \\
\hline 17 & 1.2 & $\left(6-f_{17}\right)^{*} W_{s}$ & $\left(12-i_{11}\right)^{\star} W_{s}$ & 6 & 17 & 4 & $\left(6-f_{18}\right)^{*} W_{n}$ & 20 \\
\hline 18 & 1.2 & $\left(6-f_{18}\right)^{*} W_{s}$ & $\left(12-i_{18}\right)^{*} W_{s}$ & 6 & 18 & 4 & $\left(6-f l_{19}\right)^{*} W_{\mathrm{f}}$ & 20 \\
\hline 19 & 3 & $\left(6-f_{19}\right)^{*} W_{5}$ & $\left(12-i_{19}\right)^{\star} W_{5}$ & 15 & & & & \\
\hline 20 & 2 & $\left(6-f_{20}\right)^{*} W_{s}$ & $\left(12-i_{20}\right)^{*} W_{s}$ & 10 & & & & \\
\hline 21 & 2 & $\left(6-f_{21}\right)^{*} W_{s}$ & $\left(12-i_{21}\right)^{\star} W_{s}$ & 10 & & & & \\
\hline 22 & 2 & $\left(6-f_{22}\right)^{*} W_{s}$ & $\left(12-i_{22}\right)^{\star} W_{s}$ & 10 & & & & \\
\hline 23 & 8 & $\left(6-f_{23}\right)^{*} W_{5}$ & $\left(12-i_{23}\right)^{*} W_{s}$ & 40 & & & & \\
\hline 24 & 8 & $\left(6-f_{24}\right)^{*} W_{s}$ & $\left(12-i_{24}\right)^{*} W_{s}$ & 40 & & & & \\
\hline 25 & 3,6 & $\left(6-f_{25}\right)^{*} W_{5}$ & $\left(12-i_{25}\right)^{\star} W_{5}$ & 18 & & & & \\
\hline 26 & 3,6 & $\left(6-f_{26}\right)^{*} W_{s}$ & $\left(12-i_{26}\right)^{\star} W_{S}$ & 18 & & & & \\
\hline
\end{tabular}

Reference:

Björklund M, Hamberg J, Heiden M, Barnekow-Bergkvist M. (2012) The ProFitMap-neck reliability and validity of a questionnaire for measuring symptoms and functional limitations in neck pain. Disability and Rehabilitation 34, 1096-1107 


\section{ANEXO 2 - Aprovação do Comitê de Ética em Pesquisa}

Oficio $\mathrm{n}^{\circ} 1166 / 2014$ CEP/MGV

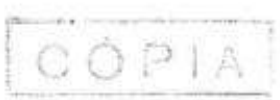

Prezadas Senhoras,

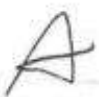

O trabalho intitulado "ADAPTAÇÃo TRANSCULTURAL PARA O PORTUGUESS-BRASILEIRO DO PROFILE FITNESS MAPPING NECK QUESTIONNAIRE (PROFITMAP-NECK)", foi analisado “AD REFERENDUM" pelo Comitê de Ética em Pesquisa, e enquadrado na categoria: APROVADO, bem como - Termo de Consentimento Livre e Esclarecido, de acordo com o Processo HCRP $n^{\circ} 4273 / 2014$.

De acordo com Carta Circular $n^{\circ}$ 003/2011/CONEP/CNS, datada de 21/03/2011, o sujeito de pesquisa ou seu representante, quando for o caso, deverá rubricar todas as folhas do Termo de Consentimento Livre e Esclarecido - TCLE - apondo sua assinatura na ultima do referido Termo; o pesquisador responsánel deverá da mesma forma, rubricar todas as folhas do Termo de Consentimento Livre e Esclarecido - TCLE - apondo sua assinatura na última página do referido Termo.

Este Comitê segue integralmente a Conferência Internacional de Harmonizaçao de Boas Práticas Clínicas (IGH-GCP), bem como a Resolução $n^{\circ}$ 196/96 CNS/MS.

$\frac{\text { Relatório Parcial e o Relatório Final da pesquisa. }}{\text { Atenciosamente. }}$

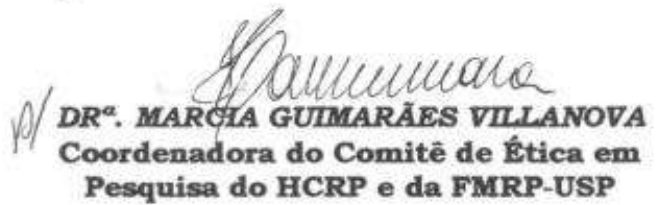

Ilustrissimas Senhoras

PROF ${ }^{\mathrm{a}} \cdot \mathrm{DR}^{\mathrm{a}}$. THAIS CRISTINA CHAVES(Orientadora)

MARIANA CÂNDIDO FERREIRA

Depto. de Treurociências e Cièncias do Comportamento

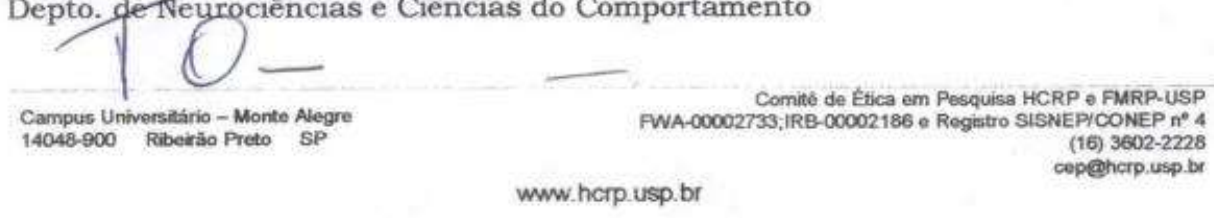


ANEXO 3 - Autorização para a adaptação transcultural do ProFitMap-neck

From: Martin.Bjorklund@hig.se

To: thaiscchaves@hotmail.com

CC: mariana.candido.ferreira@usp.br

Subject: SV: Permission to make cross cultural adaptation

Date: Thu, 2 May 2013 14:19:37+0000

Dear Prof Chaves,

I am sorry for not responding to yor latest e-mail - we have had problems with our e-mail so this is the first time that see your request.

You are very welcome to do cross cultural adaptation of the ProfiMap-neck.

Good luck!

/Martin

Martin Björklund, Ph.D., Associate Professor

Mobil/Cellphone: $+46(0) 704790430$

Akademin för hälsa och arbetsliv

Avdelningen för arbets- och folkhälsovetenskap/Department of Occupational and Public Health

Sciences

Centrum för belastningsskadeforskning, CBF/Centre for Musculoskeletal Research

Högskolan i Gävle/University of Gävle

Box 7629

SE - 90712 Ume å

Sweden

Besöksadress/Visiting address: Johan Bures vāg 11, Umeá

e-mail: mbb@hig.se

http://www.hig.se/cbf

Forskarporträtt/ Research portrait: http://www.hig.se/mbb 


\section{ANEXO 4 - Neck Disability Index}

Este questionário foi criado para dar informações ao seu doutor sobre como a sua dor no pescoço tem afetado a sua habilidade para fazer atividades diárias. Por favor, responda a cada uma das perguntas e marque em cada seção apenas uma alternativa que melhor se aplique a você.

\section{Seção 1 - Intensidade da dor}

Eu não tenho dor nesse momento.

A dor é muito leve nesse momento.

A dor é moderada nesse momento.

A dor é razoavelmente grande nesse momento.

A dor é muito grande nesse momento.

A dor é a pior que se possa imaginar nesse momento.

\section{Seção 2 - Cuidado pessoal (se lavar, se vestir, etc)}

Eu posso cuidar de mim mesmo(a) sem aumentar a dor.

Eu posso cuidar de mim mesmo(a) normalmente, mas isso faz aumentar a dor.

É doloroso ter que cuidar de mim mesmo e eu faço isso lentamente e com cuidado.

Eu preciso de ajuda, mas consigo fazer a maior parte do meu cuidado pessoal.

Eu preciso de ajuda na maioria dos aspectos relacionados a cuidar de mim mesmo(a)

(6) Eu não me visto, me lavo com dificuldade e fico na cama.

\section{Seção 3 - Levantar coisas}

\section{(6) Eu posso levantar objetos pesados sem aumentar a dor.}

(6) Eu posso levantar objetos pesados, mas isso faz aumentar a dor.

(6) A dor me impede de levantar objetos pesados do chão, mas eu consigo se eles estiverem colocados em uma boa posição, por exemplo, em uma mesa.

(6) A dor me impede de levantar objetos pesados, mas eu consigo levantar objetos com peso entre leve e médio se eles estiverem colocados em uma boa posição.

(6) Eu posso levantar objetos muito leves.

(6) Eu não posso levantar nem carregar absolutamente nada.

\section{Seção 6 - Prestar Atenção}

Eu consigo prestar atenção quando eu quero sem dificuldade.

Eu consigo prestar atenção quando eu quero com uma dificuldade leve.

Eu tenho uma dificuldade moderada em prestar atenção quando eu quero.

Eu tenho muita dificuldade em prestar atenção quando eu quero.

Eu tenho muitíssima dificuldade em prestar atenção quando eu quero.

Eu não consigo prestar atenção.

\section{Seção 7 - Trabalho}

Eu posso trabalhar tanto quanto eu quiser.

Eu só consigo fazer o trabalho que estou acostumado(a) a fazer, mas nada além disso.

Eu consigo fazer a maior parte do trabalho que estou acostumado(a) a fazer, mas nada além disso.

(6) Eu não consigo fazer o trabalho que estou acostumado(a) a fazer.

Eu mal consigo fazer qualquer tipo de trabalho.

Eu não consigo fazer nenhum tipo de trabalho.

\section{Seção 8 - Dirigir automóveis}

Eu posso dirigir meu carro sem nenhuma dor no pescoço.

Eu posso dirigir meu carro tanto quanto eu queira com uma dor leve no meu pescoço.

Eu posso dirigir meu carro tanto quanto eu queira com uma dor moderada no meu pescoço.

(6) Eu não posso dirigir o meu carro tanto quanto eu queira por causa de uma dor moderada no meu pescoço.

Eu mal posso dirigir por causa de uma dor forte no meu pescoço.

Eu não posso dirigir meu carro de maneira nenhuma.

Pergunta não se aplica por não saber dirigir ou não dirigir muitas vezes. 


\section{Anexos e 111 \\ Apêndices}

\section{Seção 4 - Leitura}

Eu posso ler tanto quanto eu queira sem dor no meu pescoço.

Eu posso ler tanto quanto eu queira com uma dor leve no meu pescoço.

Eu posso ler tanto quanto eu queira com uma dor moderada no meu pescoço.

Eu não posso ler tanto quanto eu queira por causa de uma dor moderada no meu pescoço.

(6) Eu mal posso ler por causa de uma grande dor no meu pescoço.

(6) Eu não posso ler nada.

(6) Pergunta não se aplica por não saber ou não poder ler.

\section{Seção 5- Dores de cabeça}

Eu não tenho nenhuma dor de cabeça.

Eu tenho pequenas dores de cabeça com pouca freqüência.

Eu tenho dores de cabeça moderadas com pouca freqüência.

Eu tenho dores de cabeça moderadas muito freqüentemente.

Eu tenho dores de cabeça fortes freqüentemente.

Eu tenho dores de cabeça quase o tempo inteiro.

\section{CLASSIFICAÇÃO:} pontos

(6) 10-28\% (5-14 pontos) - incapacidade leve

(6) $30-48 \%$ (15- 24 pontos) - incapacidade moderada

(6) $50-68 \%$ ( $25-35$ pontos) - incapacidade severa

(6) $72 \%$ ou mais (36 pontos ou mais) - incapacidade completa

\section{Seção 9 - Dormi}

Eu não tenho problemas para dormir.

Meu sono é um pouco perturbado (menos de uma hora sem conseguir dormir).

Meu sono é levemente perturbado (1-2 horas sem conseguir dormir).

Meu sono é moderadamente perturbado (2-3 horas sem conseguir dormir).

Meu sono é muito perturbado (3-5 horas sem conseguir dormir).

Meu sono é completamente perturbado (1-2 horas sem sono)

\section{Seção 10 - Diversão}

Eu consigo fazer todas as minhas atividades de diversão sem nenhuma dor no pescoço. Eu consigo fazer todas as minhas atividades de diversão com alguma dor no pescoço.

Eu consigo fazer a maioria, das minhas atividades de diversão por causa da dor no meu pescoço.

(6) Eu consigo fazer poucas das minhas atividades de diversão por causa da dor no meu pescoço.

() Eu mal consigo fazer qualquer atividade de diversão por causa da dor no meu pescoço. Eu não consigo fazer nenhuma atividade de diversão. 
Anexos e 112

Apêndices

\section{APÊNDICE 1 - ProFitMap-neck versão síntese de tradução T123}

Escala de Sintomas

\begin{tabular}{|c|c|c|c|c|c|c|c|}
\hline \multirow[t]{4}{*}{1} & \multirow[t]{4}{*}{ Você sente rigidez no pescoço? } & \multicolumn{6}{|c|}{ Com que frequência? } \\
\hline & & Nunca & Raramente & Às vezes & Muitas vezes & Frequentemente & Sempre \\
\hline & & \multicolumn{6}{|c|}{ Quanto? } \\
\hline & & Não sinto nada & Um pouco & $\begin{array}{l}\text { De forma } \\
\text { moderada }\end{array}$ & De forma intensa & $\begin{array}{l}\text { De forma muito } \\
\text { intensa/forte }\end{array}$ & De forma insuportável \\
\hline \multirow[t]{4}{*}{2} & \multirow[t]{4}{*}{ Você sente incomodo no pescoço? } & \multicolumn{6}{|c|}{ Com que frequência? } \\
\hline & & Nunca & Raramente & Às vezes & Muitas vezes & Frequentemente & Sempre \\
\hline & & \multicolumn{6}{|c|}{ Quanto? } \\
\hline & & Não sinto nada & Um pouco & $\begin{array}{l}\text { De forma } \\
\text { moderada }\end{array}$ & De forma intensa & $\begin{array}{l}\text { De forma muito } \\
\text { intensa/forte }\end{array}$ & De forma insuportável \\
\hline \multirow[t]{4}{*}{3} & \multirow[t]{4}{*}{ Você sente tensão no pescoço? } & \multicolumn{6}{|c|}{ Com que frequência? } \\
\hline & & Nunca & Raramente & Às vezes & Muitas vezes & Frequentemente & Sempre \\
\hline & & \multicolumn{6}{|c|}{ Quanto? } \\
\hline & & Não sinto nada & Um pouco & $\begin{array}{l}\text { De forma } \\
\text { moderada }\end{array}$ & De forma intensa & $\begin{array}{l}\text { De forma muito } \\
\text { intensa/forte }\end{array}$ & De forma insuportável \\
\hline \multirow[t]{4}{*}{4} & \multirow[t]{4}{*}{ Você tem estalos no pescoço? } & \multicolumn{6}{|c|}{ Com que frequência? } \\
\hline & & Nunca & Raramente & Às vezes & Muitas vezes & Frequentemente & Sempre \\
\hline & & \multicolumn{6}{|c|}{ Quanto? } \\
\hline & & Não sinto nada & Um pouco & $\begin{array}{l}\text { De forma } \\
\text { moderada }\end{array}$ & De forma intensa & $\begin{array}{l}\text { De forma muito } \\
\text { intensa/forte }\end{array}$ & De forma insuportável \\
\hline \multirow[t]{4}{*}{5} & \multirow[t]{4}{*}{ Você sente cansaço no pescoço? } & \multicolumn{6}{|c|}{ Com que frequência? } \\
\hline & & Nunca & Raramente & Às vezes & Muitas vezes & Frequentemente & Sempre \\
\hline & & \multicolumn{6}{|c|}{ Quanto? } \\
\hline & & Não sinto nada & Um pouco & De forma & De forma intensa & De forma muito & De forma insuportável \\
\hline
\end{tabular}


Anexos e 113

Apêndices

\begin{tabular}{|c|c|c|c|c|c|c|c|}
\hline & & & & moderada & & intensa/forte & \\
\hline \multirow[t]{4}{*}{6} & \multirow[t]{4}{*}{ Você sente fraqueza no pescoço? } & \multicolumn{6}{|c|}{ Com que frequência? } \\
\hline & & Nunca & Raramente & Às vezes & Muitas vezes & Frequentemente & Sempre \\
\hline & & \multicolumn{6}{|c|}{ Quanto? } \\
\hline & & Não sinto nada & Um pouco & $\begin{array}{l}\text { De forma } \\
\text { moderada }\end{array}$ & De forma intensa & $\begin{array}{l}\text { De forma muito } \\
\text { intensa/forte }\end{array}$ & De forma insuportável \\
\hline \multirow[t]{4}{*}{7} & \multirow[t]{4}{*}{ Você tem travamentos no pescoço? } & \multicolumn{6}{|c|}{ Com que frequência? } \\
\hline & & Nunca & Raramente & Às vezes & Muitas vezes & Frequentemente & Sempre \\
\hline & & \multicolumn{6}{|c|}{ Quanto? } \\
\hline & & Não sinto nada & Um pouco & $\begin{array}{l}\text { De forma } \\
\text { moderada }\end{array}$ & De forma intensa & $\begin{array}{c}\text { De forma muito } \\
\text { intensa/forte }\end{array}$ & De forma insuportável \\
\hline \multirow[t]{4}{*}{8} & \multirow[t]{4}{*}{ Você sente fraqueza nas mãos? } & \multicolumn{6}{|c|}{ Com que frequência? } \\
\hline & & Nunca & Raramente & Às vezes & Muitas vezes & Frequentemente & Sempre \\
\hline & & \multicolumn{6}{|l|}{ Quanto? } \\
\hline & & Não sinto nada & Um pouco & $\begin{array}{l}\text { De forma } \\
\text { moderada }\end{array}$ & De forma intensa & $\begin{array}{l}\text { De forma muito } \\
\text { intensa/forte }\end{array}$ & $\begin{array}{l}\text { De forma } \\
\text { insuportável }\end{array}$ \\
\hline \multirow[t]{4}{*}{9} & \multirow{4}{*}{$\begin{array}{l}\text { Você tem problemas de } \\
\text { sensibilidade? }\end{array}$} & \multicolumn{6}{|c|}{ Com que frequência? } \\
\hline & & Nunca & Raramente & Às vezes & Muitas vezes & Frequentemente & Sempre \\
\hline & & \multicolumn{6}{|l|}{ Quanto? } \\
\hline & & Não sinto nada & Um pouco & $\begin{array}{l}\text { De forma } \\
\text { moderada }\end{array}$ & De forma intensa & $\begin{array}{l}\text { De forma muito } \\
\text { intensa/forte }\end{array}$ & $\begin{array}{l}\text { De forma } \\
\text { insuportável }\end{array}$ \\
\hline \multirow[t]{4}{*}{10} & \multirow{4}{*}{$\begin{array}{l}\text { Você sente tem problemas } \\
\text { mandibulares? }\end{array}$} & \multicolumn{6}{|c|}{ Com que frequência? } \\
\hline & & Nunca & Raramente & $\grave{A s s}$ vezes & Muitas vezes & Frequentemente & Sempre \\
\hline & & \multicolumn{6}{|l|}{ Quanto? } \\
\hline & & Não sinto nada & Um pouco & $\begin{array}{l}\text { De forma } \\
\text { moderada }\end{array}$ & De forma intensa & $\begin{array}{l}\text { De forma muito } \\
\text { intensa/forte }\end{array}$ & $\begin{array}{l}\text { De forma } \\
\text { insuportável }\end{array}$ \\
\hline
\end{tabular}


Anexos e 114

Apêndices

\begin{tabular}{|c|c|c|c|c|c|c|c|}
\hline \multirow[t]{4}{*}{11} & \multirow[t]{4}{*}{ Você sente tontura? } & \multicolumn{6}{|c|}{ Com que frequência? } \\
\hline & & Nunca & Raramente & Às vezes & Muitas vezes & Frequentemente & Sempre \\
\hline & & \multicolumn{6}{|c|}{ Quanto? } \\
\hline & & Não sinto nada & Um pouco & $\begin{array}{l}\text { De forma } \\
\text { moderada }\end{array}$ & De forma intensa & $\begin{array}{l}\text { De forma muito } \\
\text { intensa/forte }\end{array}$ & $\begin{array}{l}\text { De forma } \\
\text { insuportável }\end{array}$ \\
\hline \multirow[t]{4}{*}{12} & \multirow[t]{4}{*}{ Você sente falta de equilíbrio? } & \multicolumn{6}{|c|}{ Com que frequência? } \\
\hline & & Nunca & Raramente & Às vezes & Muitas vezes & Frequentemente & Sempre \\
\hline & & \multicolumn{6}{|c|}{ Quanto? } \\
\hline & & Não sinto nada & Um pouco & $\begin{array}{l}\text { De forma } \\
\text { moderada }\end{array}$ & De forma intensa & $\begin{array}{l}\text { De forma muito } \\
\text { intensa/forte }\end{array}$ & $\begin{array}{c}\text { De forma } \\
\text { insuportável }\end{array}$ \\
\hline \multirow[t]{4}{*}{13} & \multirow{4}{*}{$\begin{array}{l}\text { Você se sente irritado ou tem } \\
\text { pouca paciência? }\end{array}$} & \multicolumn{6}{|c|}{ Com que frequência? } \\
\hline & & Nunca & Raramente & Às vezes & Muitas vezes & Frequentemente & Sempre \\
\hline & & \multicolumn{6}{|c|}{ Quanto? } \\
\hline & & Não sinto nada & Um pouco & $\begin{array}{l}\text { De forma } \\
\text { moderada }\end{array}$ & De forma intensa & $\begin{array}{l}\text { De forma muito } \\
\text { intensa/forte }\end{array}$ & $\begin{array}{c}\text { De forma } \\
\text { insuportável }\end{array}$ \\
\hline \multirow[t]{4}{*}{14} & \multirow[t]{4}{*}{ Você se sente deprimido? } & \multicolumn{6}{|c|}{ Com que frequência? } \\
\hline & & Nunca & Raramente & Às vezes & Muitas vezes & Frequentemente & Sempre \\
\hline & & \multicolumn{6}{|c|}{ Quanto? } \\
\hline & & Não sinto nada & Um pouco & $\begin{array}{l}\text { De forma } \\
\text { moderada }\end{array}$ & De forma intensa & $\begin{array}{l}\text { De forma muito } \\
\text { intensa/forte }\end{array}$ & $\begin{array}{c}\text { De forma } \\
\text { insuportável }\end{array}$ \\
\hline
\end{tabular}


Anexos e 115

Apêndices

\begin{tabular}{|c|c|c|c|c|c|c|c|}
\hline \multirow[t]{4}{*}{15} & \multirow[t]{4}{*}{ Você se sente estressado? } & \multicolumn{6}{|c|}{ Com que frequência? } \\
\hline & & Nunca & Raramente & Às vezes & Muitas vezes & Frequentemente & Sempre \\
\hline & & \multicolumn{6}{|c|}{ Quanto? } \\
\hline & & Não sinto nada & Um pouco & $\begin{array}{l}\text { De forma } \\
\text { moderada }\end{array}$ & De forma intensa & $\begin{array}{l}\text { De forma muito } \\
\text { intensa/forte }\end{array}$ & De forma insuportável \\
\hline \multirow[t]{4}{*}{16} & \multirow[t]{4}{*}{ Você sente náuseas? } & \multicolumn{6}{|c|}{ Com que frequência? } \\
\hline & & Nunca & Raramente & Às vezes & Muitas vezes & Frequentemente & Sempre \\
\hline & & \multicolumn{6}{|c|}{ Quanto? } \\
\hline & & Não sinto nada & Um pouco & $\begin{array}{l}\text { De forma } \\
\text { moderada }\end{array}$ & De forma intensa & $\begin{array}{l}\text { De forma muito } \\
\text { intensa/forte }\end{array}$ & De forma insuportável \\
\hline \multirow[t]{4}{*}{17} & \multirow[t]{4}{*}{ Você tem sensibilidade à luz? } & \multicolumn{6}{|c|}{ Com que frequência? } \\
\hline & & Nunca & Raramente & Às vezes & Muitas vezes & Frequentemente & Sempre \\
\hline & & \multicolumn{6}{|c|}{ Quanto? } \\
\hline & & Não sinto nada & Um pouco & $\begin{array}{l}\text { De forma } \\
\text { moderada }\end{array}$ & De forma intensa & $\begin{array}{l}\text { De forma muito } \\
\text { intensa/forte }\end{array}$ & De forma insuportável \\
\hline \multirow[t]{4}{*}{18} & \multirow[t]{4}{*}{ Você tem sensibilidade ao som? } & \multicolumn{6}{|c|}{ Com que frequência? } \\
\hline & & Nunca & Raramente & Às vezes & Muitas vezes & Frequentemente & Sempre \\
\hline & & \multicolumn{6}{|c|}{ Quanto? } \\
\hline & & Não sinto nada & Um pouco & $\begin{array}{l}\text { De forma } \\
\text { moderada }\end{array}$ & De forma intensa & $\begin{array}{l}\text { De forma muito } \\
\text { intensa/forte }\end{array}$ & De forma insuportável \\
\hline \multirow[t]{4}{*}{19} & \multirow{4}{*}{$\begin{array}{l}\text { Você tem dificuldade de } \\
\text { concentração? }\end{array}$} & \multicolumn{6}{|c|}{ Com que frequência? } \\
\hline & & Nunca & Raramente & $\grave{\text { Às vezes }}$ & Muitas vezes & Frequentemente & Sempre \\
\hline & & \multicolumn{6}{|c|}{ Quanto? } \\
\hline & & Não sinto nada & Um pouco & $\begin{array}{l}\text { De forma } \\
\text { moderada }\end{array}$ & De forma intensa & $\begin{array}{l}\text { De forma muito } \\
\text { intensa/forte }\end{array}$ & De forma insuportável \\
\hline \multirow[t]{3}{*}{20} & \multirow[t]{3}{*}{ Você tem dificuldade de engolir? } & \multicolumn{6}{|c|}{ Com que frequência? } \\
\hline & & Nunca & Raramente & Às vezes & Muitas vezes & Frequentemente & Sempre \\
\hline & & \multicolumn{6}{|c|}{ Quanto? } \\
\hline
\end{tabular}


Anexos e 116

Apêndices

\begin{tabular}{|c|c|c|c|c|c|c|c|}
\hline & & Não sinto nada & Um pouco & $\begin{array}{l}\text { De forma } \\
\text { moderada }\end{array}$ & De forma intensa & $\begin{array}{l}\text { De forma muito } \\
\text { intensa/forte }\end{array}$ & De forma insuportável \\
\hline \multirow[t]{4}{*}{21} & \multirow[t]{4}{*}{ Você tem dificuldade de respirar? } & \multicolumn{6}{|c|}{ Com que frequência? } \\
\hline & & Nunca & Raramente & Às vezes & Muitas vezes & Frequentemente & Sempre \\
\hline & & \multicolumn{6}{|c|}{ Quanto? } \\
\hline & & Não sinto nada & Um pouco & $\begin{array}{l}\text { De forma } \\
\text { moderada }\end{array}$ & De forma intensa & $\begin{array}{l}\text { De forma muito } \\
\text { intensa/forte }\end{array}$ & De forma insuportável \\
\hline
\end{tabular}

\begin{tabular}{|c|c|c|c|c|c|c|c|}
\hline \multirow[t]{4}{*}{22} & \multirow[t]{4}{*}{ Você se sente ansioso? } & \multicolumn{6}{|c|}{ Com que frequência? } \\
\hline & & Nunca & Raramente & Às vezes & Muitas vezes & Frequentemente & Sempre \\
\hline & & \multicolumn{6}{|c|}{ Quanto? } \\
\hline & & Não sinto nada & Um pouco & $\begin{array}{l}\text { De forma } \\
\text { moderada }\end{array}$ & De forma intensa & $\begin{array}{l}\text { De forma muito } \\
\text { intensa/forte }\end{array}$ & $\begin{array}{c}\text { De forma } \\
\text { insuportável }\end{array}$ \\
\hline \multirow[t]{4}{*}{23} & \multirow{4}{*}{$\begin{array}{l}\text { Você tem dor no pescoço durante } \\
\text { as atividades? }\end{array}$} & \multicolumn{6}{|c|}{ Com que frequência? } \\
\hline & & Nunca & Raramente & Às vezes & Muitas vezes & Frequentemente & Sempre \\
\hline & & \multicolumn{6}{|c|}{ Quanto? } \\
\hline & & Não sinto nada & Um pouco & $\begin{array}{l}\text { De forma } \\
\text { moderada }\end{array}$ & De forma intensa & $\begin{array}{l}\text { De forma muito } \\
\text { intensa/forte }\end{array}$ & $\begin{array}{c}\text { De forma } \\
\text { insuportável }\end{array}$ \\
\hline \multirow[t]{4}{*}{24} & \multirow{4}{*}{$\begin{array}{l}\text { Você tem dor no pescoço durante } \\
\text { o repouso? }\end{array}$} & \multicolumn{6}{|c|}{ Com que frequência? } \\
\hline & & Nunca & Raramente & Às vezes & Muitas vezes & Frequentemente & Sempre \\
\hline & & \multicolumn{6}{|c|}{ Quanto? } \\
\hline & & Não sinto nada & Um pouco & $\begin{array}{l}\text { De forma } \\
\text { moderada }\end{array}$ & De forma intensa & $\begin{array}{l}\text { De forma muito } \\
\text { intensa/forte }\end{array}$ & $\begin{array}{c}\text { De forma } \\
\text { insuportável }\end{array}$ \\
\hline \multirow[t]{4}{*}{25} & \multirow{4}{*}{$\begin{array}{l}\text { O seu problema no pescoço afeta o } \\
\text { seu sono? }\end{array}$} & \multicolumn{6}{|c|}{ Com que frequência? } \\
\hline & & Nunca & Raramente & Às vezes & Muitas vezes & Frequentemente & Sempre \\
\hline & & \multicolumn{6}{|c|}{ Quanto? } \\
\hline & & Não sinto nada & Um pouco & De forma & De forma intensa & De forma muito & De forma \\
\hline
\end{tabular}


Anexos e 117

Apêndices

\begin{tabular}{|c|c|c|c|c|c|c|c|}
\hline & & & & moderada & & intensa/forte & insuportável \\
\hline \multirow[t]{4}{*}{26} & \multirow{4}{*}{$\begin{array}{l}\text { O seu problema no pescoço afeta o } \\
\text { seu humor? }\end{array}$} & \multicolumn{6}{|c|}{ Com que frequência? } \\
\hline & & Nunca & Raramente & Às vezes & Muitas vezes & Frequentemente & Sempre \\
\hline & & \multicolumn{6}{|c|}{ Quanto? } \\
\hline & & Não sinto nada & Um pouco & $\begin{array}{l}\text { De forma } \\
\text { moderada }\end{array}$ & De forma intensa & $\begin{array}{l}\text { De forma muito } \\
\text { intensa/forte }\end{array}$ & $\begin{array}{c}\text { De forma } \\
\text { insuportável }\end{array}$ \\
\hline \multirow[t]{4}{*}{27} & \multirow{4}{*}{$\begin{array}{l}\text { Por causa do seu problema no } \\
\text { pescoço, você usa algum suporte, } \\
\text { como, por exemplo, um colar } \\
\text { cervical etc.? }\end{array}$} & \multicolumn{6}{|c|}{ Com que frequência? } \\
\hline & & Nunca & Raramente & Às vezes & Muitas vezes & Frequentemente & Sempre \\
\hline & & \multicolumn{6}{|c|}{ Quanto? } \\
\hline & & Não sinto nada & Um pouco & $\begin{array}{l}\text { De forma } \\
\text { moderada }\end{array}$ & De forma intensa & $\begin{array}{l}\text { De forma muito } \\
\text { intensa/forte }\end{array}$ & $\begin{array}{c}\text { De forma } \\
\text { insuportável }\end{array}$ \\
\hline
\end{tabular}


\begin{tabular}{l|l} 
Anexos e & 118
\end{tabular}

Apêndices

\begin{tabular}{|c|c|c|c|c|c|c|c|}
\hline \multicolumn{8}{|c|}{ Escala de Limitação Funcional } \\
\hline 1 & Como é, para você, ficar em pé? & Sem problemas & Fácil & Relativamente fácil & $\begin{array}{l}\text { Relativamente } \\
\text { difícil }\end{array}$ & Difícil & $\begin{array}{c}\text { Muito } \\
\text { difícil/Impossível }\end{array}$ \\
\hline 2 & Como é, para você, caminhar? & Sem problemas & Fácil & Relativamente fácil & $\begin{array}{c}\text { Relativamente } \\
\text { difícil }\end{array}$ & Difícil & $\begin{array}{c}\text { Muito } \\
\text { difícil/Impossível }\end{array}$ \\
\hline 3 & Como é, para você, sentar? & Sem problemas & Fácil & Relativamente fácil & $\begin{array}{c}\text { Relativamente } \\
\text { difícil }\end{array}$ & Difícil & $\begin{array}{c}\text { Muito } \\
\text { difícil/Impossível }\end{array}$ \\
\hline 4 & Como é, para você, deitar? & Sem problemas & Fácil & Relativamente fácil & $\begin{array}{l}\text { Relativamente } \\
\text { difícil }\end{array}$ & Difícil & $\begin{array}{c}\text { Muito } \\
\text { difícil/Impossível }\end{array}$ \\
\hline 5 & Como é, para você, correr? & Sem problemas & Fácil & Relativamente fácil & $\begin{array}{c}\text { Relativamente } \\
\text { difícil }\end{array}$ & Difícil & $\begin{array}{c}\text { Muito } \\
\text { difícil/Impossível }\end{array}$ \\
\hline 6 & Como é, para você, carregar algo? & Sem problemas & Fácil & Relativamente fácil & $\begin{array}{c}\text { Relativamente } \\
\text { difícil }\end{array}$ & Difícil & $\begin{array}{c}\text { Muito } \\
\text { difícil/Impossível }\end{array}$ \\
\hline 7 & Como é, para você, levantar algo? & Sem problemas & Fácil & Relativamente fácil & $\begin{array}{c}\text { Relativamente } \\
\text { difícil }\end{array}$ & Difícil & $\begin{array}{c}\text { Muito } \\
\text { difícil/Impossível }\end{array}$ \\
\hline 8 & Como é, para você, arremeçar algo? & Sem problemas & Fácil & Relativamente fácil & $\begin{array}{c}\text { Relativamente } \\
\text { difícil }\end{array}$ & Difícil & $\begin{array}{c}\text { Muito } \\
\text { difícil/Impossível }\end{array}$ \\
\hline 9 & $\begin{array}{l}\text { Como é, para você, vestir e tirar } \\
\text { camisetas? }\end{array}$ & Sem problemas & Fácil & Relativamente fácil & $\begin{array}{c}\text { Relativamente } \\
\text { difícil }\end{array}$ & Difícil & $\begin{array}{c}\text { Muito } \\
\text { difícil/Impossível } \\
\end{array}$ \\
\hline 10 & $\begin{array}{l}\text { Como é, para você, calçar e tirar } \\
\text { meias? }\end{array}$ & Sem problemas & Fácil & Relativamente fácil & $\begin{array}{c}\text { Relativamente } \\
\text { difícil }\end{array}$ & Difícil & $\begin{array}{c}\text { Muito } \\
\text { difícil/Impossível }\end{array}$ \\
\hline 11 & $\begin{array}{l}\text { Como é, para você, inclinar a cabeça } \\
\text { para frente? }\end{array}$ & Sem problemas & Fácil & Relativamente fácil & $\begin{array}{c}\text { Relativamente } \\
\text { difícil }\end{array}$ & Difícil & $\begin{array}{c}\text { Muito } \\
\text { difícil/Impossível }\end{array}$ \\
\hline 12 & $\begin{array}{l}\text { Como é, para você, inclinar a cabeça } \\
\text { para trás? }\end{array}$ & Sem problemas & Fácil & Relativamente fácil & $\begin{array}{l}\text { Relativamente } \\
\text { difícil }\end{array}$ & Difícil & $\begin{array}{c}\text { Muito } \\
\text { difícil/Impossível }\end{array}$ \\
\hline 13 & $\begin{array}{l}\text { Como é, para você, inclinar a cabeça } \\
\text { para a direita? }\end{array}$ & Sem problemas & Fácil & Relativamente fácil & $\begin{array}{c}\text { Relativamente } \\
\text { difícil }\end{array}$ & Difícil & $\begin{array}{c}\text { Muito } \\
\text { difícil/Impossível }\end{array}$ \\
\hline 14 & $\begin{array}{l}\text { Como é, para você, inclinar a cabeça } \\
\text { para a esquerda? }\end{array}$ & Sem problemas & Fácil & Relativamente fácil & $\begin{array}{c}\text { Relativamente } \\
\text { difícil }\end{array}$ & Difícil & $\begin{array}{c}\text { Muito } \\
\text { difícil/Impossível } \\
\end{array}$ \\
\hline 15 & $\begin{array}{l}\text { Como é, para você, virar a cabeça } \\
\text { para direita? }\end{array}$ & Sem problemas & Fácil & Relativamente fácil & $\begin{array}{l}\text { Relativamente } \\
\text { difícil }\end{array}$ & Difícil & $\begin{array}{c}\text { Muito } \\
\text { difícil/Impossível }\end{array}$ \\
\hline 16 & $\begin{array}{l}\text { Como é, para você, virar a cabeça } \\
\text { para a esquerda? }\end{array}$ & Sem problemas & Fácil & Relativamente fácil & $\begin{array}{c}\text { Relativamente } \\
\text { difícil }\end{array}$ & Difícil & $\begin{array}{c}\text { Muito } \\
\text { difícil/Impossível }\end{array}$ \\
\hline
\end{tabular}


Anexos e 119

Apêndices

\begin{tabular}{|c|c|c|c|c|c|c|c|}
\hline 17 & $\begin{array}{l}\text { Como é, para você, fazer o seu } \\
\text { trabalho? }\end{array}$ & Sem problemas & Fácil & Relativamente fácil & $\begin{array}{l}\text { Relativamente } \\
\text { difícil }\end{array}$ & Difícil & $\begin{array}{c}\text { Muito } \\
\text { difícil/Impossível }\end{array}$ \\
\hline 18 & $\begin{array}{l}\text { Como você avalia a condição do seu } \\
\text { pescoço? }\end{array}$ & Muito adequado & Adequado & Quase adequado & $\begin{array}{c}\text { Um pouco } \\
\text { desconfortável }\end{array}$ & Desconfortável & Muito desconfortável \\
\hline 19 & $\begin{array}{l}\text { Como você avalia sua saúde em } \\
\text { geral? }\end{array}$ & Muito satisfatória & Satisfatória & Com certa satisfação & $\begin{array}{c}\text { Relativamente } \\
\text { insatisfatória }\end{array}$ & Insatisfatória & Muito insatisfatória \\
\hline 20 & $\begin{array}{l}\text { Como você avalia sua volta ao } \\
\text { trabalho? }\end{array}$ & Muito provável & Provável & Um tanto provável & $\begin{array}{l}\text { Relativamente } \\
\text { improvável }\end{array}$ & Improvável & Muito Improvável \\
\hline
\end{tabular}




\section{APÊNDICE 2 - ProFitMap-neck versão tradução sueco-português}

\section{Profile Fitness Mapping questionnaires}

\section{רAlfta Rehab Center}

\section{ProFitMap-pescoço}

\section{Lista de sintomas}

\begin{tabular}{l} 
Voce sente: \\
$1 \quad$ Rigidez no pescoço? \\
2 Sensibilidade no pescoço? \\
3 Tensão no pescoço? \\
4 Estalos no pescoço? \\
5 Cansaço no pescoço? \\
6 Fraqueza no pescoço? \\
7 Bloqueios no pescoço? \\
8 Inabilidade nas mãos? \\
9 Disturbios sensoriais? \\
10 Desconforto na mandibula? \\
11 Tonturas? \\
12 Falta de equilibrio? \\
13 Irritabilidade ("Estopim curto")? \\
14 Abatimento? \\
15 Estressado? \\
16 Náuseas? \\
17 Sensibilidade a luz? \\
18 Sensibilidade ao barulho? \\
19 Dificuldade de concentração? \\
20 Dificuldade de engolir? \\
21 Dificuldade de respirar? \\
22 Ansiedade? \\
23 Dor no pescoço durante atividade? \\
24 Dor no pescoço durante o descanso? \\
\hline t
\end{tabular}

Intensidade?

Responda 7-12

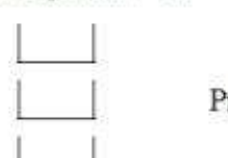

OBS!

Preencha as duas colunas!

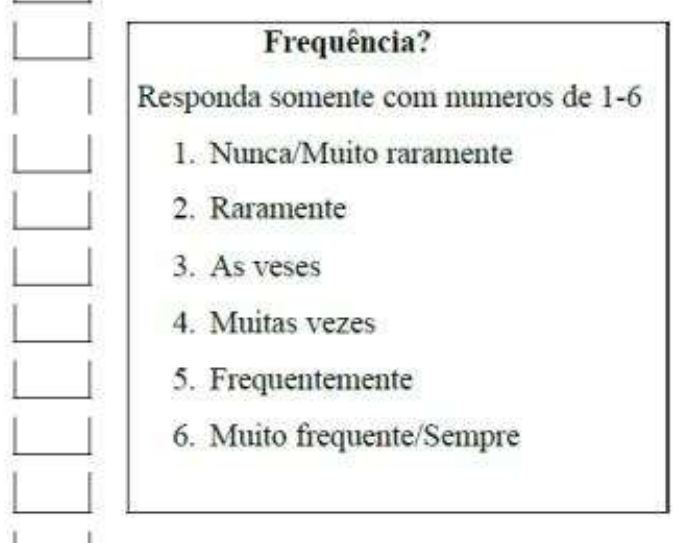

A dor no pescoşo afeta:

25 Seu sono?

26 Seu humor?

Devido à dor no pescoço você usa:

27 Colar cervical, etc? 


\section{(12 \\ Alfta Rehab Cente}

Profile Fitness Mapping questionnaires

\section{ProFitMap-pescoço}

\section{Lista de limitacões funcionais}

Devido à dor no pescoço voce consegue: De que maneira?

Responda 1-6

1 Ficar em pé?

2 Caminhar?

3 Sentar?

4 Deitar?

5 Correr?

6 Carregar?

7 Levantar?

8 Arremeçar algo?

9 Vestir e tirar camisetas?

10 Calçar e tirar meias?

11 Inclinar a cabeça para frente?

12 Inclinar a cabeça para trás?

13 Inclinar a cabeça para a direita?

14 Inclinar a cabeça para a esquerda?

15 Virar a cabeça para a direita?

16 Virar a cabeça para a esquerda?

17 Fazer o seu trabalho?

\section{Como voce cosidera:}

18 O seu problema no pescoço?

19 Sua condição em geral?

20 Seu retorno para o trabalho?
Responda somente com números de 1-6

1. Muito bem, sem problema. muito adequadamente. muito provavelmente

2. Bem, fácil, adequadamente, bastante provável

3. Razoavelmente bem, um tanto fácil, um tanto adequadamente, provávelmente

4. Um pouco mal, um pouco dificil, um pouco desconfortável, improvável

5. Mal, dificil. desconfortavelmente, bem improvável

6. Muito mal, muito dificil/impossivel, muito desconfortável, muito improvável 
APÊNDICE 3 - ProFitMap-neck versão retrotradução português-sueco

\begin{tabular}{|c|c|c|c|c|c|c|c|}
\hline \multicolumn{8}{|c|}{ Symptom skala } \\
\hline \multirow[t]{4}{*}{1} & \multirow[t]{4}{*}{ Känner du stelhet i nacken? } & \multicolumn{6}{|c|}{ Hur ofta? } \\
\hline & & Aldrig & Sällan & Ibland & Många gånger & Ofta & Alltid \\
\hline & & \multicolumn{6}{|c|}{$\begin{array}{c}\text { Hur mycket? } \\
\end{array}$} \\
\hline & & $\begin{array}{c}\text { Jag känner } \\
\text { ingenting }\end{array}$ & Litet & Ganska mycket & Starkt & Mycket starkt & Outhärdligt \\
\hline \multirow[t]{4}{*}{2} & \multirow[t]{4}{*}{ Känner du dig obekväm i nacken? } & \multicolumn{6}{|c|}{ Hur ofta? } \\
\hline & & Aldrig & Sällan & Ibland & Många gånger & Ofta & Alltid \\
\hline & & \multicolumn{6}{|c|}{$\begin{array}{c}\text { Hur mycket? } \\
\end{array}$} \\
\hline & & $\begin{array}{c}\text { Jag känner } \\
\text { ingenting }\end{array}$ & Litet & Ganska mycket & Starkt & Mycket starkt & Outhärdligt \\
\hline \multirow[t]{4}{*}{3} & \multirow[t]{4}{*}{ Känner du spänning i nacken? } & \multicolumn{6}{|c|}{ Hur ofta? } \\
\hline & & Aldrig & Sällan & Ibland & Många gånger & Ofta & Alltid \\
\hline & & \multicolumn{6}{|c|}{ Hur mycket? } \\
\hline & & $\begin{array}{l}\text { Jag känner } \\
\text { ingenting }\end{array}$ & Litet & Ganska mycket & Starkt & Mycket starkt & Outhärdligt \\
\hline \multirow[t]{4}{*}{4} & \multirow[t]{4}{*}{ Känner du smällar i nacken? } & \multicolumn{6}{|c|}{ Hur ofta? } \\
\hline & & Aldrig & Sällan & Ibland & Många gånger & Ofta & Alltid \\
\hline & & \multicolumn{6}{|c|}{ Hur mycket? } \\
\hline & & $\begin{array}{l}\text { Jag känner } \\
\text { ingenting }\end{array}$ & Litet & Ganska mycket & Starkt & Mycket starkt & Outhärdligt \\
\hline \multirow[t]{4}{*}{5} & \multirow[t]{4}{*}{ Känner du trötthet i nacken? } & \multicolumn{6}{|c|}{ Hur ofta? } \\
\hline & & Aldrig & Sällan & Ibland & Många gånger & Ofta & Alltid \\
\hline & & \multicolumn{6}{|c|}{$\begin{array}{l}\text { Hur mycket? } \\
\end{array}$} \\
\hline & & Jag känner & Litet & Ganska mycket & Starkt & Mycket starkt & Outhärdligt \\
\hline
\end{tabular}


\begin{tabular}{l|l} 
Anexos e & 123
\end{tabular}

Apêndices

\begin{tabular}{|c|c|c|c|c|c|c|c|}
\hline & & ingenting & & & & & \\
\hline \multirow[t]{4}{*}{6} & \multirow[t]{4}{*}{ Känner du svaghet i nacken? } & \multicolumn{6}{|c|}{ Hur ofta? } \\
\hline & & Aldrig & Sällan & Ibland & Många gånger & Ofta & Alltid \\
\hline & & \multicolumn{6}{|c|}{ Hur mycket? } \\
\hline & & $\begin{array}{c}\text { Jag känner } \\
\text { ingenting }\end{array}$ & Litet & Ganska mycket & Starkt & Mycket starkt & Outhärdligt \\
\hline \multirow[t]{4}{*}{7} & \multirow[t]{4}{*}{ Känner du nackspärr? } & \multicolumn{6}{|c|}{ Hur ofta? } \\
\hline & & Aldrig & Sällan & Ibland & Många gånger & Ofta & Alltid \\
\hline & & \multicolumn{6}{|c|}{ Hur mycket? } \\
\hline & & $\begin{array}{c}\text { Jag känner } \\
\text { ingenting }\end{array}$ & Litet & Ganska mycket & Starkt & Mycket starkt & Outhärdligt \\
\hline \multirow[t]{4}{*}{16} & \multirow[t]{4}{*}{ Har du kväljningar? } & \multicolumn{6}{|c|}{ Hur ofta? } \\
\hline & & Aldrig & Sällan & Ibland & Många gånger & Ofta & Alltid \\
\hline & & \multicolumn{6}{|c|}{ Hur mycket? } \\
\hline & & $\begin{array}{l}\text { Jag känner } \\
\text { ingenting }\end{array}$ & Litet & Ganska mycket & Starkt & Mycket starkt & Outhärdligt \\
\hline \multirow[t]{4}{*}{17} & \multirow[t]{4}{*}{ Är du känslig för ljus? } & \multicolumn{6}{|c|}{ Hur ofta? } \\
\hline & & Aldrig & Sällan & Ibland & Många gånger & Ofta & Alltid \\
\hline & & \multicolumn{6}{|c|}{$\begin{array}{l}\text { Hur mycket? } \\
\end{array}$} \\
\hline & & $\begin{array}{l}\text { Jag känner } \\
\text { ingenting }\end{array}$ & Litet & Ganska mycket & Starkt & Mycket starkt & Outhärdligt \\
\hline \multirow[t]{4}{*}{18} & \multirow[t]{4}{*}{ Är du känslig för ljud? } & \multicolumn{6}{|c|}{ Hur ofta? } \\
\hline & & Aldrig & Sällan & Ibland & Många gånger & Ofta & Alltid \\
\hline & & \multicolumn{6}{|c|}{ Hur mycket? } \\
\hline & & $\begin{array}{c}\text { Jag känner } \\
\text { ingenting }\end{array}$ & Litet & Ganska mycket & Starkt & Mycket starkt & Outhärdligt \\
\hline 19 & Har du svårt att koncentrera dig? & \multicolumn{6}{|c|}{ Hur ofta? } \\
\hline
\end{tabular}




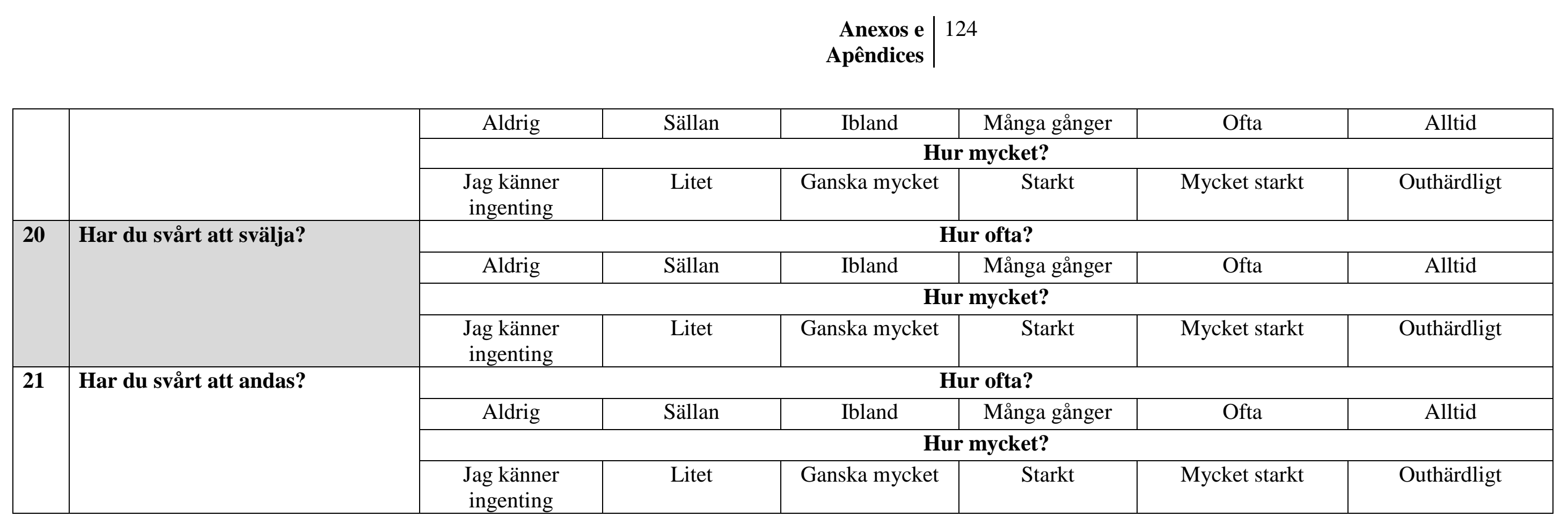


Skala för begränsade funktioner

\begin{tabular}{|c|c|c|c|c|c|c|c|}
\hline 1 & Hur är det för dig att stå? & Utan problem & Lätt & Ganska lätt & Ganska svårt & Svårt & $\begin{array}{c}\text { Mycket } \\
\text { svårt/omöjligt }\end{array}$ \\
\hline 2 & Hur är det för dig att gå? & Utan problem & Lätt & Ganska lätt & Ganska svårt & Svårt & $\begin{array}{c}\text { Mycket } \\
\text { svårt/omöjligt }\end{array}$ \\
\hline 3 & Hur är det för dig att sitta? & Utan problem & Lätt & Ganska lätt & Ganska svårt & Svårt & $\begin{array}{c}\text { Mycket } \\
\text { svårt/omöjligt }\end{array}$ \\
\hline 4 & Hur är det för dig att ligga? & Utan problem & Lätt & Ganska lätt & Ganska svårt & Svårt & $\begin{array}{c}\text { Mycket } \\
\text { svårt/omöjligt }\end{array}$ \\
\hline 5 & Hur är det för dig att springa? & Utan problem & Lätt & Ganska lätt & Ganska svårt & Svårt & $\begin{array}{c}\text { Mycket } \\
\text { svårt/omöjligt }\end{array}$ \\
\hline 6 & $\begin{array}{l}\text { Hur är det för dig att bära } \\
\text { någonting? }\end{array}$ & Utan problem & Lätt & Ganska lätt & Ganska svårt & Svårt & $\begin{array}{c}\text { Mycket } \\
\text { svårt/omöjligt } \\
\end{array}$ \\
\hline 7 & $\begin{array}{l}\text { Hur är det för dig att lyfta } \\
\text { någonting? }\end{array}$ & Utan problem & Lätt & Ganska lätt & Ganska svårt & Svårt & $\begin{array}{c}\text { Mycket } \\
\text { svårt/omöjligt }\end{array}$ \\
\hline 8 & $\begin{array}{l}\text { Hur är det för dig att kasta } \\
\text { någonting? }\end{array}$ & Utan problem & Lätt & Ganska lätt & Ganska svårt & Svårt & $\begin{array}{c}\text { Mycket } \\
\text { svårt/omöjligt }\end{array}$ \\
\hline 9 & $\begin{array}{l}\text { Hur är det för dig att sätta på och } \\
\text { ta av en tröja? }\end{array}$ & Utan problem & Lätt & Ganska lätt & Ganska svårt & Svårt & $\begin{array}{c}\text { Mycket } \\
\text { svårt/omöjligt }\end{array}$ \\
\hline 10 & $\begin{array}{l}\text { Hur är det för dig att sätta på och } \\
\text { ta av strumpor? }\end{array}$ & Utan problem & Lätt & Ganska lätt & Ganska svårt & Svårt & $\begin{array}{c}\text { Mycket } \\
\text { svårt/omöjligt }\end{array}$ \\
\hline 11 & $\begin{array}{l}\text { Hur är det för dig att böja } \\
\text { huvudet framåt? }\end{array}$ & Utan problem & Lätt & Ganska lätt & Ganska svårt & Svårt & $\begin{array}{c}\text { Mycket } \\
\text { svårt/omöjligt }\end{array}$ \\
\hline 12 & $\begin{array}{l}\text { Hur är det för dig att böja } \\
\text { huvudet bakåt? }\end{array}$ & Utan problem & Lätt & Ganska lätt & Ganska svårt & Svårt & $\begin{array}{c}\text { Mycket } \\
\text { svårt/omöjligt }\end{array}$ \\
\hline 13 & $\begin{array}{l}\text { Hur är det för dig att böja } \\
\text { huvudet till höger? }\end{array}$ & Utan problem & Lätt & Ganska lätt & Ganska svårt & Svårt & $\begin{array}{c}\text { Mycket } \\
\text { svårt/omöjligt }\end{array}$ \\
\hline 14 & $\begin{array}{l}\text { Hur är det för dig att böja } \\
\text { huvudet till vänster? }\end{array}$ & Utan problem & Lätt & Ganska lätt & Ganska svårt & Svårt & $\begin{array}{c}\text { Mycket } \\
\text { svårt/omöjligt }\end{array}$ \\
\hline
\end{tabular}


\begin{tabular}{l|l} 
Anexos e & 126
\end{tabular}

Apêndices

\begin{tabular}{|c|c|c|c|c|c|c|c|}
\hline 15 & $\begin{array}{l}\text { Hur är det för dig att vrida } \\
\text { huvudet till höger? }\end{array}$ & Utan problem & Lätt & Ganska lätt & Ganska svårt & Svårt & $\begin{array}{c}\text { Mycket } \\
\text { svårt/omöjligt }\end{array}$ \\
\hline 16 & $\begin{array}{l}\text { Hur är det för dig att vrida } \\
\text { huvudet till vänster? }\end{array}$ & Utan problem & Lätt & Ganska lätt & Ganska svårt & Svårt & $\begin{array}{c}\text { Mycket } \\
\text { svårt/omöjligt }\end{array}$ \\
\hline 17 & Hur är det för dig att arbeta? & Utan problem & Lätt & Ganska lätt & Ganska svårt & Svårt & $\begin{array}{c}\text { Mycket } \\
\text { svårt/omöjligt } \\
\end{array}$ \\
\hline 18 & Hur bedömer du din nacke? & Mycket bra & Bra & Nästan bra & Litet ubekväm & Ubekväm & Mycket ubekväm \\
\hline 19 & $\begin{array}{l}\text { Hur bedömer du ditt allmänna } \\
\text { hälsotillstånd? }\end{array}$ & $\begin{array}{c}\text { Mycket } \\
\text { tillfredsställande }\end{array}$ & $\begin{array}{l}\text { Tillfredsställand } \\
\mathrm{e}\end{array}$ & $\begin{array}{c}\text { Med viss } \\
\text { tillfredsställelse }\end{array}$ & $\begin{array}{c}\text { Ganska } \\
\text { utillfredsställand } \\
\mathrm{e} \\
\end{array}$ & Utillfredsställande & $\begin{array}{c}\text { Mycket } \\
\text { utillfredsställande }\end{array}$ \\
\hline 20 & $\begin{array}{l}\text { Hur skulle du bedöma att börja } \\
\text { arbeta igen? }\end{array}$ & Mycket möjligt & Troligt & Ganska troligt & Ganska otroligt & Otroligt & Mycket otroligt \\
\hline
\end{tabular}


\begin{tabular}{l|l} 
Anexos e & 127
\end{tabular}

Apêndices

\section{APÊNDICE 4 - ProFitMap-neck versão síntese de retrotradução RT12}

Escala de Sintomas Symptom Scale

\begin{tabular}{|c|c|c|c|c|c|c|c|}
\hline \multirow[t]{5}{*}{1} & \multirow{5}{*}{$\begin{array}{l}\text { Você sente rigidez no pescoço? } \\
\text { Do you feel stiffness in your neck? }\end{array}$} & \multicolumn{6}{|c|}{ Com que frequência? How often? } \\
\hline & & Nunca & Quase Nunca & Poucas vezes & Muitas vezes & Quase sempre & Sempre \\
\hline & & Never & Almost never & Sometimes & Often & Almost always & Always \\
\hline & & \multicolumn{6}{|c|}{ Quanto? How much? } \\
\hline & & Nada & Quase nada & Pouco & Muito & Quase insuportável & Insuportável \\
\hline & & Nothing & Almost nothing & A little bit & Very much & Almost unbearable & Unbearable \\
\hline \multirow[t]{3}{*}{2} & \multirow{3}{*}{$\begin{array}{l}\text { Você sente incômodo no pescoço? } \\
\text { Do you feel discomfort in your neck? }\end{array}$} & \multicolumn{6}{|c|}{ Com que frequência? } \\
\hline & & Nunca & Quase Nunca & Poucas vezes & Muitas vezes & Quase sempre & Sempre \\
\hline & & \multicolumn{6}{|c|}{ Quanto? } \\
\hline \multirow[t]{4}{*}{3} & \multirow{4}{*}{$\begin{array}{l}\text { Você sente tensão no pescoço? } \\
\text { Do you feel tension in your neck? }\end{array}$} & \multicolumn{6}{|c|}{ Com que frequência? } \\
\hline & & Nunca & Quase Nunca & Poucas vezes & Muitas vezes & Quase sempre & Sempre \\
\hline & & \multicolumn{6}{|c|}{ Quanto? } \\
\hline & & Nada & Quase nada & Pouco & Muito & Quase insuportável & Insuportável \\
\hline \multirow[t]{4}{*}{4} & \multirow{4}{*}{$\begin{array}{l}\text { Você tem estalos no pescoço? } \\
\text { Do you have cracking in your neck? }\end{array}$} & \multicolumn{6}{|c|}{ Com que frequência? } \\
\hline & & Nunca & Quase Nunca & Poucas vezes & Muitas vezes & Quase sempre & Sempre \\
\hline & & \multicolumn{6}{|c|}{ Quanto? } \\
\hline & & Nada & Quase nada & Pouco & Muito & Quase insuportável & Insuportável \\
\hline \multirow{3}{*}{5} & \multirow{3}{*}{$\begin{array}{l}\text { Você sente cansaço no pescoço? } \\
\text { Do you feel tiredness in your neck? }\end{array}$} & Nunca & Quase Nunca & Poucas vezes & Muitas vezes & Quase sempre & Sempre \\
\hline & & \multicolumn{6}{|c|}{ Quanto? } \\
\hline & & Nada & Quase nada & Pouco & Muito & Quase insuportável & Insuportável \\
\hline \multirow[t]{3}{*}{6} & \multirow{3}{*}{$\begin{array}{l}\text { Você sente fraqueza no pescoço? } \\
\text { Do you feel weakness in your neck? }\end{array}$} & \multicolumn{6}{|c|}{ Com que frequência? } \\
\hline & & Nunca & Quase Nunca & Poucas vezes & Muitas vezes & Quase sempre & Sempre \\
\hline & & \multicolumn{6}{|c|}{ Quanto? } \\
\hline
\end{tabular}


Anexos e 128

Apêndices

\begin{tabular}{|c|c|c|c|c|c|c|c|}
\hline & & Nada & Quase nada & Pouco & Muito & Quase insuportável & Insuportável \\
\hline \multirow[t]{4}{*}{7} & \multirow{4}{*}{$\begin{array}{l}\text { Você sente seu pescoço travar? } \\
\text { Do you feel locking in the neck? }\end{array}$} & \multicolumn{6}{|c|}{ Com que frequência? } \\
\hline & & Nunca & Quase Nunca & Poucas vezes & Muitas vezes & Quase sempre & Sempre \\
\hline & & \multicolumn{6}{|c|}{ Quanto? } \\
\hline & & Nada & Quase nada & Pouco & Muito & Quase insuportável & Insuportável \\
\hline \multirow[t]{4}{*}{8} & \multirow{4}{*}{$\begin{array}{l}\text { Você tem fraqueza/dormência nas } \\
\text { mãos devido ao seu problema no } \\
\text { pescoço? } \\
\text { Do you feel weakness/ numbness in } \\
\text { your hands due to your neck } \\
\text { problems? }\end{array}$} & \multicolumn{6}{|c|}{ Com que frequência? } \\
\hline & & Nunca & Quase Nunca & Poucas vezes & Muitas vezes & Quase sempre & Sempre \\
\hline & & \multicolumn{6}{|c|}{ Quanto? } \\
\hline & & Nada & Quase nada & Pouco & Muito & Quase insuportável & Insuportável \\
\hline \multirow[t]{4}{*}{9} & \multirow{4}{*}{$\begin{array}{l}\text { Você tem problemas de sensibilidade } \\
\text { ao toque devido ao seu problema no } \\
\text { pescoço? } \\
\text { Do you have touch sensitivity } \\
\text { problems due to your neck } \\
\text { problems? }\end{array}$} & \multicolumn{6}{|c|}{ Com que frequência? } \\
\hline & & Nunca & Quase Nunca & Poucas vezes & Muitas vezes & Quase sempre & Sempre \\
\hline & & \multicolumn{6}{|c|}{ Quanto? } \\
\hline & & Nada & Quase nada & Pouco & Muito & Quase insuportável & Insuportável \\
\hline \multirow[t]{4}{*}{10} & \multirow{4}{*}{$\begin{array}{l}\text { Você tem problemas na mandíbula? } \\
\text { Do you have jaw problems? }\end{array}$} & \multicolumn{6}{|c|}{ Com que frequência? } \\
\hline & & Nunca & Quase Nunca & Poucas vezes & Muitas vezes & Quase sempre & Sempre \\
\hline & & \multicolumn{6}{|c|}{ Quanto? } \\
\hline & & Nada & Quase nada & Pouco & Muito & Quase insuportável & Insuportável \\
\hline \multirow[t]{4}{*}{11} & \multirow{4}{*}{$\begin{array}{l}\text { Por causa do seu problema no } \\
\text { pescoço, você sente tontura? } \\
\text { Do you feel dizziness due to your } \\
\text { neck problems? }\end{array}$} & \multicolumn{6}{|c|}{ Com que frequência? } \\
\hline & & Nunca & Quase Nunca & Poucas vezes & Muitas vezes & Quase sempre & Sempre \\
\hline & & & & & nto? & & \\
\hline & & Nada & Quase nada & Pouco & Muito & Quase insuportável & Insuportável \\
\hline \multirow[t]{4}{*}{12} & \multirow{4}{*}{$\begin{array}{l}\text { Por causa do seu problema no } \\
\text { pescoço, você sente falta de } \\
\text { equilíbrio? } \\
\text { Do you feel lack of balance due to } \\
\text { your neck problems? }\end{array}$} & \multicolumn{6}{|c|}{ Com que frequência? } \\
\hline & & Nunca & Quase Nunca & Poucas vezes & Muitas vezes & Quase sempre & Sempre \\
\hline & & \multicolumn{6}{|c|}{ Quanto? } \\
\hline & & Nada & Quase nada & Pouco & Muito & Quase insuportável & Insuportável \\
\hline
\end{tabular}


\begin{tabular}{l|l} 
Anexos e & 129
\end{tabular}

Apêndices

\begin{tabular}{|c|c|c|c|c|c|c|c|}
\hline \multirow[t]{4}{*}{13} & \multirow{4}{*}{$\begin{array}{l}\text { Por causa do seu problema no } \\
\text { pescoço, você se sente irritado ou tem } \\
\text { pouca paciência? } \\
\text { Do you feel irritable or have little } \\
\text { patience due to your neck problems }\end{array}$} & \multicolumn{6}{|c|}{ Com que frequência? } \\
\hline & & Nunca & Quase Nunca & Poucas vezes & Muitas vezes & Quase sempre & Sempre \\
\hline & & \multicolumn{6}{|c|}{ Quanto? } \\
\hline & & Nada & Quase nada & Pouco & Muito & Quase insuportável & Insuportável \\
\hline \multirow[t]{4}{*}{14} & \multirow{4}{*}{$\begin{array}{l}\text { Por causa do seu problema no } \\
\text { pescoço, você se sente deprimido? } \\
\text { Do you feel depressed due to your } \\
\text { neck problems }\end{array}$} & \multicolumn{6}{|c|}{ Com que frequência? } \\
\hline & & Nunca & Quase Nunca & Poucas vezes & Muitas vezes & Quase sempre & Sempre \\
\hline & & \multicolumn{6}{|c|}{ Quanto? } \\
\hline & & Nada & Quase nada & Pouco & Muito & Quase insuportável & Insuportável \\
\hline \multirow[t]{4}{*}{15} & \multirow{4}{*}{$\begin{array}{l}\text { Por causa do seu problema no } \\
\text { pescoço, você se sente estressado? } \\
\text { Do you feel stressed due to your neck } \\
\text { problems }\end{array}$} & \multicolumn{6}{|c|}{ Com que frequência? } \\
\hline & & Nunca & Quase Nunca & Poucas vezes & Muitas vezes & Quase sempre & Sempre \\
\hline & & \multicolumn{6}{|c|}{ Quanto? } \\
\hline & & Nada & Quase nada & Pouco & Muito & Quase insuportável & Insuportável \\
\hline \multirow[t]{4}{*}{16} & \multirow{4}{*}{$\begin{array}{l}\text { Por causa do seu problema no } \\
\text { pescoço, você sente náuseas? } \\
\text { Do you feel nauseous due to your } \\
\text { neck problems }\end{array}$} & \multicolumn{6}{|c|}{ Com que frequência? } \\
\hline & & Nunca & Quase Nunca & Poucas vezes & Muitas vezes & Quase sempre & Sempre \\
\hline & & \multicolumn{6}{|c|}{ Quanto? } \\
\hline & & Nada & Quase nada & Pouco & Muito & Quase insuportável & Insuportável \\
\hline \multirow[t]{4}{*}{17} & \multirow{4}{*}{$\begin{array}{l}\text { Por causa do seu problema no } \\
\text { pescoço, você tem sensibilidade à luz? } \\
\text { Do you feel light sensitivity, due to } \\
\text { your neck problems }\end{array}$} & \multicolumn{6}{|c|}{ Com que frequência? } \\
\hline & & Nunca & Quase Nunca & Poucas vezes & Muitas vezes & Quase sempre & Sempre \\
\hline & & \multicolumn{6}{|c|}{ Quanto? } \\
\hline & & Nada & Quase nada & Pouco & Muito & Quase insuportável & Insuportável \\
\hline \multirow[t]{4}{*}{18} & \multirow{4}{*}{$\begin{array}{l}\text { Por causa do seu problema no } \\
\text { pescoço, você tem sensibilidade ao } \\
\text { som? } \\
\text { Do you have sensitivity to sound, due } \\
\text { to your neck problems? }\end{array}$} & \multicolumn{6}{|c|}{ Com que frequência? } \\
\hline & & Nunca & Quase Nunca & Poucas vezes & Muitas vezes & Quase sempre & Sempre \\
\hline & & \multicolumn{6}{|c|}{ Quanto? } \\
\hline & & Nada & Quase nada & Pouco & Muito & Quase insuportável & Insuportável \\
\hline \multirow[t]{2}{*}{19} & \multirow{2}{*}{$\begin{array}{l}\text { Por causa do seu problema no } \\
\text { pescoço, você tem dificuldade de } \\
\text { concentração? }\end{array}$} & \multicolumn{6}{|c|}{ Com que frequência? } \\
\hline & & $\begin{array}{c}\text { Nunca/Quase } \\
\text { nunca }\end{array}$ & $\begin{array}{c}\text { Nunca/Quase } \\
\text { nunca }\end{array}$ & $\begin{array}{c}\text { Nunca/Quase } \\
\text { nunca }\end{array}$ & $\begin{array}{c}\text { Nunca/Quase } \\
\text { nunca }\end{array}$ & Nunca/Quase nunca & Nunca/Quase nunca \\
\hline
\end{tabular}


Anexos e 130

Apêndices

\begin{tabular}{|c|c|c|c|c|c|c|c|}
\hline & \multirow{2}{*}{$\begin{array}{l}\text { Do you have difficulty concentrating } \\
\text { due to your neck problems? }\end{array}$} & Quanto? & & & & & \\
\hline & & Não sinto nada & Não sinto nada & Não sinto nada & Não sinto nada & Não sinto nada & Não sinto nada \\
\hline \multirow[t]{4}{*}{20} & \multirow{4}{*}{$\begin{array}{l}\text { Por causa do seu problema no } \\
\text { pescoço, você tem dificuldade de } \\
\text { engolir? } \\
\text { Do you have difficulty swallowing } \\
\text { due to your neck problems? }\end{array}$} & \multicolumn{6}{|c|}{ Com que frequência? } \\
\hline & & $\begin{array}{c}\text { Nunca/Quase } \\
\text { nunca }\end{array}$ & $\begin{array}{c}\text { Nunca/Quase } \\
\text { nunca }\end{array}$ & $\begin{array}{l}\text { Nunca/Quase } \\
\text { nunca }\end{array}$ & $\begin{array}{c}\text { Nunca/Quase } \\
\text { nunca }\end{array}$ & Nunca/Quase nunca & Nunca/Quase nunca \\
\hline & & \multicolumn{6}{|c|}{ Quanto? } \\
\hline & & Não sinto nada & Não sinto nada & Não sinto nada & Não sinto nada & Não sinto nada & Não sinto nada \\
\hline \multirow[t]{4}{*}{21} & \multirow{4}{*}{$\begin{array}{l}\text { Por causa do seu problema no } \\
\text { pescoço, você tem dificuldade de } \\
\text { respirar? } \\
\text { Do you have difficulty to breath due } \\
\text { to your neck problems? }\end{array}$} & \multicolumn{6}{|c|}{ Com que frequência? } \\
\hline & & $\begin{array}{c}\text { Nunca/Quase } \\
\text { nunca }\end{array}$ & $\begin{array}{c}\text { Nunca/Quase } \\
\text { nunca }\end{array}$ & $\begin{array}{c}\text { Nunca/Quase } \\
\text { nunca }\end{array}$ & $\begin{array}{c}\text { Nunca/Quase } \\
\text { nunca }\end{array}$ & Nunca/Quase nunca & Nunca/Quase nunca \\
\hline & & \multicolumn{6}{|c|}{ Quanto? } \\
\hline & & Não sinto nada & Não sinto nada & Não sinto nada & Não sinto nada & Não sinto nada & Não sinto nada \\
\hline \multirow[t]{4}{*}{22} & \multirow{4}{*}{$\begin{array}{l}\text { Por causa do seu problema no } \\
\text { pescoço, você se sente ansioso? } \\
\text { Do you feel anxious due to your neck } \\
\text { problems? }\end{array}$} & \multicolumn{6}{|c|}{ Com que frequência? } \\
\hline & & $\begin{array}{c}\text { Nunca/Quase } \\
\text { nunca }\end{array}$ & Raramente & Às vezes & Muitas vezes & Frequentemente & $\begin{array}{l}\text { Sempre/Quase } \\
\text { sempre }\end{array}$ \\
\hline & & & & & anto? & & \\
\hline & & Não sinto nada & Intensidade fraca & $\begin{array}{l}\text { Intensidade } \\
\text { moderada }\end{array}$ & Intensidade forte & $\begin{array}{l}\text { Intensidade muito } \\
\text { forte }\end{array}$ & $\begin{array}{l}\text { Máximo de } \\
\text { intensidade }\end{array}$ \\
\hline \multirow[t]{4}{*}{23} & \multirow{4}{*}{$\begin{array}{l}\text { Você tem dor no pescoço durante as } \\
\text { atividades? } \\
\text { Do you have neck pain during } \\
\text { activities? }\end{array}$} & \multicolumn{6}{|c|}{ Com que frequência? } \\
\hline & & $\begin{array}{c}\text { Nunca/Quase } \\
\text { nunca }\end{array}$ & $\begin{array}{c}\text { Nunca/Quase } \\
\text { nunca }\end{array}$ & $\begin{array}{l}\text { Nunca/Quase } \\
\text { nunca }\end{array}$ & $\begin{array}{c}\text { Nunca/Quase } \\
\text { nunca }\end{array}$ & Nunca/Quase nunca & Nunca/Quase nunca \\
\hline & & & & & anto? & & \\
\hline & & Não sinto nada & Não sinto nada & Não sinto nada & Não sinto nada & Não sinto nada & Não sinto nada \\
\hline \multirow[t]{4}{*}{24} & \multirow{4}{*}{$\begin{array}{l}\text { Você tem dor no pescoço durante o } \\
\text { repouso? } \\
\text { Do you have neck pain at rest? }\end{array}$} & \multicolumn{6}{|c|}{ Com que frequência? } \\
\hline & & $\begin{array}{l}\text { Nunca/Quase } \\
\text { nunca }\end{array}$ & $\begin{array}{l}\text { Nunca/Quase } \\
\text { nunca }\end{array}$ & $\begin{array}{l}\text { Nunca/Quase } \\
\text { nunca }\end{array}$ & $\begin{array}{c}\text { Nunca/Quase } \\
\text { nunca }\end{array}$ & Nunca/Quase nunca & Nunca/Quase nunca \\
\hline & & \multicolumn{6}{|c|}{ Quanto? } \\
\hline & & Não sinto nada & Não sinto nada & Não sinto nada & Não sinto nada & Não sinto nada & Não sinto nada \\
\hline
\end{tabular}


Anexos e 131

Apêndices

\begin{tabular}{|c|c|c|c|c|c|c|c|}
\hline \multirow[t]{4}{*}{25} & \multirow{4}{*}{$\begin{array}{l}\text { O seu problema no pescoço afeta o } \\
\text { seu sono? } \\
\text { Does your neck problem affect your } \\
\text { sleep? }\end{array}$} & \multicolumn{6}{|c|}{ Com que frequência? } \\
\hline & & Nunca & Quase Nunca & Poucas vezes & Muitas vezes & Quase sempre & Sempre \\
\hline & & \multicolumn{6}{|c|}{ Quanto? } \\
\hline & & Nada & Quase nada & Pouco & Muito & Quase insuportável & Insuportável \\
\hline \multirow[t]{4}{*}{26} & \multirow{4}{*}{$\begin{array}{l}\text { O seu problema no pescoço afeta o } \\
\text { seu humor? } \\
\text { Does your neck problem affect your } \\
\text { mood? }\end{array}$} & \multicolumn{6}{|c|}{ Com que frequência? } \\
\hline & & Nunca & Quase Nunca & Poucas vezes & Muitas vezes & Quase sempre & Sempre \\
\hline & & \multicolumn{6}{|c|}{ Quanto? } \\
\hline & & Nada & Quase nada & Pouco & Muito & Quase insuportável & Insuportável \\
\hline \multirow[t]{4}{*}{27} & \multirow{4}{*}{$\begin{array}{l}\text { Por causa do seu problema no } \\
\text { pescoço, você usa colar cervical? } \\
\text { Because of your neck problem, do } \\
\text { you to use cervical collar? }\end{array}$} & \multicolumn{6}{|c|}{ Com que frequência? } \\
\hline & & Nunca & Quase Nunca & Poucas vezes & Muitas vezes & Quase sempre & Sempre \\
\hline & & \multicolumn{6}{|c|}{ Quanto? } \\
\hline & & Nada & Quase nada & Pouco & Muito & Quase insuportável & Insuportável \\
\hline
\end{tabular}


Anexos e 132

Apêndices

\begin{tabular}{|c|c|c|c|c|c|c|c|}
\hline 1 & $\begin{array}{l}\text { Devido ao seu problema no pescoço, } \\
\text { como é, para você, permanecer em } \\
\text { pé? } \\
\text { Due to your neck problems, how is it } \\
\text { for you to stand upright? }\end{array}$ & $\begin{array}{c}\text { Sem problemas } \\
\text { Without problems }\end{array}$ & Fácil & $\begin{array}{l}\text { Relativamente fácil } \\
\text { Relatively easy }\end{array}$ & $\begin{array}{l}\text { Relativamente difícil } \\
\text { Relatively difficult }\end{array}$ & $\begin{array}{c}\text { Difícil } \\
\text { Difficult }\end{array}$ & $\begin{array}{c}\text { Muito difícil } \\
\text { Very Difficult }\end{array}$ \\
\hline 2 & $\begin{array}{l}\text { Devido ao seu problema no pescoço, } \\
\text { como é, para você, caminhar? } \\
\text { Due to your neck problems, how is it } \\
\text { for you to walk? }\end{array}$ & Sem problemas & Fácil & Relativamente fácil & Relativamente difícil & Difícil & Muito difícil \\
\hline 3 & $\begin{array}{l}\text { Devido ao seu problema no pescoço } \\
\text { como é, para você, permanecer } \\
\text { sentado? } \\
\text { Due to your neck problems, how is it } \\
\text { for you sitting? }\end{array}$ & Sem problemas & Fácil & Relativamente fácil & Relativamente difícil & Difícil & Muito difícil \\
\hline 4 & $\begin{array}{l}\text { Devido ao seu problema no pescoço, } \\
\text { como é, para você, permanecer } \\
\text { deitado? } \\
\text { Due to your neck problems, how is } \\
\text { it for you lying down? }\end{array}$ & Sem problemas & Fácil & Relativamente fácil & Relativamente difícil & Difícil & Muito difícil \\
\hline 5 & $\begin{array}{l}\text { Devido ao seu problema no pescoço, } \\
\text { como é, para você, correr? } \\
\text { Due to your neck problems, how is } \\
\text { it for you to run? }\end{array}$ & Sem problemas & Fácil & Relativamente fácil & Relativamente difícil & Difícil & Muito difícil \\
\hline 6 & $\begin{array}{l}\text { Devido ao seu problema no pescoço, } \\
\text { como é, para você, carregar algo? } \\
\text { Due to your neck problems, how is } \\
\text { it for you to carry something? }\end{array}$ & Sem problemas & Fácil & Relativamente fácil & Relativamente difícil & Difícil & Muito difícil \\
\hline 7 & $\begin{array}{l}\text { Devido ao seu problema no pescoco, } \\
\text { como é, para você, levantar algo? } \\
\text { Due to your neck problems, how is it } \\
\text { for you to lift something? }\end{array}$ & Sem problemas & Fácil & Relativamente fácil & Relativamente difícil & Difícil & Muito difícil \\
\hline 8 & Devido ao seu problema no pescoço, & Sem problemas & Fácil & Relativamente fácil & Relativamente difícil & Difícil & Muito difícil \\
\hline
\end{tabular}


Anexos e

Apêndices

\begin{tabular}{|c|c|c|c|c|c|c|c|}
\hline & $\begin{array}{l}\text { como é, para você, arremeçar algo? } \\
\text { Due to your neck problems, how is it } \\
\text { for you to throw something? }\end{array}$ & & & & & & \\
\hline 9 & $\begin{array}{l}\text { Devido ao seu problema no pescoço, } \\
\text { como é, para você, vestir e tirar uma } \\
\text { camiseta/camisa/blusa? } \\
\text { Due to your neck problems, how is it } \\
\text { for you to wear a T-shirt/shirt/ } \\
\text { blouse? }\end{array}$ & Sem problemas & Fácil & Relativamente fácil & Relativamente difícil & Difícil & Muito difícil \\
\hline 10 & $\begin{array}{l}\text { Devido ao seu problema no pescoço, } \\
\text { como é, para você, calçar e tirar } \\
\text { meias? } \\
\text { Due to your neck problems, how is it } \\
\text { for you to put on and take off socks? }\end{array}$ & Sem problemas & Fácil & Relativamente fácil & Relativamente difícil & Difícil & Muito difícil \\
\hline 11 & $\begin{array}{l}\text { Devido ao seu problema no pescoço, } \\
\text { como é, para você, inclinar a cabeça } \\
\text { para frente? } \\
\text { Due to your neck problems, how is it } \\
\text { for you to bend your head } \\
\text { downward? }\end{array}$ & Sem problemas & Fácil & Relativamente fácil & Relativamente difícil & Difícil & Muito difícil \\
\hline 12 & $\begin{array}{l}\text { Devido ao seu problema no pescoço, } \\
\text { como é, para você, inclinar a cabeça } \\
\text { para trás? } \\
\text { Due to your neck problems, how is it } \\
\text { for you to bend your head back? }\end{array}$ & Sem problemas & Fácil & Relativamente fácil & Relativamente difícil & Difícil & Muito difícil \\
\hline 13 & $\begin{array}{l}\text { Devido ao seu problema no pescoço, } \\
\text { como é, para você, inclinar a cabeça } \\
\text { para a direita? } \\
\text { Due to your neck problems, how is it } \\
\text { for you to bend you head to right? }\end{array}$ & Sem problemas & Fácil & Relativamente fácil & Relativamente difícil & Difícil & Muito difícil \\
\hline 14 & $\begin{array}{l}\text { Devido ao seu problema no pescoço, } \\
\text { como é, para você, inclinar a cabeça } \\
\text { para a esquerda? }\end{array}$ & Sem problemas & Fácil & Relativamente fácil & Relativamente difícil & Difícil & Muito difícil \\
\hline
\end{tabular}


Anexos e 134

Apêndices

\begin{tabular}{|c|c|c|c|c|c|c|c|}
\hline & $\begin{array}{l}\text { Due to your neck problems, how is it } \\
\text { for you to bend your head to left? }\end{array}$ & & & & & & \\
\hline 15 & $\begin{array}{l}\text { Devido ao seu problema no pescoço, } \\
\text { como é, para você, virar a cabeça } \\
\text { para direita? } \\
\text { Due to your neck problems, how is it } \\
\text { for you to turn your head to right? }\end{array}$ & Sem problemas & Fácil & Relativamente fácil & Relativamente difícil & Difícil & Muito difícil \\
\hline 16 & $\begin{array}{l}\text { Devido ao seu problema no pescoço, } \\
\text { como é, para você, virar a cabeça } \\
\text { para a esquerda? } \\
\text { Due to your neck problems, how is it } \\
\text { for you to turn your head to left? }\end{array}$ & Sem problemas & Fácil & Relativamente fácil & Relativamente difícil & Difícil & Muito difícil \\
\hline 17 & $\begin{array}{l}\text { Devido ao seu problema no pescoço, } \\
\text { como é, para você, fazer o seu } \\
\text { trabalho? } \\
\text { Due to your neck problems, how is it } \\
\text { for you to do your job? }\end{array}$ & Sem problemas & Fácil & Relativamente fácil & Relativamente difícil & Difícil & Muito difícil \\
\hline 18 & $\begin{array}{l}\text { Como você avalia a condição do seu } \\
\text { pescoço? } \\
\text { How do you evaluate the condition } \\
\text { of your neck? }\end{array}$ & $\begin{array}{l}\text { Muito boa } \\
\text { Very Good }\end{array}$ & $\begin{array}{c}\text { Boa } \\
\text { Good }\end{array}$ & $\begin{array}{l}\text { Não tão boa } \\
\text { Not so Good }\end{array}$ & $\begin{array}{l}\text { Não tão ruim } \\
\text { Not so bad }\end{array}$ & $\begin{array}{c}\text { Ruim } \\
\text { Bad }\end{array}$ & $\begin{array}{l}\text { Muito ruim } \\
\text { Very Bad }\end{array}$ \\
\hline 19 & $\begin{array}{l}\text { Como você avalia sua saúde em } \\
\text { geral? } \\
\text { How do you evaluate your health in } \\
\text { general? }\end{array}$ & $\begin{array}{c}\text { Muito boa } \\
\text { Very Good }\end{array}$ & $\begin{array}{c}\text { Boa } \\
\text { Good }\end{array}$ & $\begin{array}{l}\text { Não tão boa } \\
\text { Not so Good }\end{array}$ & $\begin{array}{l}\text { Não tão ruim } \\
\text { Not so bad }\end{array}$ & $\begin{array}{c}\text { Ruim } \\
\text { Bad }\end{array}$ & $\begin{array}{l}\text { Muito ruim } \\
\text { Very Bad }\end{array}$ \\
\hline 20 & $\begin{array}{l}\text { Como você avalia sua volta ao } \\
\text { trabalho? } \\
\text { How would do you evaluate your } \\
\text { return to work? }\end{array}$ & $\begin{array}{l}\text { Muito provável/ Não se } \\
\text { aplica } \\
\text { Very probable/ Not } \\
\text { applicable }\end{array}$ & $\begin{array}{l}\text { Provável } \\
\text { Probable }\end{array}$ & $\begin{array}{c}\text { Pouco provável } \\
\text { Little likely }\end{array}$ & $\begin{array}{c}\text { Um pouco } \\
\text { improvável } \\
\text { Little unlikely }\end{array}$ & $\begin{array}{l}\text { Improvável } \\
\text { Unlikely }\end{array}$ & $\begin{array}{l}\text { Muito Improvável } \\
\text { Very Unlikely }\end{array}$ \\
\hline
\end{tabular}


Anexos e 135

Apêndices

\section{APÊNDICE 5 - ProFitMap-neck pré-final e final}

\begin{tabular}{|c|c|c|c|c|c|c|c|}
\hline \multicolumn{8}{|c|}{ Escala de Sintomas } \\
\hline \multirow[t]{4}{*}{1} & \multirow[t]{4}{*}{ Você sente rigidez no pescoço? } & \multicolumn{6}{|c|}{ Com que frequência? } \\
\hline & & $\begin{array}{c}\text { Nunca } \\
(0)\end{array}$ & $\begin{array}{c}\text { Quase Nunca } \\
\text { (1) }\end{array}$ & $\begin{array}{c}\text { Poucas vezes } \\
\text { (2) }\end{array}$ & $\begin{array}{l}\text { Muitas vezes } \\
\text { (3) }\end{array}$ & $\begin{array}{c}\text { Quase sempre } \\
\text { (4) }\end{array}$ & $\begin{array}{c}\text { Sempre } \\
(5)\end{array}$ \\
\hline & & \multicolumn{6}{|c|}{ Quanto? } \\
\hline & & $\begin{array}{c}\text { Nada } \\
(0)\end{array}$ & $\begin{array}{l}\text { Quase nada } \\
\text { (1) }\end{array}$ & $\begin{array}{l}\text { Pouco } \\
\text { (2) }\end{array}$ & $\begin{array}{c}\text { Muito } \\
\text { (3) }\end{array}$ & $\begin{array}{c}\text { Quase insuportável } \\
\text { (4) }\end{array}$ & $\begin{array}{c}\text { Insuportável } \\
\text { (5) }\end{array}$ \\
\hline \multirow[t]{4}{*}{2} & \multirow{4}{*}{$\begin{array}{l}\text { Você sente dor leve/desconforto no } \\
\text { pescoço? }\end{array}$} & \multicolumn{6}{|c|}{ Com que frequência? } \\
\hline & & $\begin{array}{c}\text { Nunca } \\
(0)\end{array}$ & $\begin{array}{c}\text { Quase Nunca } \\
\text { (1) }\end{array}$ & $\begin{array}{c}\text { Poucas vezes } \\
\text { (2) }\end{array}$ & $\begin{array}{l}\text { Muitas vezes } \\
\text { (3) }\end{array}$ & $\begin{array}{c}\text { Quase sempre } \\
\text { (4) }\end{array}$ & $\begin{array}{c}\text { Sempre } \\
(5)\end{array}$ \\
\hline & & \multicolumn{6}{|c|}{ Quanto? } \\
\hline & & $\begin{array}{c}\text { Nada } \\
(0)\end{array}$ & $\begin{array}{l}\text { Quase nada } \\
\text { (1) }\end{array}$ & $\begin{array}{l}\text { Pouco } \\
(2)\end{array}$ & $\begin{array}{c}\text { Muito } \\
\text { (3) }\end{array}$ & $\begin{array}{c}\text { Quase insuportável } \\
(4)\end{array}$ & $\begin{array}{c}\text { Insuportável } \\
\text { (5) }\end{array}$ \\
\hline \multirow[t]{4}{*}{3} & \multirow[t]{4}{*}{ Você sente tensão no pescoço? } & \multicolumn{6}{|c|}{ Com que frequência? } \\
\hline & & $\begin{array}{c}\text { Nunca } \\
(0)\end{array}$ & $\begin{array}{c}\text { Quase Nunca } \\
(1)\end{array}$ & $\begin{array}{c}\text { Poucas vezes } \\
(2)\end{array}$ & $\begin{array}{c}\text { Muitas vezes } \\
\text { (3) }\end{array}$ & $\begin{array}{c}\text { Quase sempre } \\
(4)\end{array}$ & $\begin{array}{c}\text { Sempre } \\
(5)\end{array}$ \\
\hline & & \multicolumn{6}{|c|}{ Quanto? } \\
\hline & & $\begin{array}{l}\text { Nada } \\
(0)\end{array}$ & $\begin{array}{l}\text { Quase nada } \\
\text { (1) }\end{array}$ & $\begin{array}{l}\text { Pouco } \\
(2)\end{array}$ & $\begin{array}{c}\text { Muito } \\
\text { (3) }\end{array}$ & $\begin{array}{c}\text { Quase insuportável } \\
\text { (4) }\end{array}$ & $\begin{array}{c}\text { Insuportável } \\
(5)\end{array}$ \\
\hline \multirow[t]{4}{*}{4} & \multirow[t]{4}{*}{ Você tem estalos no pescoço? } & \multicolumn{6}{|c|}{ Com que frequência? } \\
\hline & & $\begin{array}{c}\text { Nunca } \\
(0)\end{array}$ & $\begin{array}{c}\text { Quase Nunca } \\
(1)\end{array}$ & $\begin{array}{c}\text { Poucas vezes } \\
(2)\end{array}$ & $\begin{array}{c}\text { Muitas vezes } \\
\text { (3) }\end{array}$ & $\begin{array}{c}\text { Quase sempre } \\
(4)\end{array}$ & $\begin{array}{c}\text { Sempre } \\
(5)\end{array}$ \\
\hline & & \multicolumn{6}{|c|}{ Quanto? } \\
\hline & & $\begin{array}{l}\text { Nada } \\
(0)\end{array}$ & $\begin{array}{l}\text { Quase nada } \\
\text { (1) }\end{array}$ & $\begin{array}{l}\text { Pouco } \\
(2)\end{array}$ & $\begin{array}{c}\text { Muito } \\
\text { (3) }\end{array}$ & $\begin{array}{l}\text { Quase insuportável } \\
(4)\end{array}$ & $\begin{array}{c}\text { Insuportável } \\
\text { (5) }\end{array}$ \\
\hline \multirow[t]{2}{*}{5} & \multirow[t]{2}{*}{ Você sente cansaço no pescoço? } & \multicolumn{6}{|c|}{ Com que frequência? } \\
\hline & & $\begin{array}{c}\text { Nunca } \\
(0)\end{array}$ & $\begin{array}{c}\text { Quase Nunca } \\
\text { (1) }\end{array}$ & $\begin{array}{c}\text { Poucas vezes } \\
(2)\end{array}$ & $\begin{array}{c}\text { Muitas vezes } \\
\text { (3) }\end{array}$ & $\begin{array}{c}\text { Quase sempre } \\
(4)\end{array}$ & $\begin{array}{c}\text { Sempre } \\
(5)\end{array}$ \\
\hline
\end{tabular}


Anexos e 136

Apêndices

\begin{tabular}{|c|c|c|c|c|c|c|c|}
\hline & & \multicolumn{6}{|c|}{ Quanto? } \\
\hline & & $\begin{array}{c}\text { Nada } \\
(0)\end{array}$ & $\begin{array}{l}\text { Quase nada } \\
\text { (1) }\end{array}$ & $\begin{array}{l}\text { Pouco } \\
(2)\end{array}$ & $\begin{array}{c}\text { Muito } \\
\text { (3) }\end{array}$ & Quase insuportável & $\begin{array}{c}\text { Insuportável } \\
(5)\end{array}$ \\
\hline \multirow[t]{4}{*}{6} & \multirow[t]{4}{*}{ Você sente fraqueza no pescoço? } & \multicolumn{6}{|c|}{ Com que frequência? } \\
\hline & & $\begin{array}{c}\text { Nunca } \\
(0)\end{array}$ & $\begin{array}{c}\text { Quase Nunca } \\
\text { (1) }\end{array}$ & $\begin{array}{c}\text { Poucas vezes } \\
(2)\end{array}$ & $\begin{array}{l}\text { Muitas vezes } \\
\text { (3) }\end{array}$ & $\begin{array}{c}\text { Quase sempre } \\
\text { (4) }\end{array}$ & $\begin{array}{c}\text { Sempre } \\
(5)\end{array}$ \\
\hline & & \multicolumn{6}{|c|}{ Quanto? } \\
\hline & & $\begin{array}{l}\text { Nada } \\
(0)\end{array}$ & $\begin{array}{l}\text { Quase nada } \\
\text { (1) }\end{array}$ & $\begin{array}{l}\text { Pouco } \\
\text { (2) }\end{array}$ & $\begin{array}{l}\text { Muito } \\
\text { (3) }\end{array}$ & $\begin{array}{c}\text { Quase insuportável } \\
(4)\end{array}$ & $\begin{array}{c}\text { Insuportável } \\
(5)\end{array}$ \\
\hline \multirow[t]{4}{*}{7} & \multirow[t]{4}{*}{ Você sente seu pescoço travar? } & \multicolumn{6}{|c|}{ Com que frequência? } \\
\hline & & $\begin{array}{c}\text { Nunca } \\
(0)\end{array}$ & $\begin{array}{c}\text { Quase Nunca } \\
\text { (1) }\end{array}$ & $\begin{array}{l}\text { Poucas vezes } \\
\text { (2) }\end{array}$ & $\begin{array}{l}\text { Muitas vezes } \\
\text { (3) }\end{array}$ & $\begin{array}{c}\text { Quase sempre } \\
\text { (4) }\end{array}$ & $\begin{array}{c}\text { Sempre } \\
(5)\end{array}$ \\
\hline & & \multicolumn{6}{|c|}{ Quanto? } \\
\hline & & $\begin{array}{c}\text { Nada } \\
(0)\end{array}$ & $\begin{array}{l}\text { Quase nada } \\
\text { (1) }\end{array}$ & $\begin{array}{l}\text { Pouco } \\
\text { (2) }\end{array}$ & $\begin{array}{l}\text { Muito } \\
\text { (3) }\end{array}$ & Quase insuportável & $\begin{array}{c}\text { Insuportável } \\
(5)\end{array}$ \\
\hline \multirow[t]{4}{*}{8} & \multirow{4}{*}{$\begin{array}{l}\text { Você sente falta de habilidade/ } \\
\text { fraqueza nas mãos? }\end{array}$} & \multicolumn{6}{|c|}{ Com que frequência? } \\
\hline & & $\begin{array}{c}\text { Nunca } \\
(0)\end{array}$ & $\begin{array}{c}\text { Quase Nunca } \\
\text { (1) }\end{array}$ & $\begin{array}{c}\text { Poucas vezes } \\
\text { (2) }\end{array}$ & $\begin{array}{l}\text { Muitas vezes } \\
\text { (3) }\end{array}$ & $\begin{array}{c}\text { Quase sempre } \\
\text { (4) }\end{array}$ & $\begin{array}{c}\text { Sempre } \\
(5)\end{array}$ \\
\hline & & \multicolumn{6}{|c|}{ Quanto? } \\
\hline & & $\begin{array}{c}\text { Nada } \\
(0)\end{array}$ & $\begin{array}{l}\text { Quase nada } \\
\text { (1) }\end{array}$ & $\begin{array}{l}\text { Pouco } \\
\text { (2) }\end{array}$ & $\begin{array}{c}\text { Muito } \\
\text { (3) }\end{array}$ & Quase insuportável & $\begin{array}{c}\text { Insuportável } \\
(5)\end{array}$ \\
\hline \multirow[t]{4}{*}{9} & \multirow{4}{*}{$\begin{array}{l}\text { Você tem problemas } \\
\text { formigamento/dormência nos braços, } \\
\text { pescoço e mãos? }\end{array}$} & \multicolumn{6}{|c|}{ Com que frequência? } \\
\hline & & $\begin{array}{c}\text { Nunca } \\
(0)\end{array}$ & $\begin{array}{c}\text { Quase Nunca } \\
\text { (1) }\end{array}$ & $\begin{array}{c}\text { Poucas vezes } \\
\text { (2) }\end{array}$ & $\begin{array}{l}\text { Muitas vezes } \\
\text { (3) }\end{array}$ & $\begin{array}{c}\text { Quase sempre } \\
\text { (4) }\end{array}$ & $\begin{array}{c}\text { Sempre } \\
(5)\end{array}$ \\
\hline & & \multicolumn{6}{|c|}{ Quanto? } \\
\hline & & $\begin{array}{c}\text { Nada } \\
(0)\end{array}$ & $\begin{array}{l}\text { Quase nada } \\
\text { (1) }\end{array}$ & $\begin{array}{l}\text { Pouco } \\
\text { (2) }\end{array}$ & $\begin{array}{c}\text { Muito } \\
\text { (3) }\end{array}$ & $\begin{array}{l}\text { Quase insuportável } \\
\text { (4) }\end{array}$ & $\begin{array}{c}\text { Insuportável } \\
(5)\end{array}$ \\
\hline \multirow[t]{3}{*}{10} & \multirow[t]{3}{*}{ Você tem problemas na mandíbula? } & \multicolumn{6}{|c|}{ Com que frequência? } \\
\hline & & $\begin{array}{l}\text { Nunca } \\
(0)\end{array}$ & $\begin{array}{l}\text { Quase Nunca } \\
\text { (1) }\end{array}$ & $\begin{array}{l}\text { Poucas vezes } \\
\text { (2) }\end{array}$ & $\begin{array}{l}\text { Muitas vezes } \\
\text { (3) }\end{array}$ & $\begin{array}{c}\text { Quase sempre } \\
\text { (4) }\end{array}$ & $\underset{(5)}{\text { Sempre }}$ \\
\hline & & \multicolumn{6}{|c|}{ Quanto? } \\
\hline
\end{tabular}


Anexos e 137

Apêndices

\begin{tabular}{|c|c|c|c|c|c|c|c|}
\hline & & $\begin{array}{l}\text { Nada } \\
(0)\end{array}$ & $\begin{array}{c}\text { Quase nada } \\
\text { (1) }\end{array}$ & $\begin{array}{l}\text { Pouco } \\
(2)\end{array}$ & $\begin{array}{c}\text { Muito } \\
(3)\end{array}$ & $\begin{array}{c}\text { Quase insuportável } \\
\text { (4) }\end{array}$ & $\begin{array}{c}\text { Insuportável } \\
(5)\end{array}$ \\
\hline \multirow[t]{4}{*}{11} & \multirow[t]{4}{*}{ Você sente tontura? } & \multicolumn{6}{|c|}{ Com que frequência? } \\
\hline & & $\begin{array}{l}\text { Nunca } \\
(0)\end{array}$ & $\begin{array}{l}\text { Quase Nunca } \\
\text { (1) }\end{array}$ & $\begin{array}{l}\text { Poucas vezes } \\
\text { (2) }\end{array}$ & $\begin{array}{l}\text { Muitas vezes } \\
\text { (3) }\end{array}$ & $\begin{array}{l}\text { Quase sempre } \\
\text { (4) }\end{array}$ & $\begin{array}{c}\text { Sempre } \\
(5)\end{array}$ \\
\hline & & \multicolumn{6}{|c|}{ Quanto? } \\
\hline & & $\begin{array}{l}\text { Nada } \\
(0)\end{array}$ & $\begin{array}{l}\text { Quase nada } \\
\text { (1) }\end{array}$ & $\begin{array}{l}\text { Pouco } \\
(2)\end{array}$ & $\begin{array}{c}\text { Muito } \\
\text { (3) }\end{array}$ & $\begin{array}{c}\text { Quase insuportável } \\
\text { (4) }\end{array}$ & $\begin{array}{c}\text { Insuportável } \\
\text { (5) }\end{array}$ \\
\hline \multirow[t]{4}{*}{12} & \multirow[t]{4}{*}{ Você sente falta de equilíbrio? } & \multicolumn{6}{|c|}{ Com que frequência? } \\
\hline & & $\begin{array}{c}\text { Nunca } \\
(0)\end{array}$ & $\begin{array}{l}\text { Quase Nunca } \\
\text { (1) }\end{array}$ & $\begin{array}{c}\text { Poucas vezes } \\
(2)\end{array}$ & $\begin{array}{c}\text { Muitas vezes } \\
\text { (3) }\end{array}$ & $\begin{array}{c}\text { Quase sempre } \\
\text { (4) }\end{array}$ & $\begin{array}{c}\text { Sempre } \\
(5)\end{array}$ \\
\hline & & \multicolumn{6}{|c|}{ Quanto? } \\
\hline & & $\begin{array}{c}\text { Nada } \\
(0)\end{array}$ & $\begin{array}{l}\text { Quase nada } \\
\text { (1) }\end{array}$ & $\begin{array}{l}\text { Pouco } \\
(2)\end{array}$ & $\begin{array}{c}\text { Muito } \\
\text { (3) }\end{array}$ & $\begin{array}{l}\text { Quase insuportável } \\
\text { (4) }\end{array}$ & $\begin{array}{c}\text { Insuportável } \\
\text { (5) }\end{array}$ \\
\hline \multirow[t]{4}{*}{13} & \multirow{4}{*}{$\begin{array}{l}\text { Você se sente irritado ou tem pouca } \\
\text { paciência? }\end{array}$} & \multicolumn{6}{|c|}{ Com que frequência? } \\
\hline & & $\begin{array}{c}\text { Nunca } \\
(0)\end{array}$ & $\begin{array}{l}\text { Quase Nunca } \\
\text { (1) }\end{array}$ & $\begin{array}{c}\text { Poucas vezes } \\
(2)\end{array}$ & $\begin{array}{c}\text { Muitas vezes } \\
\text { (3) }\end{array}$ & $\begin{array}{c}\text { Quase sempre } \\
\text { (4) }\end{array}$ & $\begin{array}{c}\text { Sempre } \\
(5)\end{array}$ \\
\hline & & \multicolumn{6}{|c|}{ Quanto? } \\
\hline & & $\begin{array}{l}\text { Nada } \\
(0)\end{array}$ & $\begin{array}{l}\text { Quase nada } \\
\text { (1) }\end{array}$ & $\begin{array}{l}\text { Pouco } \\
(2)\end{array}$ & $\begin{array}{c}\text { Muito } \\
\text { (3) }\end{array}$ & $\begin{array}{l}\text { Quase insuportável } \\
\text { (4) }\end{array}$ & $\begin{array}{c}\text { Insuportável } \\
\text { (5) }\end{array}$ \\
\hline \multirow[t]{4}{*}{14} & \multirow[t]{4}{*}{ Você se sente deprimido? } & \multicolumn{6}{|c|}{ Com que frequência? } \\
\hline & & $\begin{array}{l}\text { Nunca } \\
(0)\end{array}$ & $\begin{array}{l}\text { Quase Nunca } \\
\text { (1) }\end{array}$ & $\begin{array}{c}\text { Poucas vezes } \\
\text { (2) }\end{array}$ & $\begin{array}{l}\text { Muitas vezes } \\
\text { (3) }\end{array}$ & $\begin{array}{c}\text { Quase sempre } \\
\text { (4) }\end{array}$ & $\begin{array}{c}\text { Sempre } \\
(5)\end{array}$ \\
\hline & & \multicolumn{6}{|c|}{ Quanto? } \\
\hline & & $\begin{array}{l}\text { Nada } \\
(0)\end{array}$ & $\begin{array}{l}\text { Quase nada } \\
\text { (1) }\end{array}$ & $\begin{array}{c}\text { Pouco } \\
(2)\end{array}$ & $\begin{array}{c}\text { Muito } \\
(3)\end{array}$ & $\begin{array}{c}\text { Quase insuportável } \\
\text { (4) }\end{array}$ & $\begin{array}{c}\text { Insuportável } \\
\text { (5) }\end{array}$ \\
\hline \multirow[t]{4}{*}{15} & \multirow[t]{4}{*}{ Você se sente estressado? } & \multicolumn{6}{|c|}{ Com que frequência? } \\
\hline & & $\begin{array}{c}\text { Nunca } \\
(0)\end{array}$ & $\begin{array}{l}\text { Quase Nunca } \\
\text { (1) }\end{array}$ & $\begin{array}{c}\text { Poucas vezes } \\
\text { (2) }\end{array}$ & $\begin{array}{c}\text { Muitas vezes } \\
\text { (3) }\end{array}$ & $\begin{array}{c}\text { Quase sempre } \\
\text { (4) }\end{array}$ & $\begin{array}{c}\text { Sempre } \\
(5)\end{array}$ \\
\hline & & \multicolumn{6}{|c|}{ Quanto? } \\
\hline & & Nada & Quase nada & Pouco & Muito & Quase insuportável & Insuportável \\
\hline
\end{tabular}


\begin{tabular}{l|l} 
Anexos e & 138
\end{tabular}

Apêndices

\begin{tabular}{|c|c|c|c|c|c|c|c|}
\hline & & (0) & (1) & (2) & (3) & (4) & (5) \\
\hline \multirow[t]{4}{*}{16} & \multirow[t]{4}{*}{ Você sente náuseas? } & \multicolumn{6}{|c|}{ Com que frequência? } \\
\hline & & $\begin{array}{c}\text { Nunca } \\
(0)\end{array}$ & $\begin{array}{l}\text { Quase Nunca } \\
\text { (1) }\end{array}$ & $\begin{array}{c}\text { Poucas vezes } \\
\text { (2) }\end{array}$ & $\begin{array}{c}\text { Muitas vezes } \\
\text { (3) }\end{array}$ & $\begin{array}{c}\text { Quase sempre } \\
\text { (4) }\end{array}$ & $\begin{array}{c}\text { Sempre } \\
(5)\end{array}$ \\
\hline & & \multicolumn{6}{|c|}{ Quanto? } \\
\hline & & $\begin{array}{l}\text { Nada } \\
(0)\end{array}$ & $\begin{array}{l}\text { Quase nada } \\
\text { (1) }\end{array}$ & $\begin{array}{l}\text { Pouco } \\
\text { (2) }\end{array}$ & $\begin{array}{c}\text { Muito } \\
\text { (3) }\end{array}$ & $\begin{array}{c}\text { Quase insuportável } \\
\text { (4) }\end{array}$ & $\begin{array}{c}\text { Insuportável } \\
\text { (5) }\end{array}$ \\
\hline \multirow[t]{4}{*}{17} & \multirow[t]{4}{*}{ Você tem sensibilidade à luz? } & \multicolumn{6}{|c|}{ Com que frequência? } \\
\hline & & $\begin{array}{l}\text { Nunca } \\
(0)\end{array}$ & $\begin{array}{c}\text { Quase Nunca } \\
\text { (1) }\end{array}$ & $\begin{array}{c}\text { Poucas vezes } \\
\text { (2) }\end{array}$ & $\begin{array}{c}\text { Muitas vezes } \\
\text { (3) }\end{array}$ & $\begin{array}{c}\text { Quase sempre } \\
\text { (4) }\end{array}$ & $\begin{array}{c}\text { Sempre } \\
(5)\end{array}$ \\
\hline & & \multicolumn{6}{|c|}{ Quanto? } \\
\hline & & $\begin{array}{c}\text { Nada } \\
(0)\end{array}$ & $\begin{array}{l}\text { Quase nada } \\
\text { (1) }\end{array}$ & $\begin{array}{l}\text { Pouco } \\
(2)\end{array}$ & $\begin{array}{c}\text { Muito } \\
\text { (3) }\end{array}$ & $\begin{array}{l}\text { Quase insuportável } \\
\text { (4) }\end{array}$ & $\begin{array}{c}\text { Insuportável } \\
\text { (5) }\end{array}$ \\
\hline \multirow[t]{4}{*}{18} & \multirow[t]{4}{*}{ Você tem sensibilidade ao som? } & \multicolumn{6}{|c|}{ Com que frequência? } \\
\hline & & $\begin{array}{c}\text { Nunca } \\
(0)\end{array}$ & $\begin{array}{c}\text { Quase Nunca } \\
\text { (1) }\end{array}$ & $\begin{array}{c}\text { Poucas vezes } \\
\text { (2) }\end{array}$ & $\begin{array}{c}\text { Muitas vezes } \\
\text { (3) }\end{array}$ & $\begin{array}{c}\text { Quase sempre } \\
\text { (4) }\end{array}$ & $\begin{array}{c}\text { Sempre } \\
(5)\end{array}$ \\
\hline & & \multicolumn{6}{|c|}{ Quanto? } \\
\hline & & $\begin{array}{l}\text { Nada } \\
(0)\end{array}$ & $\begin{array}{l}\text { Quase nada } \\
\text { (1) }\end{array}$ & $\begin{array}{l}\text { Pouco } \\
(2)\end{array}$ & $\begin{array}{c}\text { Muito } \\
\text { (3) }\end{array}$ & $\begin{array}{l}\text { Quase insuportável } \\
(4)\end{array}$ & $\begin{array}{c}\text { Insuportável } \\
\text { (5) }\end{array}$ \\
\hline \multirow[t]{4}{*}{19} & \multirow{4}{*}{$\begin{array}{l}\text { Por causa do seu problema no } \\
\text { pescoço, você tem dificuldade de } \\
\text { concentração? }\end{array}$} & \multicolumn{6}{|c|}{ Com que frequência? } \\
\hline & & $\begin{array}{c}\text { Nunca } \\
(0)\end{array}$ & $\begin{array}{c}\text { Quase Nunca } \\
\text { (1) }\end{array}$ & $\begin{array}{c}\text { Poucas vezes } \\
\text { (2) }\end{array}$ & $\begin{array}{c}\text { Muitas vezes } \\
\text { (3) }\end{array}$ & $\begin{array}{c}\text { Quase sempre } \\
\text { (4) }\end{array}$ & $\begin{array}{c}\text { Sempre } \\
(5)\end{array}$ \\
\hline & & \multicolumn{6}{|c|}{ Quanto? } \\
\hline & & $\begin{array}{c}\text { Nada } \\
(0)\end{array}$ & $\begin{array}{l}\text { Quase nada } \\
\text { (1) }\end{array}$ & $\begin{array}{l}\text { Pouco } \\
\text { (2) }\end{array}$ & $\begin{array}{c}\text { Muito } \\
\text { (3) }\end{array}$ & $\begin{array}{c}\text { Quase insuportável } \\
\text { (4) }\end{array}$ & $\begin{array}{c}\text { Insuportável } \\
\text { (5) }\end{array}$ \\
\hline \multirow[t]{4}{*}{20} & \multirow[t]{4}{*}{ Você tem dificuldade de engolir? } & \multicolumn{6}{|c|}{ Com que frequência? } \\
\hline & & $\begin{array}{c}\text { Nunca } \\
(0)\end{array}$ & $\begin{array}{c}\text { Quase Nunca } \\
\text { (1) }\end{array}$ & $\begin{array}{c}\text { Poucas vezes } \\
\text { (2) }\end{array}$ & $\begin{array}{l}\text { Muitas vezes } \\
\text { (3) }\end{array}$ & $\begin{array}{c}\text { Quase sempre } \\
\text { (4) }\end{array}$ & $\begin{array}{c}\text { Sempre } \\
(5)\end{array}$ \\
\hline & & \multicolumn{6}{|c|}{ Quanto? } \\
\hline & & $\begin{array}{c}\text { Nada } \\
(0)\end{array}$ & $\begin{array}{l}\text { Quase nada } \\
\text { (1) }\end{array}$ & $\begin{array}{l}\text { Pouco } \\
\text { (2) }\end{array}$ & $\begin{array}{c}\text { Muito } \\
\text { (3) }\end{array}$ & $\begin{array}{c}\text { Quase insuportável } \\
\text { (4) }\end{array}$ & $\begin{array}{c}\text { Insuportável } \\
\text { (5) }\end{array}$ \\
\hline
\end{tabular}


\begin{tabular}{l|l} 
Anexos e & 139
\end{tabular}

Apêndices

\begin{tabular}{|c|c|c|c|c|c|c|c|}
\hline \multirow[t]{4}{*}{21} & \multirow{4}{*}{$\begin{array}{l}\text { Por causa do seu problema no } \\
\text { pescoço, você tem dificuldade de } \\
\text { respirar? }\end{array}$} & \multicolumn{6}{|c|}{ Com que frequência? } \\
\hline & & $\begin{array}{c}\text { Nunca } \\
(0)\end{array}$ & $\begin{array}{c}\text { Quase Nunca } \\
\text { (1) }\end{array}$ & $\begin{array}{c}\text { Poucas vezes } \\
\text { (2) }\end{array}$ & $\begin{array}{c}\text { Muitas vezes } \\
\text { (3) }\end{array}$ & $\begin{array}{c}\text { Quase sempre } \\
\text { (4) }\end{array}$ & $\begin{array}{c}\text { Sempre } \\
(5)\end{array}$ \\
\hline & & \multicolumn{6}{|c|}{ Quanto? } \\
\hline & & $\begin{array}{c}\text { Nada } \\
(0)\end{array}$ & $\begin{array}{l}\text { Quase nada } \\
\text { (1) }\end{array}$ & $\begin{array}{l}\text { Pouco } \\
\text { (2) }\end{array}$ & $\begin{array}{l}\text { Muito } \\
\text { (3) }\end{array}$ & $\begin{array}{c}\text { Quase insuportável } \\
\text { (4) }\end{array}$ & $\begin{array}{c}\text { Insuportável } \\
\text { (5) }\end{array}$ \\
\hline \multirow[t]{4}{*}{22} & \multirow[t]{4}{*}{ Você se sente ansioso? } & \multicolumn{6}{|c|}{ Com que frequência? } \\
\hline & & $\begin{array}{c}\text { Nunca } \\
(0)\end{array}$ & $\begin{array}{c}\text { Quase Nunca } \\
\text { (1) }\end{array}$ & $\begin{array}{c}\text { Poucas vezes } \\
\text { (2) }\end{array}$ & $\begin{array}{l}\text { Muitas vezes } \\
\text { (3) }\end{array}$ & $\begin{array}{c}\text { Quase sempre } \\
\text { (4) }\end{array}$ & $\begin{array}{c}\text { Sempre } \\
(5)\end{array}$ \\
\hline & & \multicolumn{6}{|c|}{ Quanto? } \\
\hline & & $\begin{array}{c}\text { Nada } \\
(0)\end{array}$ & $\begin{array}{l}\text { Quase nada } \\
\text { (1) }\end{array}$ & $\begin{array}{l}\text { Pouco } \\
\text { (2) }\end{array}$ & $\begin{array}{l}\text { Muito } \\
\text { (3) }\end{array}$ & $\begin{array}{c}\text { Quase insuportável } \\
\text { (4) }\end{array}$ & $\begin{array}{c}\text { Insuportável } \\
\text { (5) }\end{array}$ \\
\hline \multirow[t]{4}{*}{23} & \multirow{4}{*}{$\begin{array}{l}\text { Você tem dor no pescoço durante as } \\
\text { atividades? }\end{array}$} & \multicolumn{6}{|c|}{ Com que frequência? } \\
\hline & & $\begin{array}{c}\text { Nunca } \\
(0)\end{array}$ & $\begin{array}{c}\text { Quase Nunca } \\
\text { (1) }\end{array}$ & $\begin{array}{l}\text { Poucas vezes } \\
\text { (2) }\end{array}$ & $\begin{array}{l}\text { Muitas vezes } \\
\text { (3) }\end{array}$ & $\begin{array}{c}\text { Quase sempre } \\
\text { (4) }\end{array}$ & $\begin{array}{c}\text { Sempre } \\
(5)\end{array}$ \\
\hline & & \multicolumn{6}{|c|}{ Quanto? } \\
\hline & & $\begin{array}{c}\text { Nada } \\
(0)\end{array}$ & $\begin{array}{l}\text { Quase nada } \\
\text { (1) }\end{array}$ & $\begin{array}{l}\text { Pouco } \\
(2)\end{array}$ & $\begin{array}{l}\text { Muito } \\
\text { (3) }\end{array}$ & $\begin{array}{c}\text { Quase insuportável } \\
(4)\end{array}$ & $\begin{array}{c}\text { Insuportável } \\
(5)\end{array}$ \\
\hline \multirow[t]{4}{*}{24} & \multirow{4}{*}{$\begin{array}{l}\text { Você tem dor no pescoço durante o } \\
\text { repouso? }\end{array}$} & \multicolumn{6}{|c|}{ Com que frequência? } \\
\hline & & $\begin{array}{c}\text { Nunca } \\
(0)\end{array}$ & $\begin{array}{c}\text { Quase Nunca } \\
\text { (1) }\end{array}$ & $\begin{array}{c}\text { Poucas vezes } \\
\text { (2) }\end{array}$ & $\begin{array}{c}\text { Muitas vezes } \\
\text { (3) }\end{array}$ & $\begin{array}{c}\text { Quase sempre } \\
\text { (4) }\end{array}$ & $\begin{array}{c}\text { Sempre } \\
(5)\end{array}$ \\
\hline & & \multicolumn{6}{|c|}{ Quanto? } \\
\hline & & $\begin{array}{l}\text { Nada } \\
(0)\end{array}$ & $\begin{array}{l}\text { Quase nada } \\
\text { (1) }\end{array}$ & $\begin{array}{l}\text { Pouco } \\
(2)\end{array}$ & $\begin{array}{l}\text { Muito } \\
\text { (3) }\end{array}$ & $\begin{array}{l}\text { Quase insuportável } \\
(4)\end{array}$ & $\begin{array}{c}\text { Insuportável } \\
(5)\end{array}$ \\
\hline \multirow[t]{4}{*}{25} & \multirow{4}{*}{$\begin{array}{l}\text { O seu problema no pescoço afeta o } \\
\text { seu sono? }\end{array}$} & \multicolumn{6}{|c|}{ Com que frequência? } \\
\hline & & $\begin{array}{c}\text { Nunca } \\
(0)\end{array}$ & $\begin{array}{l}\text { Quase Nunca } \\
\text { (1) }\end{array}$ & $\begin{array}{l}\text { Poucas vezes } \\
\text { (2) }\end{array}$ & $\begin{array}{l}\text { Muitas vezes } \\
\text { (3) }\end{array}$ & $\begin{array}{c}\text { Quase sempre } \\
\text { (4) }\end{array}$ & $\begin{array}{c}\text { Sempre } \\
(5)\end{array}$ \\
\hline & & \multicolumn{6}{|c|}{ Quanto? } \\
\hline & & $\begin{array}{c}\text { Nada } \\
(0)\end{array}$ & $\begin{array}{l}\text { Quase nada } \\
\text { (1) }\end{array}$ & $\begin{array}{l}\text { Pouco } \\
\text { (2) }\end{array}$ & $\begin{array}{c}\text { Muito } \\
\text { (3) }\end{array}$ & $\begin{array}{c}\text { Quase insuportável } \\
\text { (4) }\end{array}$ & $\begin{array}{c}\text { Insuportável } \\
(5)\end{array}$ \\
\hline 26 & O seu problema no pescoço afeta 0 & \multicolumn{6}{|c|}{ Com que frequência? } \\
\hline
\end{tabular}


Anexos e 140

Apêndices

\begin{tabular}{|c|c|c|c|c|c|c|}
\hline \multirow[t]{3}{*}{ seu humor? } & $\begin{array}{c}\text { Nunca } \\
(0)\end{array}$ & $\begin{array}{c}\text { Quase Nunca } \\
\text { (1) }\end{array}$ & $\begin{array}{c}\text { Poucas vezes } \\
\text { (2) }\end{array}$ & $\begin{array}{c}\text { Muitas vezes } \\
\text { (3) }\end{array}$ & $\begin{array}{c}\text { Quase sempre } \\
\text { (4) }\end{array}$ & $\begin{array}{c}\text { Sempre } \\
(5)\end{array}$ \\
\hline & \multicolumn{6}{|c|}{ Quanto? } \\
\hline & $\begin{array}{c}\text { Nada } \\
(0)\end{array}$ & $\begin{array}{l}\text { Quase nada } \\
\text { (1) }\end{array}$ & $\begin{array}{l}\text { Pouco } \\
\text { (2) }\end{array}$ & $\begin{array}{c}\text { Muito } \\
\text { (3) }\end{array}$ & $\begin{array}{c}\text { Quase insuportável } \\
(4)\end{array}$ & $\begin{array}{c}\text { Insuportável } \\
\text { (5) }\end{array}$ \\
\hline
\end{tabular}


\begin{tabular}{l|l} 
Anexos e & 141
\end{tabular}

Apêndices

Escala de Limitação Funcional

\begin{tabular}{|c|c|c|c|c|c|c|c|}
\hline \multicolumn{8}{|c|}{ Escala de Limitação Funcional } \\
\hline 1 & $\begin{array}{l}\text { Devido ao seu problema no pescoço, } \\
\text { como é, para você, permanecer em } \\
\text { pé? }\end{array}$ & $\begin{array}{l}\text { Sem problemas } \\
\text { (0) }\end{array}$ & $\begin{array}{c}\text { Fácil } \\
(1)\end{array}$ & $\begin{array}{l}\text { Relativamente fácil } \\
\text { (2) }\end{array}$ & $\begin{array}{l}\text { Relativamente difícil } \\
\text { (3) }\end{array}$ & $\begin{array}{l}\text { Difícil } \\
\text { (4) }\end{array}$ & $\begin{array}{l}\text { Muito difícil } \\
\quad(5)\end{array}$ \\
\hline 2 & $\begin{array}{l}\text { Devido ao seu problema no pescoço, } \\
\text { como é, para você, caminhar? }\end{array}$ & $\begin{array}{c}\text { Sem problemas } \\
(0)\end{array}$ & $\begin{array}{l}\text { Fácil } \\
\text { (1) }\end{array}$ & $\begin{array}{l}\text { Relativamente fácil } \\
\text { (2) }\end{array}$ & $\begin{array}{c}\text { Relativamente difícil } \\
\text { (3) }\end{array}$ & $\begin{array}{l}\text { Difícil } \\
\text { (4) }\end{array}$ & $\begin{array}{l}\text { Muito difícil } \\
\text { (5) }\end{array}$ \\
\hline 3 & $\begin{array}{l}\text { Devido ao seu problema no pescoço } \\
\text { como é, para você, permanecer } \\
\text { sentado? }\end{array}$ & $\begin{array}{l}\text { Sem problemas } \\
(0)\end{array}$ & $\begin{array}{l}\text { Fácil } \\
(1)\end{array}$ & $\begin{array}{c}\text { Relativamente fácil } \\
\text { (2) }\end{array}$ & $\begin{array}{c}\text { Relativamente difícil } \\
\text { (3) }\end{array}$ & $\begin{array}{c}\text { Difícil } \\
(4)\end{array}$ & $\begin{array}{l}\text { Muito difícil } \\
\text { (5) }\end{array}$ \\
\hline 4 & $\begin{array}{l}\text { Devido ao seu problema no pescoço, } \\
\text { como é, para você, permanecer } \\
\text { deitado? }\end{array}$ & $\begin{array}{l}\text { Sem problemas } \\
\text { (0) }\end{array}$ & $\begin{array}{l}\text { Fácil } \\
\text { (1) }\end{array}$ & $\begin{array}{l}\text { Relativamente fácil } \\
\text { (2) }\end{array}$ & $\begin{array}{c}\text { Relativamente difícil } \\
\text { (3) }\end{array}$ & $\begin{array}{l}\text { Difícil } \\
\text { (4) }\end{array}$ & $\begin{array}{l}\text { Muito difícil } \\
\text { (5) }\end{array}$ \\
\hline 5 & $\begin{array}{l}\text { Devido ao seu problema no pescoço, } \\
\text { como é, para você, correr? }\end{array}$ & $\begin{array}{l}\text { Sem problemas } \\
(0)\end{array}$ & $\begin{array}{l}\text { Fácil } \\
\text { (1) }\end{array}$ & $\begin{array}{l}\text { Relativamente fácil } \\
\text { (2) }\end{array}$ & $\begin{array}{c}\text { Relativamente difícil } \\
\text { (3) }\end{array}$ & $\begin{array}{c}\text { Difícil } \\
(4)\end{array}$ & $\begin{array}{l}\text { Muito difícil } \\
\quad(5)\end{array}$ \\
\hline 6 & $\begin{array}{l}\text { Devido ao seu problema no pescoço, } \\
\text { como é, para você, carregar algo? }\end{array}$ & $\begin{array}{l}\text { Sem problemas } \\
(0)\end{array}$ & $\begin{array}{l}\text { Fácil } \\
(1)\end{array}$ & $\begin{array}{c}\text { Relativamente fácil } \\
\text { (2) }\end{array}$ & $\begin{array}{c}\text { Relativamente difícil } \\
\text { (3) }\end{array}$ & $\begin{array}{c}\text { Difícil } \\
(4)\end{array}$ & $\begin{array}{c}\text { Muito difícil } \\
\text { (5) }\end{array}$ \\
\hline 7 & $\begin{array}{l}\text { Devido ao seu problema no pescoço, } \\
\text { como é, para você, levantar algo? }\end{array}$ & $\begin{array}{l}\text { Sem problemas } \\
(0)\end{array}$ & $\begin{array}{c}\text { Fácil } \\
(1)\end{array}$ & $\begin{array}{c}\text { Relativamente fácil } \\
(2)\end{array}$ & $\begin{array}{c}\text { Relativamente difícil } \\
\text { (3) }\end{array}$ & $\begin{array}{c}\text { Difícil } \\
(4)\end{array}$ & $\begin{array}{l}\text { Muito difícil } \\
\text { (5) }\end{array}$ \\
\hline 8 & $\begin{array}{l}\text { Devido ao seu problema no pescoço, } \\
\text { como é, para você, arremeçar algo? }\end{array}$ & $\begin{array}{c}\text { Sem problemas } \\
(0)\end{array}$ & $\begin{array}{c}\text { Fácil } \\
(1)\end{array}$ & $\begin{array}{c}\text { Relativamente fácil } \\
(2)\end{array}$ & $\begin{array}{l}\text { Relativamente difícil } \\
\text { (3) }\end{array}$ & $\begin{array}{c}\text { Difícil } \\
(4)\end{array}$ & $\begin{array}{l}\text { Muito difícil } \\
\text { (5) }\end{array}$ \\
\hline 9 & $\begin{array}{l}\text { Devido ao seu problema no pescoço, } \\
\text { como é, para você, vestir e tirar } \\
\text { camisetas? }\end{array}$ & $\begin{array}{l}\text { Sem problemas } \\
(0)\end{array}$ & $\begin{array}{l}\text { Fácil } \\
\text { (1) }\end{array}$ & $\begin{array}{c}\text { Relativamente fácil } \\
\text { (2) }\end{array}$ & $\begin{array}{c}\text { Relativamente difícil } \\
\text { (3) }\end{array}$ & $\begin{array}{l}\text { Difícil } \\
\text { (4) }\end{array}$ & $\begin{array}{l}\text { Muito difícil } \\
\text { (5) }\end{array}$ \\
\hline 10 & $\begin{array}{l}\text { Devido ao seu problema no pescoço, } \\
\text { como é, para você, calçar e tirar } \\
\text { meias? }\end{array}$ & $\begin{array}{l}\text { Sem problemas } \\
\text { (0) }\end{array}$ & $\begin{array}{l}\text { Fácil } \\
\text { (1) }\end{array}$ & $\begin{array}{l}\text { Relativamente fácil } \\
\text { (2) }\end{array}$ & $\begin{array}{c}\text { Relativamente difícil } \\
\text { (3) }\end{array}$ & $\begin{array}{l}\text { Difícil } \\
\text { (4) }\end{array}$ & $\begin{array}{l}\text { Muito difícil } \\
\text { (5) }\end{array}$ \\
\hline 11 & $\begin{array}{l}\text { Devido ao seu problema no pescoço, } \\
\text { como é, para você, inclinar a cabeça } \\
\text { para frente? }\end{array}$ & $\begin{array}{l}\text { Sem problemas } \\
\text { (0) }\end{array}$ & $\begin{array}{l}\text { Fácil } \\
\text { (1) }\end{array}$ & $\begin{array}{l}\text { Relativamente fácil } \\
\text { (2) }\end{array}$ & $\begin{array}{c}\text { Relativamente difícil } \\
\text { (3) }\end{array}$ & $\begin{array}{l}\text { Difícil } \\
\text { (4) }\end{array}$ & $\begin{array}{l}\text { Muito difícil } \\
\text { (5) }\end{array}$ \\
\hline 12 & Devido ao seu problema no pescoço, & Sem problemas & Fácil & Relativamente fácil & Relativamente difícil & Difícil & Muito difícil \\
\hline
\end{tabular}


Anexos e 142

Apêndices

\begin{tabular}{|l|l|c|c|c|c|c|}
\hline & $\begin{array}{l}\text { como é, para você, inclinar a cabeça } \\
\text { para trás? }\end{array}$ & $(0)$ & $(1)$ & $(2)$ & $(3)$ \\
\hline $\mathbf{1 3}$ & $\begin{array}{l}\text { Devido ao seu problema no pescoço, } \\
\text { como é, para você, inclinar a cabeça } \\
\text { para a direita? }\end{array}$ & $\begin{array}{c}\text { Sem problemas } \\
(0)\end{array}$ & $\begin{array}{c}\text { Fácil } \\
(1)\end{array}$ & $\begin{array}{c}\text { Relativamente fácil } \\
(2)\end{array}$ & $\begin{array}{c}\text { Relativamente difícil } \\
(3)\end{array}$ & $\begin{array}{c}\text { Difícil } \\
(4)\end{array}$ \\
\hline $\mathbf{1 4}$ & $\begin{array}{l}\text { Devido ao seu problema no pescoço, } \\
\text { como é, para você, inclinar a cabeça } \\
\text { para a esquerda? }\end{array}$ & $\begin{array}{c}\text { Sem problemas } \\
(0)\end{array}$ & $\begin{array}{c}\text { Fácil } \\
(1)\end{array}$ & $\begin{array}{c}\text { Relativamente fácil } \\
(2)\end{array}$ & $\begin{array}{c}\text { Relativamente difícil } \\
(3)\end{array}$ & $\begin{array}{c}\text { Muito difícil } \\
(5)\end{array}$ \\
\hline $\mathbf{1 5}$ & $\begin{array}{l}\text { Devido ao seu problema no pescoço, } \\
\text { como é, para você, virar a cabeça } \\
\text { para direita? }\end{array}$ & $\begin{array}{c}\text { Sem problemas } \\
(0)\end{array}$ & $\begin{array}{c}\text { Fácil } \\
(1)\end{array}$ & $\begin{array}{c}\text { Relativamente fácil } \\
(2)\end{array}$ & $\begin{array}{c}\text { Relativamente difícil } \\
(3)\end{array}$ & $\begin{array}{c}\text { Muito difícil } \\
(5)\end{array}$ \\
\hline $\mathbf{1 6}$ & $\begin{array}{l}\text { Devido ao seu problema no pescoço, } \\
\text { como é, para você, virar a cabeça } \\
\text { para a esquerda? }\end{array}$ & $\begin{array}{c}\text { Sem problemas } \\
(0)\end{array}$ & $\begin{array}{c}\text { Fácil } \\
(1)\end{array}$ & $\begin{array}{c}\text { Relativamente fácil } \\
(2)\end{array}$ & $\begin{array}{c}\text { Relativamente difícil } \\
(3)\end{array}$ & $\begin{array}{c}\text { Muito difícil } \\
(5)\end{array}$ \\
\hline $\mathbf{1 7}$ & $\begin{array}{l}\text { Como você avalia o seu problema no } \\
\text { pescoço? }\end{array}$ & $\begin{array}{c}\text { Muito bem } \\
(0)\end{array}$ & $\begin{array}{c}\text { Bem } \\
(1)\end{array}$ & $\begin{array}{c}\text { Não tão bem } \\
(2)\end{array}$ & $\begin{array}{c}\text { Muito difícil } \\
(5)\end{array}$ \\
\hline $\mathbf{1 8}$ & $\begin{array}{l}\text { Como você avalia sua saúde em } \\
\text { geral? }\end{array}$ & $\begin{array}{c}\text { Muito bem } \\
(0)\end{array}$ & $\begin{array}{c}\text { Bem } \\
(1)\end{array}$ & $\begin{array}{c}\text { Não tão bem } \\
(2)\end{array}$ & $\begin{array}{c}\text { Não tão mal } \\
(3)\end{array}$ \\
\hline
\end{tabular}




\section{Anexos e 143 Apêndices}

\section{ANEXO ProFitMap- neck - CÁLCULO DO ESCORE TOTAL E SUBESCALAS}

- A tabela abaixo mostra o peso $(\mathrm{P})$ e o máximo de pontos possível para cada questão do ProFitMap-neck, e o cálculo de pontos para cada índice.

- Frequência (f) é a resposta para as perguntas sobre a frequência que você sente os sintomas.

- Para a Escala Sintomas/Frequência a seguinte pontuação deve ser atribuída para cada questão a titulo de obtenção da pontuação total da ferramenta:

$$
\begin{aligned}
& \text { Nunca }=7 \\
& \text { Quase Nunca }=8 \\
& \text { Poucas vezes }=9 \\
& \text { Muitas vezes }=10 \\
& \text { Quase sempre }=11 \\
& \text { Sempre }=12
\end{aligned}
$$

- Intensidade (i) é a resposta para as perguntas sobre a intensidade que você sente os sintomas.

- Para a Escala Sintomas/Intensidade a seguinte pontuação deve ser atribuída para cada questão a titulo de obtenção da pontuação total da ferramenta:

$$
\begin{aligned}
& \text { Nada }=1 \\
& \text { Quase nada }=2 \\
& \text { Pouco }=3 \\
& \text { Muito }=4 \\
& \text { Quase insuportável }=5 \\
& \text { Insuportável = } 6
\end{aligned}
$$

- As respostas para as perguntas na escala de Limitação funcional (lf).

- Para a Escala Limitação Funcional:

Sem problemas $=1$

Fácil $=2$

Relativamente fácil $=3$

Relativamente difícil $=4$

Difícil $=5$

Muito difícil $=6$

- O resultado de cada índice é expresso como porcentagem do máximo da soma dos pontos, onde $100 \%$ é o melhor resultado possível. Ajustes para perguntas não respondidas devem ser feitos retirando os pontos máximos dessas perguntas do denominador antes de calcular a porcentagem.

- Para obter a pontuação do domínio Sintomas/Intensidade Geral somar apenas as pontuações de todas as questões (pontuação máxima $=322$ pontos), exceto questões 11 e 12 que fazem parte do domínio equilíbrio (pontuação máxima 17 pontos).

- Para obter a pontuação do domínio Sintomas/Frequência somar apenas as pontuações de todas as questões (pontuação máxima $=339$ pontos).

- Para obter a pontuação do domínio Limitação Funcional-Atividades de Vida Diária e Postura somar apenas as pontuações de todas as questões exceto questões 1 a 10 (pontuação máxima 106 pontos) e para obter a pontuação do domínio Movimentos e Percepção de Saúde somar as questões 11 a 18 (pontuação máxima 130 pontos).

- Total da Escala de Sintomas/Intensidade e Sintomas/Frequência = 339 .

- Total da Escala de Limitação Funcional = 236 pontos. 
\begin{tabular}{l|l} 
Anexos e & 144
\end{tabular}

Apêndices

\section{Escala para sintomas (s)}

\begin{tabular}{|c|c|c|c|c|c|c|c|c|}
\hline \multicolumn{5}{|c|}{ Escala para sintomas (s) } & \multicolumn{4}{|c|}{$\begin{array}{c}\text { Escala para limitações } \\
\text { funcionais (lf) }\end{array}$} \\
\hline Pergunta $_{\mathrm{s}}$ & $\begin{array}{c}\text { Peso } \\
\left(\mathbf{P}_{s}\right)\end{array}$ & $\begin{array}{l}\text { Índice de } \\
\text { fequência } \\
\text { de pontos }\end{array}$ & $\begin{array}{l}\text { Índice de } \\
\text { intensidad } \\
\text { e de }\end{array}$ & $\begin{array}{l}\text { Máximo de } \\
\text { pontos }\end{array}$ & $\underset{b}{\text { Pergunta }_{f}}$ & $\begin{array}{r}\text { Peso } \\
\left(\mathbf{P}_{\mathrm{fb}}\right)\end{array}$ & $\begin{array}{l}\text { Função } \\
\text { de } \\
\text { pontos }\end{array}$ & $\begin{array}{c}\text { Máximo } \\
\text { de } \\
\text { pontos }\end{array}$ \\
\hline 1 & 2 & $(6-\mathrm{f} 1) * \mathrm{Ps}$ & $(12-\mathrm{i} 1)^{*} \mathrm{Ps}$ & 10 & 1 & 2 & $(6-l f 1)^{*} P_{1 f}$ & 12 \\
\hline 2 & 2 & $(6-f 2) * P s$ & $(12-i 2) *$ Ps & 10 & 2 & 3 & $\left(6-l_{2}\right) * P_{l f}$ & 15 \\
\hline 3 & 2 & $(6-\mathrm{f} 3)^{*} \mathrm{Ps}$ & $(12-i 3) *$ Ps & 10 & 3 & 2 & $(6-l f 3) *$ Plf & 12 \\
\hline 4 & 1 & $\left(6-f_{4}\right) * P s$ & $(12-14)^{*} \mathrm{Ps}$ & 5 & 4 & 3 & $\left(6-l_{4}\right) * P_{1 f}$ & 15 \\
\hline 5 & 12 & $(6-f 5) * P s$ & $(12-\mathrm{i} 5)^{*} \mathrm{Ps}$ & 6 & 5 & 2 & $(6-1 \mathrm{lf} 5) * \mathrm{P}_{\mathrm{lf}}$ & 10 \\
\hline 6 & 2 & $\left(6-f_{6}\right) * P s$ & $(12-16) * \mathrm{Ps}$ & 10 & 6 & 1 & $\left(6-l_{6} 6\right) * P_{1 f}$ & 6 \\
\hline 7 & 24 & $(6-f 7) * P s$ & $(12-i 7)^{*}$ Ps & 12 & 7 & 1 & $(6-1 f 7) *$ Plf & 6 \\
\hline 8 & 24 & $(6-f 8) * P s$ & $(12-18)^{*} \mathrm{Ps}$ & 12 & 8 & 1 & $(6-1 f 8) * P_{1 f}$ & 6 \\
\hline 9 & 24 & $(6-f 9) * \operatorname{Ps}$ & $(12-i 9) *$ Ps & 12 & 9 & 2 & $(6-l f 9) * P_{l f}$ & 12 \\
\hline 10 & 24 & $(6-\mathrm{f} 10) * \mathrm{Ps}$ & $(12-\mathrm{i} 10) * \mathrm{Ps}$ & 12 & 10 & 2 & $(6-1 \mathrm{f} 10) * \mathrm{P}_{1 f}$ & 12 \\
\hline 11 & 3 & $(6-f 11) * P s$ & $(12-i 11) *$ Ps & 15 & 11 & 3 & $(6-l f 11) * P_{1 f}$ & 15 \\
\hline 12 & 24 & $(6-\mathrm{f} 12) * \mathrm{Ps}$ & $(12-\mathrm{i} 12)^{*} \mathrm{Ps}$ & 12 & 12 & 3 & $\left(6-\operatorname{lf}_{12}\right) * \mathrm{P}_{1 f}$ & 15 \\
\hline 13 & 2 & $\left(6-f_{13}\right) * P_{s}$ & $(12-i 13) * \operatorname{Ps}$ & 10 & 13 & 3 & $\left(6-l_{13}\right) * P_{l f}$ & 15 \\
\hline 14 & 2 & $\left(6-\mathrm{f}_{14}\right) * \mathrm{Ps}$ & $(12-\mathrm{i} 14)^{*} \mathrm{Ps}$ & 10 & 14 & 3 & $\left(6-l_{14}\right) * \mathrm{P}_{1 f}$ & 15 \\
\hline 15 & 2 & $\left(6-f_{15}\right) * P s$ & $(12-\mathrm{i} 15)^{*} \mathrm{Ps}$ & 10 & 15 & 3 & $\left(6-l_{1 f} 15\right) * P_{1 f}$ & 15 \\
\hline 16 & 4 & $\left(6-f_{16}\right) * P s$ & $(12-\mathrm{i} 16) * \mathrm{Ps}$ & 20 & 16 & 3 & $\left(6-l_{1 f} 16\right) * P_{1 f}$ & 15 \\
\hline 17 & 12 & $\left(6-f_{17}\right) * \operatorname{Ps}$ & $(12-i 17)^{*} \mathrm{Ps}$ & 6 & 17 & 4 & $(6-1 f 18) * P_{1 f}$ & 20 \\
\hline 18 & 12 & $(6-\mathrm{f} 18) * \mathrm{Ps}$ & $(12-\mathrm{i} 18)^{*} \mathrm{Ps}$ & 6 & 18 & 4 & $(6-l f 19) * P_{1 f}$ & 20 \\
\hline 19 & 3 & $\left(6-f_{19}\right) * \operatorname{Ps}$ & $(12-i 19) *$ Ps & 15 & & & & \\
\hline 20 & 2 & $\left(6-f_{20}\right) * P s$ & $(12-i 20) * P s$ & 10 & & & & \\
\hline 21 & 2 & $\left(6-f_{21}\right) * P s$ & $(12-\mathrm{i} 21)^{*} \mathrm{Ps}$ & 10 & & & & \\
\hline 22 & 2 & $\left(6-f_{2} 2\right) * P s$ & $(12-i 22) * \operatorname{Ps}$ & 10 & & & & \\
\hline 23 & 8 & $(6-f 23) * \operatorname{Ps}$ & $(12-\mathrm{i} 23) * \mathrm{Ps}$ & 40 & & & & \\
\hline 24 & 8 & $\left(6-f_{24}\right) * P s$ & $(12-i 24) * P s$ & 40 & & & & \\
\hline 25 & 36 & $(6-\mathrm{f} 25) * \mathrm{Ps}$ & $(12-\mathrm{i} 25) * \mathrm{Ps}$ & 18 & & & & \\
\hline 26 & 36 & $(6-\mathrm{f} 26) * \mathrm{Ps}$ & $(12-i 26) * P s$ & 18 & & & & \\
\hline
\end{tabular}

\section{Escala para limitações} funcionais (lf) 
Anexos e 145

Apêndices

\section{APÊNDICE 6 - Questionário semi-estruturado teste da versão pré-final}

Nome do paciente:

Data:

Tempo de aplicação da ferramenta:

1. Você conseguiu entender aos enunciados de todos os itens do questionário? Se não, por favor, marque com um X o quadrado correspondente à questão (ou questões) não compreendida(s).

\begin{tabular}{|c|c|c|c|}
\hline \multicolumn{2}{|r|}{ Escala de Sintomas } & \multicolumn{2}{|r|}{ Escala Funcional } \\
\hline 1 & & 1 & \\
\hline 2 & & 2 & \\
\hline 3 & & 3 & \\
\hline 4 & & 4 & \\
\hline 5 & & 5 & \\
\hline 6 & & 6 & \\
\hline 7 & & 7 & \\
\hline 8 & & 8 & \\
\hline 9 & & 9 & \\
\hline 10 & & 10 & \\
\hline 11 & & 11 & \\
\hline 12 & & 12 & \\
\hline 13 & & 13 & \\
\hline 14 & & 14 & \\
\hline 15 & & 15 & \\
\hline 16 & & 16 & \\
\hline 17 & & 17 & \\
\hline 18 & & 18 & \\
\hline 19 & & 19 & \\
\hline 20 & & 20 & \\
\hline
\end{tabular}


Anexos e 146

Apêndices

\begin{tabular}{|l|l|}
\hline 21 & \\
\hline 22 & \\
\hline 23 & \\
\hline 24 & \\
\hline 25 & \\
\hline 26 & \\
\hline 27 & \\
\hline
\end{tabular}

Agora, por favor, responda qual foi a sua dificuldade referente ao item assinalado (Se houver mais de um item, não se esqueça de mencionar quais são).

2. As opções de resposta foram claras para responder ao item solicitado? Em caso de resposta negativa, por favor, sugira opções.

3. Você tem alguma sugestão para a mudança do lay-out (estrutura/organização) desse questionário?

4. Você tem alguma sugestão para tornar as questões do questionário mais fáceis de serem entendidas? 


\title{
APÊNDICE 7 - TERMO DE CONSENTIMENTO LIVRE ESCLARECIDO PARA OS PARTICIPANTES DA PESQUISA
}

\author{
Pesquisadores responsáveis: Profa. Dra. Thaís Cristina Chaves (chavestc@ fmrp.usp.br) Fone:(016)36024694 e Mariana \\ Cândido Ferreira (mariana.candido.ferreira@usp.br) Fone:(016) 988121291
}

\section{“ADAPTAÇÃO TRANSCULTURAL PARA O PORTUGUÊS E VALIDAÇÃO DO PROFILE FITNESS MAPPING NECK PAIN"}

Esclarecimento Geral - Este estudo será realizado para disponibilizar uma versão em português de uma escala que avalia os sintomas e a incapacidade relacionada à dor cervical crônica, o qual é constituído por 44 itens.

Objetivo do Estudo - Tornar disponível no português- brasileiro a escala Profile Fitness Mapping Neck Pain - (Perfil da Capacidade e Mapeamento da dor cervical) para avaliar a interferência dos sintomas e limitações na função da coluna superior em indivíduos com dor cervical crônica (presente há pelo menos 3 meses).

Explicação dos Procedimentos da Pesquisa - Em uma primeira etapa, um pesquisador responsável aplicará a escala para avaliar e observar as dificuldades dos pacientes que apresentam dor cervical crônica, com relação às questões. Tais dificuldades serão utilizadas como subsídio para possíveis alterações na versão final da escala. Em alguns pacientes a mesma será aplicada novamente após uma semana, para avaliação da precisão das respostas fornecidas. O questionário será respondido pelo próprio participante. Este procedimento deverá durar em torno de 15 minutos. Após preenchimento do questionário ProFitMap Neck, outro questionário deverá ser respondido (Neck Disability Index). Essa pesquisa será conduzida no Ambulatório de Cefaléia e Algias Craniofaciais do Hospital das Clínicas da Faculdade de Medicina de Ribeirão Preto.

Possíveis Benefícios - Não há benefícios diretamente destinados a mim durante a participação nesta pesquisa e que os dados obtidos pelos responsáveis pela pesquisa auxiliaram no maior conhecimento a respeito dos aspectos físico, mental e social que envolvem a saúde dos pacientes com dor cervical crônica.

Desconforto e risco - Existe um risco mínimo nessa pesquisa relacionado ao sigilo de identidade, entretanto todas as informações colhidas serão mantidas em sigilo assim como minha identidade através da adoção de senhas em arquivos e numeração dos dados nas planilhas.

Seguro de Saúde ou de Vida - Não existe nenhum tipo de seguro de saúde ou de vida que possa me beneficiar em função da minha participação neste estudo.

Liberdade de Participação - A minha participação neste estudo depende plenamente da minha autorização. É meu direito deixar de participar deste estudo em qualquer momento sem que isso incorra em qualquer penalidade ou prejuízo à minha pessoa. E fui informado de que não terei nenhum gasto adicional devido à participação nesse projeto.

Sigilo de Identidade - As informações obtidas nesta pesquisa não serão de maneira alguma associadas à identidade dos participantes e não poderão ser consultadas por pessoas leigas sem autorização oficial. Estas informações poderão ser utilizadas para fins científicos, desde que fiquem resguardadas a privacidade e anonimato dos participantes da pesquisa.

Eventuais dúvidas sobre os aspectos éticos relacionados a essa pesquisa devem ser elucidados junto ao Comitê de Ética em Pesquisa do Hospital das Clínicas da Faculdade de Medicina de Ribeirão Preto (F: 36022228).

Os responsáveis pelo estudo me explicaram todos os riscos envolvidos, a necessidade da pesquisa e se prontificaram a responder todas as minhas dúvidas sobre a pesquisa. Eu aceitei participar neste estudo de livre e espontânea vontade. Entendo que é meu direito manter uma cópia deste consentimento.

$\mathrm{Eu}$, portador do RG

$\mathrm{n}^{\mathrm{o}}$ : , declaro que tenho anos de idade. de de 20 